University of Michigan Law School

University of Michigan Law School Scholarship Repository

Law \& Economics Working Papers

3-1-2010

\title{
The Failure of Mandated Disclosure
}

Omri Ben-Shahar

University of Chicago Law School, omri@uchicago.edu

Carl E. Schneider

University of Michigan Law School, carlschn@umich.edu

Follow this and additional works at: https://repository.law.umich.edu/law_econ_current

Part of the Law and Economics Commons

\section{Working Paper Citation}

Ben-Shahar, Omri and Schneider, Carl E., "The Failure of Mandated Disclosure" (2010). Law \& Economics Working Papers. 9.

https://repository.law.umich.edu/law_econ_current/art9

This Article is brought to you for free and open access by University of Michigan Law School Scholarship Repository. It has been accepted for inclusion in Law \& Economics Working Papers by an authorized administrator of University of Michigan Law School Scholarship Repository. For more information, please contact mlaw.repository@umich.edu. 
Preliminary Draft

Winter 2010

\title{
The FAILURE OF MANDATEd Disclosure
}

\author{
Omri Ben-Shahar and Carl E. Schneider*
}

\begin{abstract}
This article explores the spectacular prevalence, and failure, of the single most common technique for protecting personal autonomy in modern society: mandated disclosure. The article has four sections:

(1) A comprehensive summary of the recurring use of mandated disclosures, in many forms and circumstances, in the areas of consumer and borrower protection, patient informed consent, contract formation, and constitutional rights;

(2) A survey of the empirical literature documenting the failure of the mandated disclosure regime in informing people and in improving their decisions;

(3) An account of the multitude of reasons mandated disclosures fail, focusing on the political dynamics underlying the enactments of these mandates, the incentives of disclosers to carry them out, and, most importantly, on the ability of disclosees to use them;

(4) An argument that mandated disclosure not only fails to achieve its stated goal but also leads to unintended consequences that often harm the very people it intends to serve.
\end{abstract}

\footnotetext{
* Ben-Shahar is the Frank \& Bernice J. Greenberg Professor of Law, University of Chicago. Schneider is the Chauncey Stillman Professor of Law \& Professor of Internal Medicine, University of Michigan. Helpful comments were provided by workshop participants at Georgetown. Financial support from the Olin Program at the University of Chicago and the Elkes Fund at the University of Michigan is gratefully acknowledged.
} 


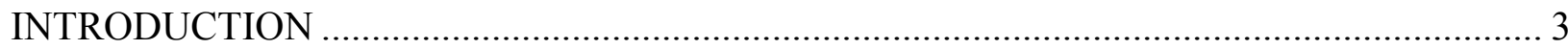

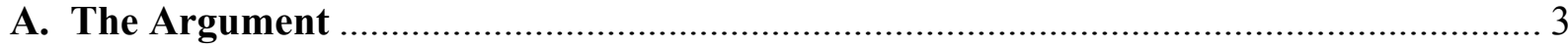

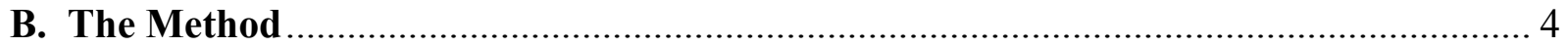

C. The Style

I. The "Disclosure Empire": The Pervasiveness of Mandated Disclosure ................. 5

A. Three Paradigmatic Examples of Mandated Disclosure …………………………….... 5

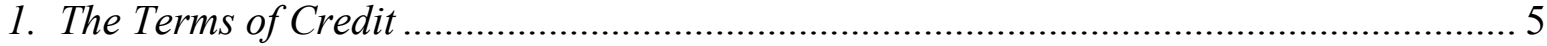

2. Informed Consent ................................................................................................ 7

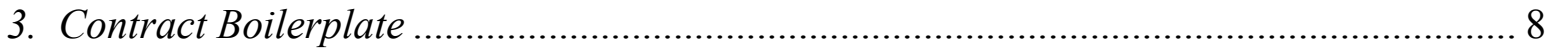

B. Other Provinces in the Disclosure Empire.............................................................. 9

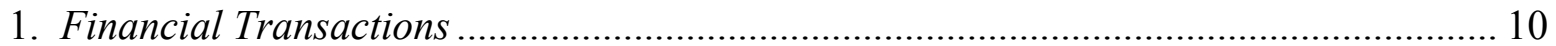

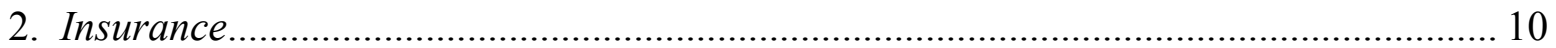

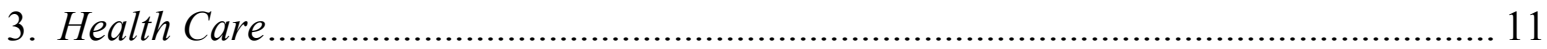

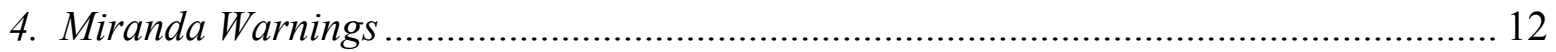

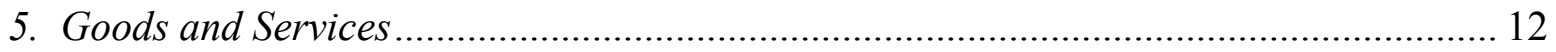

II. The Documented FaILure OF Mandated Disclosure............................................... 15

A. The Three Paradigmatic Cases of Mandated Disclosure …………………………..... 15

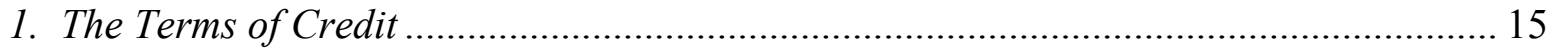

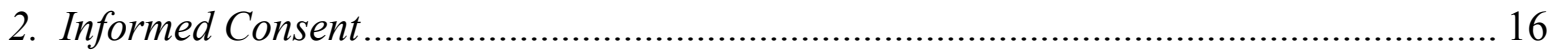

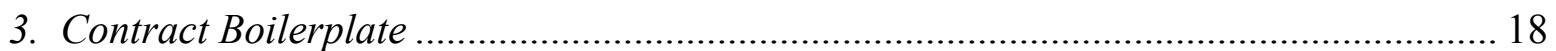

B. The Failures of Other Mandated Disclosures......................................................... 19

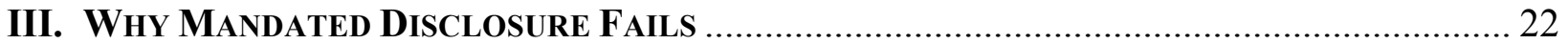

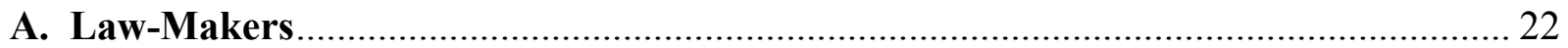

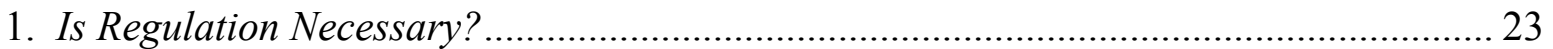

2. Is Mandated Disclosure the Best Form of Regulation? ……............................................ 23

3. What Is the Proper Scope of the Disclosure Mandate? .................................................... 26

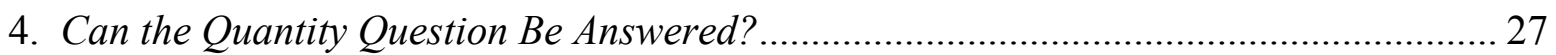

5. Can the Standard of Disclosure Be Articulated Effectively? ……................................. 28

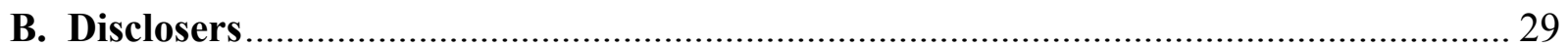

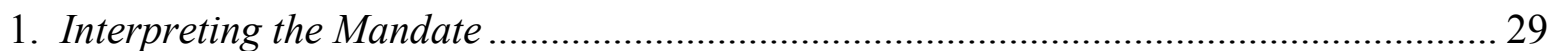

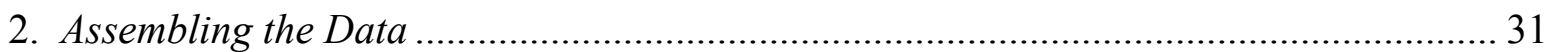

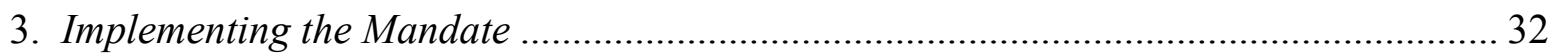

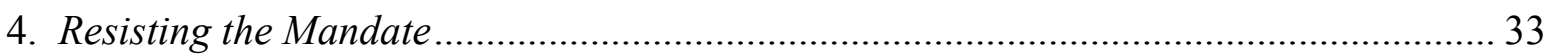

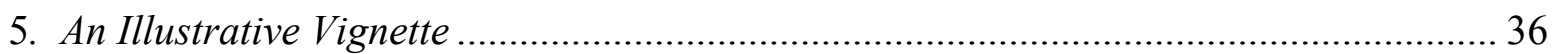


C. Disclosees. Error! Bookmark not defined.

1. Deciding and Living Error! Bookmark not defined.

a. Let This Cup Pass From Me. Error! Bookmark not defined.

b. The Accumulation Problem Error! Bookmark not defined.

2. Acquiring the Information Error! Bookmark not defined.

3. Understanding the Information Error! Bookmark not defined.

a. Illiteracy and Innumeracy Error! Bookmark not defined.

b. Through a Glass Darkly... Error! Bookmark not defined.

4. Analyzing the Information Error! Bookmark not defined.

a. Calculating Error! Bookmark not defined.

b. Choosing Error! Bookmark not defined.

IV. Does MANDATE Disclosure JuSTIFY ITS Costs? ....................................................... 54

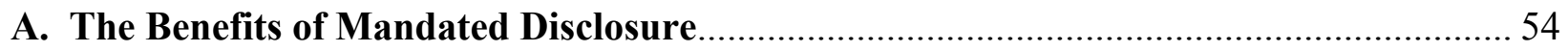

1. An "Agency" Benefit ................................................................................................. 54

2. An Educational Benefit ………………………………....................................... 55

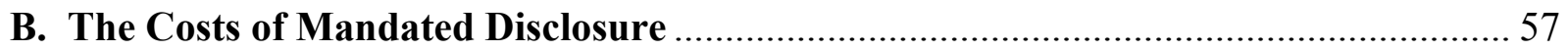

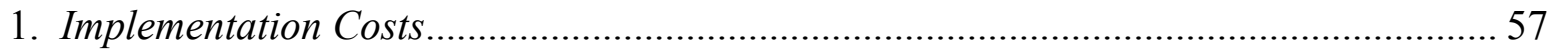

2. Unintended Harms of Mandated Disclosure ………................................................ 58

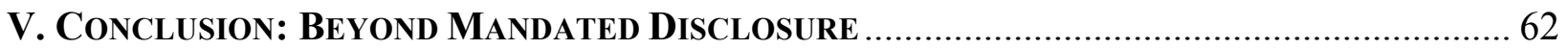


Law \& Economics W orking Papers, Art. 9 [2010]

\section{INTRODUCTION}

\section{A. The Argument}

A key regulatory technique is much used but little remarked - "mandated disclosure." It aspires to improve complex decisions people make in their economic and social relationships and particularly to protect the naïve in dealing with the sophisticated. The technique is to require "the discloser" to give "the disclosee" information to use to make better decisions, and particularly to keep the discloser from abusing its superior position.

For example: You are shopping for a loan. Or you are told you need prostate-cancer surgery. Or you are buying a computer on-line. Or you are under arrest and under questioning. You've never faced your choice before. It turns on facts and practices you don't know. The mortgagee, the doctor, the vendor, and the police are experienced and have interests of their own.

Mandated disclosure is supposed to give you information with which to analyze your choices carefully and to choose optimally. Thus truth-in-lending laws require your lender to highlight credit terms. The law of informed consent requires your doctor to describe prostatectomies, radiation, chemotherapy, and watchful waiting. Contract doctrine requires your vendor to tell you your contract's terms, like warranties and mandatory arbitration. Miranda requires the police to tell you your rights. Thus informed, you understand your choices well enough to make an intelligent decision about your mortgage, your cancer, your computer, or your confession.

Mandated disclosure is everywhere. Numberless federal and state statutes, administrative regulations, and court rulings stipulate (sometimes marvelously elaborate) disclosure requirements: businesses that issue car, student, or automobile loans; mortgagees; home-equity lenders; credit-card companies; banks accepting deposits; mutual funds; securities brokers; credit-reporting agencies; investment advisors; ATM operators; pawnshops; payday lenders; rent-to-own dealers; installment-sales vendors; insurers of lives, property, health, cars, rented vehicles, self-storage facilities, and much else; car-towing companies; car-repair shops; motor clubs; residential real-estate agencies, developers, and landlords; time-share programs, sellers and lessors of mobile homes; membership camping facilities; providers of home improvements, services, and repairs; home-alarm installers; vocational schools; traffic-violator schools; agents selling electricity; immigration consultants; dog breeders and sellers; travel services and travel agencies; art dealers; police; doctors; hospitals; managed-care organizations; colleges and universities; restaurants and other food establishments; halal food dealers; and endlessly more. To say nothing, for example, of the common law obligation to disclose information prior to a contract; or of the federal and state campaign finance regulation, recently trimmed to not much more than mandated disclosure.

Mandated disclosure addresses a real problem: Modernity showers us with consequential and complex decisions about which we know little. Unsophisticated people must work with, depend on, and contend with specialized people and enterprises that routinely handle and become expert in complex transactions. People must make decisions about financial matters of many 
kinds. They face medical choices. They buy things whose working they don't understand and whose quality they cannot evaluate under terms they do not know.

Not only does mandated disclosure address a real problem - it rests on a plausible assumption: that in making decisions, more information is better than less. More information helps people make better decisions, thus bolstering their autonomy. Since people can no longer customize most transactions (since their menu contains a few non-negotiable bundles of attributes) disclosing helps restore some individual control. It may also induce enterprises to behave more efficiently.

Although mandated disclosure addresses a real problem and rests on a plausible assumption, it chronically fails to accomplish its purpose, as empirical evidence about many mandates shows. Even where mandated disclosure seems to succeed, its costs in money, effort, and time generally swamp its benefits. And mandated disclosure has unintended and undesirable consequences, including driving out better regulation and hurting the people it is supposed to help.

Not only does the empirical evidence show that mandated disclosure regularly fails, failure is inherent in the technique. First, mandated disclosure rests on false assumptions about how people live, think, and make decisions. Second, it rests on false assumptions about the decisions it intends to improve. Third, its success requires an impossibly long series of unlikely achievements by law-makers, disclosers, and disclosees. That is, the prerequisites of successful mandated disclosure are so numerous and so onerous that they are rarely met.

Because the mandated-disclosure mantra - more information is better than less - sounds plausible, we must be clear about our topic and our argument. We are not asking what information people need to make good decisions. We are asking whether a regulatory technique - mandated disclosure - works. We are not saying that information never helps people make decisions. Our argument is directed at a regulatory technique in which a law-maker requires a "discloser" to give a "disclosee" a standard disclosure - pre-packaged information the law-maker thinks the disclosee needs to choose wisely.

Our tasks, then, are to identify mandated disclosure as a distinctive regulatory method, to suggest the breadth of its use, to review the evidence of its failure, and to explain why it fails. Our task is not to propose an alternative. Mandated disclosure has been used so extensively one might say so indiscriminately - that it is asked to solve many kinds of problems in many kinds of areas. We doubt that any single regulatory method can be so widely effective. We believe that commentators and law-makers must instead undertake the burdensome and politically painful work of tailoring solutions to problems. We close by suggesting some paths toward this harder but more rewarding work.

\section{B. The Method}

Our argument has four steps. The first is to identify mandated disclosure as a distinctive regulatory technique. The second is to show how extensive and intensive mandated disclosure is. For both these purposes, we searched for statutes that mandate disclosures in three states 
Law \& Economics W orking Papers, Art. 9 [2010]

(California, Michigan, and Illinois) and located several hundred of them. Less systematically, we looked for Federal statutes, administrative regulations, and case law that mandate disclosures. In Part I we give abundant examples of the many sectors in which disclosure is mandated, the kinds of information that must be disclosed, and the format that disclosure takes.

The third step is to ask whether these mandates work. They are used in so many unrelated fields that we cannot assess them ourselves. Instead, we survey the empirical literature. The gravamen of that literature is that mandated disclosure generally fails to achieve its goals.

The fourth step, perhaps the most substantial one, is to explain that failure. We canvass the systematic factors that keep law-makers, disclosers, and disclosees from accomplishing all the things they would have to do to make mandated disclosure work reliably.

\section{The Style}

Writing about mandated disclosure raises the same problem mandating disclosure does: The amount of information exceeds the discloser's ability to describe it intelligibly and the disclosee's ability to understand it usefully. To survey the spectacular profusion of mandated disclosure would require marching through acres of statutes, regulations, and cases and to make the same mistake lawmakers make - pointlessly burdening our audience. In sanity's name, we have eliminated data that are more disruptive than helpful, especially the footnotes that cite statutes, regulations, and cases that mandate disclosure. The skeptical or curious may consult an on-line version of the article replete with citations. ${ }^{1}$

In like manner, we urge readers to read only what they need. In particular, parts I and II, which catalog information, need be scrutinized only by the skeptical. If you accept what is quickly obvious - that mandated disclosure is pervasive - you can skim Part I. If you accept what is less obvious but richly documented - that this device has been largely ineffective - you can skim Part II. You can then concentrate on Parts III and IV, which not only do much of the article's analytic work but also provide yet further evidence of the pervasiveness and the ineffectiveness of mandated disclosure.

\section{The "Disclosure Empire": The Pervasiveness of Mandated Disclosure}

Mandated disclosure is now a standard weapon in the arsenals of legislatures, courts, administrative agencies, and commentators. In this Part, we describe several paradigmatic examples of mandated disclosure to show just how standard the weapon has become, and survey the entire landscape of the mandatory disclosure device.

\section{A. Three Paradigmatic Examples of Mandated Disclosure}

\section{The Terms of Credit}

1 DISCLAIMER: DESPITE THE REPRESENTATION ABOVE, THE PRESENT DRAFT DOES INCLUDE ALL THE FOOTNOTES. 
Selecting terms on which to borrow money exemplifies the kind of decisions mandated disclosure seeks to improve - unfamiliar, complex, and consequential. Lenders have information relevant to the decision but may have reasons not to educate borrowers. Law-makers have deployed truth-in-lending laws to compel lenders to inform borrowers, generally in considerable detail.

For example, the Truth in Lending Act of 1968 (TILA), as implemented by Regulation Z, and many state laws make lenders disclose interest rates and fees. ${ }^{2}$ Sometimes these statutes specify metrics intended to summarize complex credit obligations; sometimes they specify disclosure phrases, like options to prepay, minimum payments, and much more. ${ }^{3}$ For example, try to decipher this Illinois "mini"-TILA (which is typical of statutes that require disclosing a specific statement:

(m) ... Unearned finance charges under the Rule of 78ths are computed by calculating for all fully unexpired monthly installment periods, as originally scheduled or deferred, which follow the day of prepayment, the portion of the precomputed interest that bears the same ratio to the total precomputed interest as the balances scheduled to be outstanding during that monthly installment period bear to the sum of all scheduled monthly outstanding balances originally contracted for. ${ }^{4}$

TILA was a prototype consumer-protection statute and became the template for most consumer-credit legislation, ${ }^{5}$ legislation which now mandates detailed disclosures for credit generally, credit cards, automobile loans, student loans, mortgages, and other home-secured loans. ${ }^{6}$ Credit-card issuers, for example, must disclose all a contract's terms and highlight in a uniform way critical terms like APRs and fees. ${ }^{7}$

Attempts to protect poor borrowers often recruit disclosure requirements. Pawnshops-a primary financial resource for the vulnerable-must detail interest payments, redemption options, fees and charges, and statutory caps. ${ }^{8}$ Payday lenders must tell borrowers that their loans will not solve their long-term problems, that other debt-management services may be

${ }^{2} 15$ U.S.C. $\S \S 1601$ et seq.; Regulation Z, 12 C.F.R $\S 226$; see also USCA $\S 4302$ (disclosure in loan solicitations and documents of terms, interest, fees, penalties, etc.) The most important disclosure in TILAs is the APR - a uniform measure of the cost of credit. See Truth in Lending Act, Pub. L. No. 90321, $\S 107,82$ Stat. 146, 149 (1968), 15 U.S.C. $\S 1606$ (LexisNexis 2008) (defining the APR); Truth in Lending Act, Pub. L. No. 90-321, § 121-31, 82 Stat. 146, 152-57 (1968), 15 U.S.C. $\S \S 1631-49$ (LexisNexis 2008) (requiring disclosure of the APR).

${ }^{3}$ Michigan MCLS $\S 390.1222$ (2008) (payment, penalties and options for educational loans).

${ }^{4} 205$ ILCS 670/16: Disclosure of Terms of Contract.

5 Edward L. Rubin, Legislative Methodology: Some Lessons from the Truth-in-Lending Act, 80 Georgetown L. J. 233, 234 (1991).

${ }^{6}$ Regulation M, 12 C.F.R. § 213. See also Press Release, Federal Reserve (Sept. 27, 1996), online at www.federalreserve.gov/boarddocs/press/boardacts/1996/19960927/default.htm.

${ }^{7}$ Cal. Civ. Code $\S \S 1748.11$ (a), 1748.13(a) (2007) (disclosure by creditors of the terms of the credit card account during enrollment; and disclosure on each billing statement of the effects of making less than full payment).

${ }^{8}$ Pawnbroker Regulation Act, 205 ILCS 510/2 (pawnbrokers disclosures in Illinois). 
available, and that they cannot be criminally prosecuted to collect the loan. ${ }^{9}$ Rent-to-own dealers must reveal the "true" cost of changing a rental to a purchase and of other fees. ${ }^{10}$ Retail installment sales must be accompanied by information about many financial aspects of the transaction. $^{11}$

Disclosure requirements dominate regulation of another kind of credit - mortgages, including high-risk mortgages. ${ }^{12}$ Mortgage disclosure acts require written statements about: obligations to obtain mortgage insurance, "13 "all material facts" in mortgage-brokerage agreements; ${ }^{14}$ borrowers' rights to renounce obligations after entering mortgage-rescue services; ${ }^{15}$ lender's obligations to disclose changes in loan terms $;{ }^{16}$ and more. Lenders must even say that defaulting can lead to foreclosure and that it is prudent to shop for low rates. ${ }^{17}$

\section{Informed Consent}

Patients often face unfamiliar but vital choices, which depend upon complex factors about which they understand little. Doctors understand these choices better but may lack the time, interest, inclination, or ingenuity to educate the patient. So that patients may make their own medical decisions, doctors must tell them the advantages and disadvantages of their choices. ${ }^{18}$ Few disclosure mandates have been as richly favored as this doctrine of informed consent. Courts, legislatures, and administrative agencies have mandated it in many forms and fora for many decades. The medical and research establishments have made it their conventional wisdom, with barely a whisper of dissent.

Informed consent can require extensive disclosures. Ailments and treatments are innumerable, and doctors are told to give patients all the information a reasonable person would

9 Payday Loan Reform Act, 815 ILCS 122/2-20 (disclosures in English and Spanish by payday lenders).

${ }^{10}$ Cal. Civ. Code $\S 1812.623$ (2007); Michigan MCLS $\S 445.953$ (2008) ("rental-purchase" agreements).

${ }^{11}$ Michigan MCLS $\S 445.853$ (2008) (disclosure in retail installment sale of overall price, the feeds, insurance, remaining balance, time-price differentials, and more); Ill. Admin. Code Tit. 14, $\$ 475.610$ (disclosure in credit sale advertising); Motor Vehicle Retail Installment Sales Act, 815 ILCS 375/2.9 (1967) (disclosure in installment sales of cars).

${ }^{12}$ High Risk Home Loan Act, 815 ILCS 137/95 (2004) (Disclosure to borrower that "YOU MIGHT BE ABLE TO OBTAIN A LOAN AT A LOWER COST ... CLOSING COSTS AND FEES VARY BASED ON MANY FACTORS ... YOU COULD LOSE YOUR HOME AND ANY MONEY YOU PUT INTO IT IF YOU DO NOT MEET YOUR PAYMENT OBLIGATIONS UNDER THE LOAN...").

${ }^{13}$ Mortgage Insurance Limitation and Notification Act, 765 ILCS 930/15 (disclosure of requirement to obtain insurance).

${ }^{14}$ Residential Mortgage License Act, 205 ILCS 635/5-7(a)(3) (Illinois statute requiring disclosures by mortgage brokers of "all material facts" that might affect the borrower).

${ }^{15}$ Mortgage Rescue Fraud Act, 765 ILCS 940/10 (2007) (disclosure by "distressed property consultants" of the rights of clients to cancel and to delay payments).

${ }^{16} 205$ ILCS 636/5-9 (any material change in loan terms have to be disclosed timely).

${ }^{17}$ Michigan MCLS $§ 445.1637$ (2007) (pre-mortgage educational disclosures); Cal. Civ. Code $§ 2971$ (2007) (disclosure that a home equity loan is secured by the home and "failure to repay the loan for any reason could cause you to lose your home.").

${ }^{18}$ Two classic cases are Canterbury v. Spence, 464 F2d 772 (DC Cir 1972), and Cobbs v. Grant, 502 P2d 1 (Calif 1972). A legislative example is Georgia Code Annotated § 31-9-6.1. 
want in making the decision. This formulation has been understood increasingly broadly. For example, "[c]ourts are becoming more receptive to including physician-specific and financial information within the scope of informed consent." 19

We will pay particular attention to disclosure of conflicts of interest. In one muchnoticed case, the court held "that a physician who is seeking a patient's consent for a medical procedure must ... disclose personal interests unrelated to the patient's health, whether research or economic, that may affect his medical judgment." ${ }^{, 0}$ And one court extended the principle by holding that doctors may be obliged to tell patients about their competence to perform procedures and the superior competence of other doctors. ${ }^{21}$

In addition, states "have enacted limited expansions of informed consent duties, generally in response to focused advocacy by patient groups." 22 Such mandates are often intended more to persuade than to inform. For example, more than a third of the states specify information doctors must give patients about treating breast cancer with lumpectomies. ${ }^{23}$ Some states tell doctors what to tell women seeking abortions. For example, Planned Parenthood of Eastern Pennsylvania v. Casey, found constitutional provisions of $18 \mathrm{~Pa}$. Cons.Stat. $\S 3205$ (1990), which required doctors to tell women

the nature of the procedure, the health risks of the abortion and of childbirth, and the "probable gestational age of the unborn child." The physician . . . must inform the woman of the availability of printed materials published by the State describing the fetus and providing information about medical assistance for childbirth, information about child support from the father, and a list of agencies which provide adoption and other services as alternatives to abortion. ${ }^{24}$

Informed consent reaches its acme - or nadir - in the IRB system. No researcher at an institution receiving federal funds who interacts with or collects "private" information about a human being may proceed without the approval of an "Institutional Review Board" that (among other things) must ratify the language in which the consent of research subjects is sought. ${ }^{25}$

\section{Contract Boilerplate}

19 Tracy E. Miller \& William M. Sage, Disclosing Physician Financial Incentives, 281 JAMA 1424, 1426 (1999). For example, one "court ruled that payments received from a pharmaceutical manufacturer to prescribe a particular medication were within a physician's informed consent obligation." Ibid.

${ }^{20}$ Moore v. Regents of the University of California, 793 P.2d 479, 485 (Cal. 1990).

${ }^{21}$ Johnson v. Kokemoor, 545 NW2d 495 (Wisc 1996).

22 William M. Sage, Regulating Through Information Disclosure Laws and American Health Care, 99 Columbia L Rev 1701 (1999).

${ }^{23}$ Joan H. Krause, Reconceptualizing Informed Consent in an Era of Health Care Cost Containment, 85 Iowa L Rev 261 (1999).

24505 US 833 (1992).

25 See generally 45 CFR 46. 
Truth-in-lending acts and informed-consent doctrine concern specific transactions. The common law, however, has long required contracting party to make disclosures. ${ }^{26}$ Recently, much attention has been given to a particular set of contract disclosures - the fine print of contracts. Many terms of many consumer transactions are drafted by businesses and tucked away in the package ("shrinkwraps"), or displayed online with an "I Agree" button ("clickwraps"), or printed on the back of order forms. These terms usually treat contingent contractual rights - like warranties, dispute resolution, and remedies. Because this obscurely written and placed boilerplate may conceal unanticipated and tricky traps, legislators, courts, and commentators have devised disclosure requirements. In response to several court decisions holding these standard forms binding even if not disclosed prior to the transaction, ${ }^{27}$ reform has been percolating. For example, the ALI's proposed Principles of the Law of Software Contracting exclude such terms from the contract if there is no opportunity to read before a purchase. $^{28}$ The rationale is typical: to protect the autonomy of consumers. ${ }^{29}$ Similarly, the European Draft Common Frame of Reference (a proposed EC commercial code) deals with the "consumer at a significant informational disadvantage" by mandating disclosures. ${ }^{30}$

The "opportunity to read" principle also appears in specific contexts. For example, the Magnuson-Moss Warranty Act and UCC Section 2-316 both require a warranty disclaimer to be "conspicuously" disclosed in "simple and readily understood language."31 Similar state laws apply to issues like mandatory arbitration, ${ }^{32}$ risk warnings, and disclosure of modifications of the contract. $^{33}$ The familiar ALLCAPS font in consumer contracts is the artifact of such requirements.

The doctrine of unconscionability also generates contract disclosure requirements. Undisclosed terms can be procedurally unconscionable, especially if they conflict with consumers' reasonable expectations. ${ }^{34}$ A clause waiving liability for negligence - if not illegal per se - must be clearly and conspicuously printed or explicitly pointed out. ${ }^{35}$

\section{B. Other Provinces in the Disclosure Empire}

\footnotetext{
${ }^{26}$ For an illuminating discussion of the general contract law disclosure doctrine, see Richard Craswell, Taking Information Seriously: Misrepresentation and Nondisclosure in Contract and Law and Elsewhere, 92 Virg. L.Rev. 565 (2006).

${ }^{27}$ ProCD v. Zeidenberg, 86 F.3d 1447 (7 $7^{\text {th }}$ Cir. 1996); Hill v. Gateway 2000, 105 F.3d 1147 (7th Cir. 1997).

${ }^{28}$ The American Law Institute, Principles of the Law of Software Contracts, Discussion Draft (March 30, 2007) $\S \S 2.01(\mathrm{c})(1), 2.02(\mathrm{c})(2)$.

${ }^{29}$ ALI Principles, Reporter's note Promoting Reading and the Opportunity to Read Terms, at 130-131.

${ }^{30}$ Principles, Definitions and Model Rules of European Private Law, Draft Common Frame of Reference (2008) (hereinafter 'DCFR') $\S \S$ II.-3:103, 3:105.

${ }^{31} 15$ U.C.S.A. § 2302; Uniform Commercial Code $\S \S 2-316,2-719$.

${ }^{32}$ E.g., Cal. Health \& Saf. Code $\S 1363.1$ (2008) (disclosure of mandatory arbitration in health plan contracts).

${ }^{33} 205$ ILCS 635/5-9 (disclosure of any material change in terms of loan).

${ }^{34}$ Richard Craswell, Property Rules and Liability Rules in Unconscionability and Related Doctrines, 60 U. Chi. L.Rev. 1, 55-60 (1993).

${ }^{35}$ Edward L. Rubin, Toward a General Theory of Waiver, 28 UCLA L Rev 478, 522-523 (1980-1981).
} 


\section{Financial Transactions}

Numerous statutes apply TILA-like rules to other financial accounts: depository, savings, mutual funds, etc. ${ }^{36}$ These disclosures are sometimes comprehensive, as in TILA or the Good Faith Estimates in mortgage disclosures, which include numerous items. Other times, the disclosures are "segregated"-statutes that mandate disclosure of a particular item in a separate form, in attempt to highlight its presence. For example, recently the Fed promulgated a new regulation to address the problem of high overdraft fees on ATM and Debit withdrawal. ${ }^{37}$ The regulation did not mandate the actual fees banks charge. It only required that consumers be allowed to opt in to the scheme, by receiving a disclosure notice on a separate form and signing a separate dotted line.

Financial disclosures stretch to every domain of consumer protection. Businesses planning to use clients' financial information must tell them of their right to opt out and explain, in fine print, how to. ${ }^{38}$ Financial brokers must disclose their experience, obligations, and fees and even warn clients that the State does not recommend using their services. ${ }^{39}$ Investment advisers must confess a catalog of past misdeeds, including rule violations and disciplinary actions. ${ }^{40}$ Credit-reporting agencies must tell consumers their federal and state rights. ${ }^{41}$ Creditors bundling credit insurance with a loan must tell customers whether the insurance is required by law and that it might be duplicative. ${ }^{42}$ ATM operators must warn customers not to use ATMs at night, alone, or in perilous circumstances. ${ }^{43}$

A classic instance of mandated disclosure is the congeries of securities laws and regulations. These are significantly intended for and used by experts and thus fall outside our scope. However, they also govern sales to the laity, and some of their provisions are specifically intended to help amateurs.

\section{Insurance}

\footnotetext{
${ }^{36}$ Banks must disclose information to depositors when they open accounts or request some transactions. See Cal. Fin. Code $\S 23035(d)(2008)$; Consumer Deposit Account Act, 205 ILCS 605/3 (Illinois financial institution disclosures of consumer deposit accounts terms). The Truth in Savings Act - as implemented by Regulation DD - tells depository institutions what costs and terms they must reveal and how. See 12 U.S.C. $\S \S 4301$ et seq.; Regulation DD, 12 C.F.R. $\S 230$ (2000). SEC regulations require disclosing mutual fund fees. See Shareholder Reports and Quarterly Portfolio Disclosure of Registered Management Investment Companies, Exchange Act Release Nos. 33-8393, 34-49333, IC-26372, File No. S7-51-02, 17 C.F.R. $\S \S 210,239,249,270, \& 274$; RIN 3235-AG64, 2004 SEC LEXIS 474 (Feb. 27, 2004).

${ }^{37}$ See http://www.federalreserve.gov/newsevents/press/bcreg/bcreg20091112a1.pdf.

${ }^{38}$ Michigan MCLS $\S 500.519,529,543$ (2008) (disclosure of consumers' right to opt out of the transfer of their private information to third parties).

${ }^{39}$ Illinois Loan Brokers Act, 815 ILCS 175/15-30 (Illinois 1995) (disclosures required by loan brokers).

${ }^{40}$ Ill. Admins. Code. Tit. 14, $§ 130.847$ (Financial and Disciplinary Information that investment advisers must disclose to clients).

${ }^{41}$ Fair Credit Reporting Act $\S 608(\mathrm{c})(2)$.

${ }^{42} \mathrm{Cal}$ Ins. Code $\S 1758.97$ (2007) (disclosure by credit insurance agents).

${ }^{43}$ Automated Teller Machine Security Act, 205 ILCS 695/15.
} 
Insurance transactions require complex calculations about cloudy contingencies. Insurance buyers cannot easily tell the value of their purchase, since it depends on actuarial estimates they do not know and cannot analyze. Nor can the quality of the insurance be ascertained until a loss materializes, when it's too late to switch to a better product. These burdens are compounded when insurance is bundled with financial investment (as in life insurance or mortgage-related insurance products). So lawmakers try to protect the bewildered.

Some protection involves regulatory oversight, such as precertification of the standardized insurance policy, but much of it comes from a mosaic of disclosure statutes. Often insurers must not only state policy terms, they also must highlight terms that are especially important or that might cause unexpected agonies. So fees separate from the policy premiums must be disclosed. ${ }^{44}$ Insurance financing acts require disclosure of the ways premiums can be paid. $^{45}$ Insurance products with investment risks must reveal them. ${ }^{46}$ Residential property insurance acts require a reminder that rebuilding costs may differ from market value. ${ }^{47}$ Some legislators have drafted a residential-property insureds" "bills of rights" which, too, must be disclosed. $^{48}$ And since disclosure requirements are supposed to deter people from buying unneeded insurance, consumers must be reminded that they need not buy insurance that is bundled with another service, like car-rental/auto-insurance ${ }^{49}$ or self-storage/propertyinsurance. ${ }^{50}$

Life insurance proliferates opportunities to make bad decisions. For example, people sometimes regret assigning insurance benefits. Their right to change their minds must be disclosed. $^{51}$ Similarly, a statute might require a viatical settlement provider to tell the viator about alternatives like accelerated benefits from the life insurer; to state all the adverse consequences of the settlement, like tax, creditor rights, and loss of Medicaid rights; and to explain all the other benefits forfeited. ${ }^{52}$

\section{Health Care}

Informed consent is only the beginning of disclosure requirements in health law. For example, because Congress believed advance directives were insufficiently used, the Patient Self-Determination Act (PSDA) requires hospitals, nursing facilities, home health agencies,

${ }^{44} 215$ ILCS 5/500-80 (disclosure of insurance commissions).

${ }^{45}$ Cal. Ins. Code $\S 778(4)(a)(2007)$ (disclosure by insurance broker-agent of finance and repayment obligations relating to fire and casualty insurance premiums); 215 ILCS 5/513a9 (disclosures in premium financing and premium insurance agreements).

${ }^{46}$ Cal. Ins. Code $\S 762$ (2007) (disclosure by seller of the risks involved in the investment) 215 ILCS $5 / 1409$ (disclosure when the advertised insurance product involves investment risk).

${ }^{47}$ Cal. Ins. Code $\S \S 10101,10102$ (a) (2008) (disclosures in residential property insurance).

${ }^{48}$ Cal. Ins. Code $\$ 10103.5$ (2007) (disclosures and explanations the "Bill of Rights" must contain).

${ }^{49} \mathrm{Cal}$. Ins. Code $\S 1758.86$ (2007) (disclose that insurance is not mandatory and may already be provided by other sources); 215 ILCS 5/500-105 and 625 ILCS 27/20 (Illinois statute, same).

${ }^{50} 215$ ILCS 5/500-107 (disclosure by storage facility that coverage may be duplicate).

${ }^{51}$ Michigan MCL $\S 500.2080$ (2008) (right of insured to revoke assignment of life insurance proceeds to cemetery or funeral services).

52215 ILCS $158 / 35$. In a viatical settlement, terminally ill insureds sell their death benefits in exchange for annuities or other immediate support payments. 
hospices, and managed care organizations to give patients "written information . . concerning (i) an individual's rights under State law . . . to make decisions concerning . . . medical care, including the right to ... refuse ... treatment and the right to formulate advance directives, and (ii) the written policies of the provider . . . respecting the implementation of such rights . . ..,53 Because HHS believed patients' privacy was endangered, HIPAA elaborately requires institutions to tell patients their privacy rules. Because conflicts of interest are widely feared, health-care services must disclose their use of "financial bonuses in referrals or allocation of services. $^{54}$

Another bounteous fount of mandated disclosure is a program both employers and the government have recently promoted: "consumer-directed health-care." It gives consumers an economic stake in choosing their health-care plan; their doctors, hospitals, and other providers; and tests and treatments. ${ }^{55}$ As the former HHS secretary said, "We have a better option, to provide beneficiaries with reliable information about the cost and quality of their care. When given that kind of information, we know that consumers will make decisions that drive costs down and the quality up." ${ }^{, 56}$ This program will work only if patients are informed about the costs and quality of all that they buy, and so disclosures have both been directly mandated and indirectly necessitated.

\section{Miranda Warnings}

The Supreme Court famously enforced the Fifth Amendment by mandating disclosures. "[T] he person in custody must, prior to interrogation, be clearly informed that he or she has the right to remain silent, and that anything the person says may be used against that person in court; the person must be clearly informed that he or she has the right to consult with an attorney and to have that attorney present during questioning, and that, if he or she is indigent, an attorney will be provided at no cost to represent him or her." $" 57$ Many jurisdictions try to make the disclosure "meaningful" by requiring, for example, that it be in a language the suspect understands, that the suspect be asked whether he understood the warning, and that the suspect be told of his right to end questioning.

\section{Goods and Services}

Many consumers have encountered market-wide disclosure rules like price-labelling requirements, ${ }^{58}$ nutrition facts, or truth-in-advertising laws. ${ }^{59}$ Less familiar are sector-specific

\footnotetext{
${ }^{53} 42$ USCA $\S 1395 \mathrm{cc}(\mathrm{f})(1)(\mathrm{A})$.

${ }^{54}$ Cal. Health \& Saf. Code $\S 1367.10$ (2007) (health-service plans disclosure of financial incentives).

${ }^{55}$ For an extended treatment, see Carl E. Schneider \& Mark A. Hall, The Patient Life: Can Consumers Direct Health Care? 35 American Journal of Law \& Medicine 7, 62 - 65 (2009).

${ }^{56}$ Robert Pear, Bush Proposes Linking the Medicare Drug Premium to Beneficiaries' Income, NY Times, Feb 16, 2008 (quoting Michael Levitt).

${ }^{57}$ Miranda v. Arizona, 384 U.S. 436 (1966).

${ }^{58}$ E.g., N.Y. Agriculture and Markets Law 214-I (Consol. 2001).

${ }^{59}$ See, e.g., $\S 15$ of the FTC Act, 15 U.S.C $\S 55(\mathrm{a})(1)$ (1976) (when an advertisement is misleading). See also Beales et al, supra note , at 495-501.
} 
rules. Even a glimpse at the extensive and eclectic list shows how much law-makers rely on mandated disclosure.

Notorious exploitation and improvident purchases have inspired statutes dealing with "death products" - caskets, burial and funeral services, and cemetery plots ${ }^{60}$ The FTC's Funeral Industry Practices Rule requires price disclosures. ${ }^{61}$ States oblige service providers to disclose matters relating to their expertise, the payment scheme, customers' options to withdraw from commitments, items not included in the "package," and even notification that "THERE IS NO SCIENTIFIC OR OTHER EVIDENCE THAT ANY CASKET WITH A SEALING DEVICE WILL PRESERVE HUMAN REMAINS."62

Many mandated disclosures apply to car transactions. Dealers must reveal problems with the vehicle. ${ }^{63}$ Used-car sellers must report odometer readings (for the forgetful buyer?). ${ }^{64}$ Cartowing services must state their charges, policies, and insurance before towing. ${ }^{65}$ Repair shops and parts sellers must disclose their fee structure and the kind of parts they use and give itemized estimates. $^{66}$ Many specific repairs, like installing ball joints, have their own information mandates. ${ }^{67}$ Car rental agencies must describe customers' liability for lost and damaged cars and how it might be covered if customers decline rental-company insurance. ${ }^{68}$ Motor clubs that refer members to dealers must reveal referral fees dealers pay. ${ }^{69}$

Real-estate agents must tell homebuyers about the agents' duties to them. ${ }^{70}$ Residential real-estate developers must name anyone owning at least $10 \%$ of the business. Residential landlords must admit to code violations and provide case numbers of pending litigation. ${ }^{71}$ Time- $^{-}$

\footnotetext{
${ }^{60}$ The classic expose is Jessica Mitford, The American Way of Death (Vintage, 2000).

${ }^{61} 39$ C.F.R $\S 453$ (especially $\S 453.2$ ). See also FED. TRADE COMM'N, FACTS FOR BUSINESS: COMPLYING WITH THE FUNERAL RULE (2004), available online at http://www.ftc.gov/bcp/conline/pubs/buspubs/funeral.pdf.

${ }^{62}$ For caskets, see Cal. Bus. \& Prof. Code $\S 17530.7$ (2007) (disclosures regarding the casket product and that the seller is not a funeral director). For pre-need cemetery sales, see, Illinois Pre-Need Cemetery Sales Act, 815 ILCS 390/14(a); for pre-need burial, see Illinois Funeral or Burial Funds Act, 225 ILCS 45/1a-1(a)(3)(A). See also Ill. Admin. Code Tit. 38, § 610 EXH. A (required disclosures include all the term, descriptions, payment time, and cancellation policy).

${ }^{63}$ Cal. Civ. Code $\S 1793.23$ (2007) (disclosure if car was repurchased due to defect or is a "lemon law buyback"); 625 ILCS 5/5-104.2 (1993)(disclose if car was repurchased due to failure of warranty).

${ }^{64}$ Michigan MCLS § 257.233a (disclosure of odometer and whether it reflects actual mileage).

${ }^{65}$ Illinois 625 ILCS 5/18d-120 and 5/18-130 (disclosure to vehicle owner or operation before towing of damaged or disabled vehicle).

${ }^{66}$ Automotive Repair Act, 815 ILCS 306/15, 306/20, and 306/50 (1998) and 815 ILCS 308/15, 20, and 50 (disclosure of estimated itemized repair costs); See also Cal. Bus. \& Prof. Code auto replacement parts dealers; 9875.1 (2007)(disclose if repair parts are derived from secondary source and who warrants them);

${ }^{67}$ Chicago 4-228 § 120 (disclosures regarding ball joint assemblies).

${ }^{68}$ Cal. Civ. Code $\$ 1936$ (2008) (disclosures at the car rental counter).

${ }^{69}$ Cal. Ins. Code $§ 12150(1)$ (2007) (disclosure by motor clubs of arrangements with referred dealers).

${ }^{70}$ Michigan MCLS $\S 339.2517$ (2008) (disclosure by real estate agent to buyers "all information known to the buyer's agent about the willingness of the seller to complete the sale or to accept a lower price.")

${ }^{71}$ Chicago 5-12 § 100 (disclosures affecting habitability).
} 


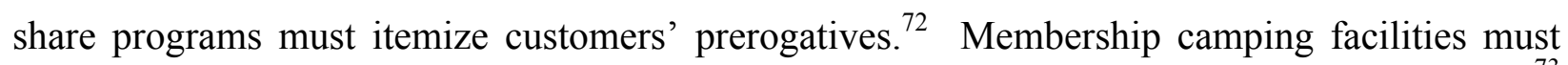
reveal the operator's experience, the chief officers' business backgrounds, and much more. ${ }^{73}$ Mobil-home sellers or lessors must annually disclose fees, obligations, and rent increases. ${ }^{74}$

Home-improvement contracts and home-service and -repair contracts must disclose clients' rights, including a lay (but long) definition of a mechanic's lien. ${ }^{75}$ Statutes even target specific activities: alarm installer, for example, must disclose and define any mechanic's lien. ${ }^{76}$

Vocational schools enjoy lengthy (and costly) disclosure mandates, including more than 20 statistics about graduation rates, re-enrollments, exam pass rates, graduates' job prospects, and more. ${ }^{77}$ Barber, nail, and cosmetology schools must disclose graduation rates and placement statistics. $^{78}$ Traffic-violator schools must astonish applicants with warnings that they might meet repeat traffic offenders and that instructors are less robustly trained than those in licensed driving schools (who in turn disclose quite a bit themselves). ${ }^{79}$ Colleges and universities must provide current and prospective students with crime statistics. ${ }^{80}$

The list goes on: sellers of electricity must disclose their remuneration, ${ }^{81}$ immigration consultants their past frauds, ${ }^{82}$ dog dealers and breeders the buyers' rights to return sick or dead animals. ${ }^{83}$ Travel services and agents must specify orally and in writing travelers' right to certain claims. ${ }^{84}$ Art dealers must reveal subtleties like medium, artist, and signature. ${ }^{85}$ Restaurants and food establishments must warn about not-overcooked food. ${ }^{86}$ They also have to post signs in

${ }^{72}$ Cal. Bus. \& Prof. Code $\S 11211,11216$ (2007) (disclosure in exchange program and in time-shares);

${ }^{73}$ Cal. Civ. Code $\S 1812.302$ (2007) (disclosures by camping operators regarding their experience and record, as well as the facilities available).

${ }^{74}$ Mobile Home Landlord and Tenant Rights Act, 765 ILCS 745/6.5 (2004).

${ }^{75}$ Cal. Bus. \& Prof. Code $\S 7159$ (2007) (disclosure by home improvement contractors of multiple aspects of the statutory rights and obligations, including what it means to be subject to a mechanic's lien.); $\$ 7159.10$ (a long list of disclosures in service contracts between $\$ 500$ and $\$ 750$ ).

${ }^{76}$ Cal. Bus. \& Prof. Code $\S 7599.54$ (2007) (disclosure by alarm installers).

${ }^{77}$ Private Business and Vocational Schools Act, 105 ILCS 425/15.1 (Illinois disclosure statute applying to enrollment in vocations schools).

${ }^{78}$ Barber, Cosmetology, Esthetics, and Nail Technology Act, 225 ILCS 410/3B-12(a) (Illinois, 1985) (numerous disclosures required in school enrollment agreements)

${ }^{79}$ Cal. Veh. Code. $§ 11200(1)$ (2007) (disclosure by traffic violator schools); NJSA 13:23-5.16 (disclosure by driving schools).

${ }^{80} 20$ USC $\S 1092$ (f).

${ }^{81} 220$ ILCS 5/16-115C(e)(1) (disclosure by agent its income from third parties).

${ }^{82}$ The Consumer Fraud and Deceptive Business Practices Act, 815 ILCS 505/2AA (persons providing "immigration assistance service" must disclose that they are not attorneys, not accredited to represent before the government, and that they are not entitled to retain any documents for any purposes).

${ }^{83}$ Cal. Health \& Saf. Cod $\S \S 122100,122190$ (2007) (disclosure by breeders and by pet dealers of buyers' right in case dogs purchased are ill or die).

${ }^{84}$ Cal. Bus. \& Prof. Code $\S 17550.13$ (2007) (disclosure by "sellers of travel" of passengers' rights to make certain claims for refunds).

${ }^{85}$ Cal. Civ. Cod. $\S \S 1742,1744$ (2007) (matters that must be disclosed prior to sale of fine print, photograph, or sculpture).

${ }^{86}$ Michigan MCLS § 289.6149 (2008) (public disclosure of risks of undercooked or raw food, and the manner in which it has to be made). 
toilets reading: "No person who is affected with any disease in a communicable form, or is a carrier of such disease, or who has a gastrointestinal disturbance, sore throat or a discharging or infected wound, sore or lesion, shall handle food, drink, utensils, or equipment."87 And food dealers must explain "the basis upon which . . [Halal] representations are made." 88

We have not exhausted the catalog of mandated disclosures, but we have surely exhausted our readers (and ourselves). This sampling suggests that mandated disclosure is a staple of the regulatory repertory.

\section{The Documented FaIlure OF MAndated Disclosure}

The great paradox of the Disclosure Empire is that even as it grows, so also grows the evidence that mandated disclosure repeatedly fails to accomplish its ends. We proffer several kinds of evidence of that failure. First, disclosers do not always provide and disclosees do not always receive information. Second, disclosees often do not read disclosed information, do not understand it when they read it, and do not use it even if they understand it. Third, mandated disclosure does not improve disclosees' decisions. Following the model of the previous Part, we first discuss the evidence about the three paradigmatic examples and then survey other areas.

\section{A. The Three Paradigmatic Cases of Mandated Disclosure}

\section{The Terms of Credit}

Truth-in-lending legislation is a crown jewel of the Disclosure Empire, and if mandated disclosure works anywhere, it should work here. Unlike some disclosure regimes, TILA ${ }^{89}$ was actually given thought. Congress spent eight years debating it. The bill's proponents largely got the law they wanted. ${ }^{90}$ They expected disclosure of APRs to produce sensible shopping for credit. Administrative agencies have repeatedly labored and issued regulations intended to make TILA work.

Consumers are more aware of APRs, but they remain confused about using them. One leading study, for example, showed that as knowledge of the APR increased, knowledge of the finance charge itself (expressed in dollars) declined. ${ }^{91}$ Many studies find consumers' understanding of APRs severely limited. ${ }^{92}$ Apparently, most consumers (mistakenly) think the disclosed rate is a percentage of the initial balance, rather than the average or declining balance. So they consistently imagine the finance charges are twice the actual figure. In short, truth-in-

\footnotetext{
${ }^{87}$ Chicago city ordinance [CITE]

${ }^{88} 815$ ILCS 505/2LL(a) (2007).

${ }^{89} 15$ U.S.C. $\S \S 1601$ et seq., especially $\S 1606$ and $\S \S 1631-49$.

90 Edward L. Rubin, Legislative Methodology: Some Lessons from the Truth-in-Lending Act, 80 Georgetown L. J. 233, 242 (1991).

91

${ }^{92}$ Regina Y. Chang and Sherman Hanna, Consumer Credit Search Behaviori, 16 J. Consumer Stud. \& Home Econ. 207 (1992); James H. McAlexander and Debra L. Scammon, Are Disclosures Sufficient? A Micro Analysis of Impact in the Financial Services Market, 7 J. Pub. Pol'y \& Marketing 186 (1988);
} 
lending legislation has made consumers more aware but left them poorly informed. ${ }^{93}$ Furthermore, understanding of terms TILA doesn't cover - like the dollar amount of finance charges in open-end credit transactions - is poor. For example, $90 \%$ of consumers misunderstand the relation between the interest rate lenders quote and the APR and thus misperceive the cost of credit. $^{94}$ Worse, only well-educated and well-off consumers seem to have enjoyed whatever increased awareness of credit terms TILA brought. ${ }^{95}$

More fundamentally, there is little reason to think disclosure statutes improved the terms borrowers pay. For example, one study suggests that the Credit and Charge Card Disclosure Act of 1988 did not increase competition in the credit card industry. Interest rates and funding costs did not exhibit any measurable improvement following the disclosure act. ${ }^{96}$

\section{Informed Consent}

Informed consent has been conventional wisdom so long enough that many studies explore it. They show that informed consent does not achieve its purpose. ${ }^{97}$ First, doctors give patients nothing like the information they would need to make educated decisions. For example, Braddock et al examined discussions between doctors and patients, particularly "(1) the patient's role in decision making, (2) the nature of the decision, (3) alternatives, (4) pros (benefits) and cons (risks) of the alternatives, (5) uncertainties associated with the decision, (6) an assessment of the patient's understanding of the decision, and (7) an exploration of the patient's preferences." The "completeness of informed decision making was low. . . [F] ew decisions (9.0\%) met criteria for completeness of informed decision making." 98

Second, good ways to communicate information have proved elusive. Forms used to provide information frequently exceed readability standards. 99 "Many patients have limited health literacy and can have difficulty understanding information even when efforts are made to communicate it appropriately. ${ }^{100}$

\footnotetext{
${ }^{93}$ Rubin, supra note \&\&, at 235-236.

94 Jinkook Lee \& Jeanne M. Hogarth, The Price of Money: Consumers Understanding of APRs and Contract Interest Rates, 18 Journal of Public Policy \& Marketing 66, 67 (1999).

95 Jean Kinsey and Ray McAlister, Consumer Knowledge of the Costs of Open-End-Credit, $15 \mathrm{~J}$. Consumer Affairs 249 (1981).

${ }^{96}$ Sherrill Shaffer, The Competitive Impact of Disclosure Requirements in the Credit Card Industry, 15 Journal of Regulatory Economics 183, (1999).

${ }^{97}$ For a brief exposition of this case, see Carl E. Schneider, After Autonomy, Wake Forest L Rev 411 (2006). For a detailed assessment of it, see Carl E. Schneider, The Practice of Autonomy: Patients, Doctors, and Medical Decisions (Oxford U Press, 1998). For an extended comparison of the law of informed consent and the reality of it, see the first chapter of Marsha Garrison \& Carl E. Schneider, The Law of Bioethics: Individual Autonomy and Social Regulation (West, 2009) ( $2^{\text {nd }}$ ed).

${ }_{98}^{98}$ Decision Making in Outpatient Practice: Time to Get Back to Basics, 282 JAMA 2313 (1999).

99 M.K. Paasche-Orlow et al, Readability Standards for Informed-Consent Forms as Compared with Actual Readability, 20 NEJM 348 (2003).

${ }^{100}$ Margaret L. Schwarze et al, Exploring Patient Preferences for Infrainguinal Bypass Operation, 202 Journal of the American College of Surgeons 445, 450 (2006) (doi: 10.1016/j.jamcollsurg.2005.11.009).
} 
Third, and critically, even when doctors lavish information on patients, many of them neither understand nor remember it. Even when asked simple questions immediately after far more education than clinicians can ever offer, patients commonly can answer only a third to a half of them. ${ }^{101}$ Endless studies reveal that despite extravagant efforts at educating patients, they cannot remember and presumably have not really understood the risks of treatment that were revealed to them. While memory of risk disclosures is most often studied, there is also highly plausible evidence that patients do not properly understand the possible benefits of treatments. In one study, for example, "patients' expectations of improvements in their functional status after infrainguinal bypass operation were greater than those suggested by previous research."102

Fourth, despite decades of legal and medical efforts, patients regularly make life and death decisions without the most basic information and with many misconceptions. In one large study, for example, fewer than half the breast-cancer patients understood survival rates and fewer than a fifth understood recurrence rates, even though the patients thought those factors important and had consulted "a relatively large variety of information sources."103 Fifth, even if these educational problems could be solved, the information proffered would frequently go unused. Patients rarely change their minds when given informed consent. ${ }^{104}$ Patients numerously prefer not to make medical decisions, and the sicker and older they are, the less they wish to do so. Furthermore, patients frequently make decisions before having been "consented" and often rely on a single factor. ${ }^{105}$

Could informed consent work if only doctors tried harder? No. Even the most dedicated efforts disappoint. For example, one study truly tried to enlighten patients about conflicts of interest created by the ways HMOs paid doctors. It "went to unusual lengths to ensure that the essential information was conveyed. Information . . . was disclosed by mail, followed by phone calls in which subjects' understanding was tested and reinforced through repetition and simple quiz questions." While knowledge of incentives was greatly increased, a majority still could not correctly answer more than half of the questions. ${ }^{106}$ "[E]ven the extensive and [desperately] impractical methods used here to attempt to convey only limited knowledge of incentives fell well short of complete success.",107

Even when legislatures have made special efforts to use informed consent in focused ways, the news has been discouraging. Statutes have used expert boards to formulate special

${ }^{101}$ E.g., David A. Herz et al, Informed Consent: Is It a Myth?, 30 Neurosurgery 453 (1992).

102 Margaret L. Schwarze et al, Exploring Patient Preferences for Infrainguinal Bypass Operation, 202 Journal of the American College of Surgeons 445, 449 (2006) (doi: 10.1016/j.jamcollsurg.2005.11.009).

103 Angela Fagerlin et al, An Informed Decision? Breast Cancer Patients and Their Knowledge About Treatment, _ Patient Education \& Counseling __ (2006).

${ }^{104}$ Ruth R. Faden, et al, Disclosure of Information to Patients in Medical Care, 19 Medical Care 718, 732 (1981); Paul S. Appelbaum, Charles W. Lidz, \& Alan Meisel, Informed Consent: Legal Theory and Clinical Practice 202 (Oxford U Press, 1987).

${ }^{105}$ Carl E. Schneider, The Practice of Autonomy: Patients, Doctors, and Medical Decisions (Oxford U Press, 1998).

${ }^{106}$ Mark A. Hall et al, How Disclosing HMO Physician Incentives Affects Trust, 21 Health Affairs 197, 203 (2002).

${ }^{107}$ Ibid at 205. 
disclosures about mastectomies and even threatened physician-discipline procedures. ${ }^{108}$ But while these statutes were "associated with slight increases (6 to 13 percent)" in use of lumpectomies, the "increases were transient, . . lasting from 3 to 12 months."

If informed consent should work anywhere, it is in consent to participate in research: The disclosures' exact words and procedures must be approved in advance by a regulatory agency (the IRB). But again the evidence is disappointing. For example, trials of cancer treatments are riskier than most research, so disclosures have been extensively examined. Research subjects have urgent reasons to understand their choices. In an especially careful but otherwise typical study, extravagant time was spent educating the subjects. They lengthily assessed their choices and consulted "additional sources of information and had support from family or friends. Nonetheless, knowledge varied widely and there were important misunderstandings. Major deficiencies included not being aware of non-standard treatment, the potential for incremental risk or discomfort, the unproven nature of treatment, and the uncertainty of benefits to self." 110 More specifically, many of them "did not realize that the treatment being researched was not proven to be the best for their cancer, that the study used non-standard treatments or procedures, that participation might carry incremental risk, or that they might not receive direct medical benefit from participation.",111

A final indication of the failure of informed consent is that its advocates must continue to add new disclosures for it to work. Standard informed consent having failed, one study advocates adding all this: (1) "[I]n-depth exploration by providers of patients' affective and cognitive processes." (2) Exploration of "uncertainties and limitations both in the provider's own knowledge and in the state of the science." (3) An inquiry into patients" "motivations, beliefs, and values." (4) Exploration of how patients think decisions should be made. (5) An individualized process "in the context of an ongoing relationship with a trusted health care provider."

\section{Contract Boilerplate}

Even when the standard form contract is available, very few people read it. Empirical work is scant, perhaps because of the folk knowledge that no one reads boilerplate. Still, some direct as well as indirect evidence suggests that almost no consumers read boilerplate, even when it is fully and conspicuously disclosed.

Anecdotal evidence comes from an experiment by PCpitstop.com, which put a clause in an end-user license agreement promising $\$ 1000$ to a user who responded. After four months and

\footnotetext{
108 Joan H. Krause, Reconceptualizing Informed Consent in an Era of Health Care Cost Containment, 85 Iowa L Rev 261 (1999).

109 Ann Butler Nattinger et al, The Effect of Legislative Requirements on the Use of Breast-Conserving Surgery, 335 NEJM 1035 (1996).

${ }^{110}$ Steven Joffe et al, Quality of Informed Consent in Cancer Clinical Trials: A Cross-Sectional Survey, 358 Lancet 1772, 1775 (2001).

${ }^{111}$ Ibid at 1774.

112 Gail Geller et al, "Decoding” Informed Consent: Insights from Women Regarding Breast Cancer Susceptibility Testing, 27 Hastings Center Report 28 (March/April 1997).
} 
3000 downloads someone finally did. ${ }^{113}$ (All this in a forum for the sophisticated and savvy.) More systematically, Bakos et al found that roughly 1 in 1000 people actually scrolls through online boilerplate, when it is disclosed prior to the agreement. ${ }^{114}$ Worse, that "reader" spent a median time of 29 seconds on the webpage. Since these pages of legalese average over 2,000 words, since people can read fewer than 150 words in that time, and since boilerplate is notoriously complex, readership is effectively zero. ${ }^{115}$

\section{B. The Failures of Other Mandated Disclosures}

The Patient Self-Determination Act (PSDA) requires health-care institutions to tell patients about advance directives so that they might decide how they should be treated when incompetent to make decisions. The living will is the primary means of doing so. The PSDA appears not to have encouraged people to use living wills, and living wills cannot easily reflect people's considered preferences or state them in effective ways. ${ }^{116}$ In short, the law "has 'done a disservice to most real patients and their families and caregivers.' It has promoted the execution of uninformed and under-informed advance directives .... . The PSDA looks like a utter failure." 117 Many efforts have been made to help consumers in the various instantiations of consumer-directed health-care. Surveys of patients and clinicians suggest that report cards have little effect. ${ }^{118}$ Patients are rarely aware of these disclosures, and even more rarely understand and use them. ${ }^{119}$ A study of Medicare beneficiaries, for example, showed that $90 \%$ either knew nothing or had limited knowledge about HMOs, and only 16 percent had adequate knowledge to choose between traditional Medicare and an HMO. ${ }^{120}$ Another study found that $67 \%$ of respondents did not have a good grasp of the differences between traditional fee-for-service and HMO plans, and many did not know the most fundamental facts about HMO plans. Only about $20 \%$ of insurance purchasers reported using any systematic approach for selecting highperforming, cost-effective plans. Most purchasers just looked to see if the plan was accredited,

\footnotetext{
${ }^{113}$ See http://pcpitstop.com/spycheck/eula.asp.

${ }^{114}$ Yannis Bakos, Florencia Marotta-Wurgler, and David R. Trossen, Does Anyone Read the Fine Print? Testing a Law and Economics Approach to Standard Form Contracts (Mimeo., 2009).

${ }^{115}$ In a less rigorous study, Robert Hillman surveyed first-year Cornell Contracts students on their readership of boilerplate and found XX. See Robert Hillman, Online Standard Form Contracting Practices - A Survey and Discussion of Legal Implications, in Is CONSUMER PROTECTION AN ANACHRONISM IN THE INFORMATION ECONOMY (2006) We suspect this study significantly overstates true readership ratios. It is not clear that reports by the survey subjects are credible. Furthermore, the findings apply at best to an amiable but atypical population - contract-law students.

${ }^{116}$ For an extended defense of this position, see Angela Fagerlin \& Carl E. Schneider, Enough: The Failure of the Living Will, 34 Hastings Center Report 30 (March/April 2004).

117 Thaddeus Mason Pope, The Maladaptation of Miranda to Advance Directives: a Critique of the Implementation of the Patient Self-Determination Act, 9 Health Matrix 139, 167 (1999).

${ }^{118}$ E. Schneider and A. Epstein, Use of Public Performance Reports: A Survey of Patients Undergoing Cardiac Surgery, 279 J. Amer. Med. Assoc. 1638 (1998); M.N. Marshall et al., the Public Release of Performance Data: What do We Expect to Gain? A Review of Evidence, 283 JAMA 1866 (2000).

119 Arnold M. Epstein, Rolling Down the Runway: The Challenges Ahead for Quality Report Cards, 16 Journal of American Medical Affairs 1691 (1998).

${ }^{120}$ Judith H. Hibbard et al, Can Medicare Beneficiaries Make Informed Choices?, 17 Health Affairs 181 (1998).
} 
and did not personally investigate any other aspects. ${ }^{121}$

Evaluations of medical care and disclosure of "report cards" might produce better care even if consumers rarely read the evaluations, since providers presumably will work to win good reviews. Indeed, some studies based on clinical data speak of significant improvements in care, but these findings notoriously struggle with selection biases. ${ }^{122}$ One study showed that providers seek to protect their ratings by shifting their efforts from unreported dimensions of care toward the reported dimensions and found no evidence that overall quality of care had increased. ${ }^{123} \mathrm{~A}$ recent and refined study concluded that report cards had undesirable consequences. ${ }^{124}$ First, providers became reluctant to treat severely ill patients, which led to reduced welfare for those neediest patients. Second, report cards led to sorting of patients to providers based on the severity of illness, with the healthier patients being treated in higher rated hospitals and sicker patients treated in hospitals with worse grades. This, along with the tendency to substitute towards more cautious but less effective medical therapies, led to higher costs and worse outcomes, especially for sicker patients.

HIPAA regulations prescribe numerous rules for doctors and hospitals intended to protect patients' privacy. Studies show, however, that the disclosure forms are written at a level hopelessly beyond the reading level of most people. ${ }^{25}$ Other findings indicate that nobody tries to read the HIPAA forms. (The University of Michigan Hospital's form runs to six large pages of print so small that Schneider cannot read it with his glasses on. . $^{126}$ Mandated disclosure of privacy policies outside health care do no better. For example, a survey of internet users found that less than $1 \%$ of them even noticed the disclosed policies. ${ }^{127}$

${ }^{121}$ James S. Lubalin \& Lauren Harris-Kojetin, What Do Consumers Want and Need to Know in Making Health Care Choices? 56 Med. Care Res. Rev. 67 (1999).

${ }^{122}$ E. Hannan et al., Improving the Outcomes of Coronary Artery Bypass Surgery in New York State, 271 J. Amer. Med. Assoc. 761 (1994); D. Mukamel and A. Mushlin, Quality of Care Information Makes a Difference: An Anlaysis of Market Share and Price Changes After Publication of the New York State Cardiac Surgery Mortality Reports, 36 Med. Care 945 (1998); E.D. Peterson et al., The Effects of New York's Bypass Surgery Provider Profiling on Access to Care and Patient Outcomes in the Elderly, $32 \mathrm{~J}$. Amer. College of Cardiology 993 (1998). For statistical critiques of these studies, see Jesse Green and Neil Wintfeld, Report Cards on Cardiac Surgeons Assessing New York State's Approach, 332 New England J. of Med. 1229 (1995); T. Hofer et Al., The Unreliability of Individual Physician "Report Cards" for Assessing the Costs and Quality of a Chronic Disease, 281 JAMA 2098 (1999).

${ }^{123}$ Susan Feng Lu, Multitasking, Information Disclosures and Product Quality Evidence from Nursing Homes (Simon School working paper No. FR 09-03, Univ. of Rochester 2009).

${ }^{124}$ David Dranove et al, Is More Information Better? The Effects of 'Report Cards' on Health Care Providers, 111 J. Pol. Econ. 555 (2003).

${ }^{125}$ S. Walfish \& K.M. Watkins, Readability Level of Health Insurance Portability and Accountability Act Notices of Privacy Practices Utilized by Academic Medical Centers, 28 Eval Health Prof 479 (2005); M. Hochhauser, Readability of HIPAA Privacy Notices, www.benefitslink.com/articles/hipaareadability.pdf (visited Nov. 23, 2009).

${ }^{126}$ See Carl E. Schneider, HIPAA-crazy, 36 Hastings Center Report 10 (January/February 2006).

${ }^{127}$ B.J. Fogg et al, Consumer Reports WebWatch, How Do People Evaluate a Web Site's Credibility?: Results from a Large Study 86 (2002) (http://www.consumerwebwatch.org/pdfs/stanfordPTL.pdf). 
One area in which disclosure seems relatively successful is nutrition labeling. Many Americans report being more aware of nutrition facts and changing their purchasing. For example, Alan Mathios suggests that even before mandatory nutrition labeling, low-fat salad dressing had voluntary disclosures, but labeling forced high-fat level to be explicitly exposed and thus buyers could distinguish between the worse and the worst, thus associated with a decline in sales for the highest fat products. ${ }^{128}$ But the question is how to distinguish between correlation and causation. Changes in consumption, especially the rise of demand for low-fat foods and the decline in demand for high-fat foods, are associated with mandated disclosure, but the trend may have been set before the disclosure regulation, as a result of various factors: consumer change of tastes, the obesity plague, aggressive advertising by low-fat food manufacturers, and more.

Furthermore, consumers have other ways to acquire nutrition information. Manufacturers highlight nutrition advantages and make comparative claims. Perversely, because of disclosure mandates in the Nutrition Labeling and Education Act, the amount of nutrition information in manufacturers' advertising and voluntary campaigns narrowed substantially. Fewer comparative claims are made; claims focus on narrower issues (e.g., total fat); and advertising of "good foods" like fruits and vegetables has fallen significantly. ${ }^{129}$ To be sure, voluntarily disclosed information can be biased and misleading, and the FTC has been monitoring it. But if mandatory merely replaces voluntary disclosure its value is questionable.

It is also sobering that while food labeling affects people's decisions, few succeed in changing their overall diets. It is found, for example, that reduced consumption of one high-fat food (e.g., red meat) is offset by increased consumption of another high-fat food (e.g, dairy products). ${ }^{130}$

Two kinds of evidence suggest the scope of the failure of Miranda warnings. First, those warnings are not understood. Asked to paraphrase Miranda provisions directly after hearing each provision, "[o]nly $38.5 \%$ of detainees achieved good comprehension for the easy ( $<$ sixth grade) level, and substantially fewer $(20.5 \%)$ achieved good comprehension for the moderate (8th to 10 th grade) level. . . . [V]ery few detainees $(6.8 \%)$ accurately recalled even at the easy $(<$ sixth grade) level that there is no cost for a court-appointed attorney." when Rogers "examined whether college students espousing knowledge of their Miranda rights

\footnotetext{
${ }^{128}$ A. Mathios, The Impact of Mandatory Disclosure Laws on Product Choices: An Analysis of the Salad Dressing Market, 43 J. Law Econ. 651 (2000).

${ }^{129}$ Pauline M. Ippolito \& Janis K. Pappalardo, Advertising Nutrition and Health: Evidence from Food Advertising 197-1997 (Federal Trade Commission, Bureau of Economic Staff Report, 2002); Pauline M. Ippolito and Alan D. Mathios, Information, Advertising, and Health Choices: A Study of the Cereal Market, 21 Rand J. Econ. 459 (1990); see also Pauline M. Ippolito and Alan D. Mathios, Information and Advertising: The Case of Fat Consumption in the United States, 85 Amer. Econ. Rev. 91 (1995).

${ }^{130}$ Brenda M. Derby and Alan S. Levy, Do Food Labels Work?, in Handbook of Marketing and Society (Bloom and Gundlach, eds., 2001) 372, 389; Putler, Daniel S. and Elizabeth Frazao, Assessing the Effects of Nutrition Education Programs on the Consumption and Composition of Fat Intake, in Economics of Food Safety, (Julie A. Caswell, ed., 1991).

${ }^{131}$ Richard Rogers, A Little Knowledge is a Dangerous Thing . . . Emerging Miranda Research and Professional Roles For Psychologists, 63 American Psychologist 776, 779 (2008).
} 
were accurate in their self-appraisals," he found that "[n]early all (95.6\%) believed that any confession would nullify their right to counsel."132

The second kind of evidence that Miranda does not work as intended is that "the overwhelming majority of suspects (some $78 \%$ to $96 \%$ ) waive their rights . . . This ... has not been disputed by scholars on any side of the Miranda debate. As Patrick Malone pointed out . . . 'Miranda warnings have little or no effect on a suspect's propensity to talk . . . Next to the warning label on cigarette packs, Miranda is the most widely ignored piece of official advice in our society.",133

Even people with every advantage are unhelped. Yale faculty, staff, graduate students, and undergraduates were interrogated by the FBI after a ' 60 s draft protest. The warnings were "almost wholly ineffective, and this obtains even when the suspect is intelligent, and the interrogation is polite, noncustodial, and at the suspect's home." "134 Each man waived his rights, and after being better informed about the legal meaning of doing so, regretted it.

We could go on. We could say, for example, that disclosure by used car dealers of items such as prior use, odometer readings, warranties, and safety checks did nothing to improve the excess price paid by poor buyers relative to more wealthy ones. ${ }^{135}$ But we will stop this survey here. At this point, we prefer to shift to another, more fundamental step of our argument $-\mathrm{a}$ theoretical exploration why mandated disclosure is so likely to fail.

\section{Why MANDATEd Disclosure FAILS}

We have shown that mandated disclosure regularly - though not inevitably - fails to achieve its purpose of improving disclosees' decisions. We next argue that failure is inherent in the regulatory technique. Success requires three "actors" - law-makers, disclosers, and disclosees - to play their parts properly. Each part is challenging. Rarely can each actor meet all accomplish all that is needed, and so rarely does mandated disclosure succeed.

\section{A. Law-Makers}

For mandated disclosure to work, the law-maker must set the mandates correctly. First, it must correctly identify a problem that needs a regulatory solution. Second, it must correctly decide that mandated disclosure is appropriate. Third, it must correctly decide what disclosure to mandate. Fourth, it must correctly and comprehensibly articulate the standard of disclosure. Each step is problematic, and the law-maker's incentives lead it toward excessive mandates:

\footnotetext{
132 Ibid at 781 .

${ }^{133}$ Richard A. Leo, Questioning the Relevance of Miranda in the Twenty-First Century, 99 Michigan L Rev 1000, 1012-3, quoting Patrick Malone, You Have the Right to Remain Silent: Miranda After Twenty Years, 55 AM. SCHOLAR 367, 368(1986).

134 John Griffiths \& Richard E. Ayres, A Postscript to the Miranda Project: Interrogation of Draft Protestors, 77 Yale L J 300, 318 (1967).

135 Kenneth McNeil et al., Market Discrimination Against the Poor and the Impact of Consumer Disclosure Laws: The Used Car Industry, 13 Law \& Society Rev. 695, 699 (1979).
} 
there are incentives to regulate when regulation is unnecessary, to use mandated disclosure when it is ineffective, to state mandates too broadly, and to articulate standards too loosely.

\section{Is Regulation Necessary?}

Law-makers live amid demands for action. "Trouble stories" - tales of someone's misfortune that might represent a systematic problem - inspire many of these demands. The family that lost a house to foreclosure, the patient who died, and the swindled consumer evoke sympathy and anger. Indignation, political pressure, and a sense of duty drive law-makers to try to prevent the story from recurring.

Trouble stories, however, are dubious bases for regulation. They are anecdotes and may not represent a problem extensive and serious enough to necessitate regulation. For example, the atrocities of Nazi doctors and the Public Health Service research at Tuskegee have been the primary justification for the system of university and hospital committees that license "humansubject" research. Troubling though these stories are, they tell us little about how often and how seriously people in this country in this era are injured by unethical medical researchers, much less by unethical social scientists.

Another example. A decade ago a research subject died. A researcher had a financial interest in a company that might have benefited if the research succeeded. ${ }^{136}$ This trouble story has become central in "proving" that researchers with financial interests in their work will be dangerously zealous. Exemplifying the over-reaction scandals provide, "one conflict of interest committee chair remarked, "The future of academic health centers depends on [conflict of interest oversight] being done right." 137 Researchers may be tempted to take advantage of research subjects for financial gain, but are they tempted and do they succumb often enough to justify regulating conflicts of interest?

Not only are trouble stories often unrepresentative, they are asymmetrical. They push in only one direction - toward regulation. What might induce lawmakers to forego or revoke regulation? What would be evidence that the problem was infrequent and minor? While the pressure for more is salient, politically charged, and time-sensitive, the pressure for less is not. The injured research subject or the defrauded consumer is conspicuous; the people who can be saved by suppressed research, or the consumers who pay for regulation remain anonymous.

\section{Is Mandated Disclosure the Best Form of Regulation?}

Mandated disclosure is a Lorelei, luring law-makers onto the rocks of regulatory failure. It is alluring because it resonates with two fundamental American ideologies. The first is freemarket principles. While mandated disclosure constrains unfettered rapacity and counteracts caveat emptor, the intervention is soft and leaves everything substantive alone: prices, quality, entry. Instead of specifying the outcomes of transactions or dictating choices, it proffers

\footnotetext{
${ }^{136}$ Gelsinger materials from Simon.

${ }^{137}$ Kevin P. Weinfurt et al, Disclosing Conflicts of Interest in Clinical Research: Views of Institutional Review Boards, Conflict of Interest Committees, and Investigators, 34 Journal of Law, Medicine \& Ethics 581, 583 (2006).
} 
information for making better decisions. ${ }^{138}$ Second, mandated disclosure serves the autonomy principle. It implements the belief that people make better decisions for themselves than anyone can make for them and that people are presumptively entitled to freedom in making decisions.

The more-information-is-better mantra seems to serve both the free-market and autonomy principles. The mantra convinces widely and well. In defending mandated disclosure, the Federal Trade Commission said, "It is a basic tenet of our economic system that information in the hands of consumers facilitates rational purchase decisions; and, moreover, is an absolute necessity for efficient functions of the economy."139 The political appeal of the mantra is further evidenced by the ease with which law-makers mandate disclosure. For example, a flagship disclosure statute — the Truth-in-Lending Act of 1968 - passed by ninety-two to zero majority in the Senate. ${ }^{140}$ The PSDA passed without opposition in the Senate. ${ }^{141}$ Courts adopted informed consent with little apparent doubt.

Mandated disclosure appeals to law-makers for other reasons. First, it looks cheap. It requires almost no government expenditures, and its costs seem to be imposed on the villain of the story, the stronger party who withholds information.

Second, mandated disclosure looks easy. It only requires more communication between parties who are already communicating. In hindsight, one can usually identify the information that could have led the disclosee to a better conclusion. For example, Rena Truman's doctor repeatedly urged her to have a Pap smear but did not specify the consequences of not having one. She died of cervical cancer. The California Supreme Court apparently reasoned like the dissenter on the Court of Appeal: "[C]an it be doubted that, had the decedent in this case known that for $\$ 6$ and mild discomfort she could discover the existence of cervical cancer and thus survive, she would have taken the test? Central to her failure to take the test was a clear lack of understanding of the significance of the doctor's recommendation." 142

Third, mandated disclosure looks effective. Mandated information often seems relevant to a difficult decision. If asked, consumers often say they want the information. Even unenthusiastic commentators imagine that while mandates may not help, they cannot hurt. And the dogma of disclosure seems unfalsifiable: Even when it fails, it only means that the content of

138 See the excellent discussion in Howard Beales et al, The Efficient Regulation of Consumer Information, 24 J. Law \& Econ. 491, 513 (1981). See also Colin Camerer et al, Asymmetric Paternalism, 151 U. Penn. L. Rev. (2003); Cass Sunstein \& Richard Thaler, Libertarian Paternalism, 70 U. Chi. L. Rev. 1159 (2003).

${ }^{139}$ Statement of Basis and Purpose, Labeling and Advertising of Home Insulation, 44 Fed. Reg. 50218, 50222 (1979).

${ }^{140}$ Edward L. Rubin, Legislative Methodology: Some Lessons from the Truth-in-Lending Act, 80 Georgetown L. J. 233, 255 (1991).

${ }^{141}$ Elizabeth Leibold McCloskey, The Patient Self-Determination Act, 1 Kennedy Inst of Ethics J 163, 168 (1991). McCloskey, the sponsor's aide thinks "Reinhold Niebuhr would have enjoyed watching the legislative process," for translating "a good idea into a good law is . . a a Niebuhrian dream." Ibid at 164.

${ }^{142}$ Truman v. Thomas, 611 P2d 902 (Cal 1980). For a detailed examination of that case and the assumption that Ms. Truman would have behaved differently if Dr. Thomas had told her the risks of not having a Pap smear, see Mark A. Hall \& Carl E. Schneider, When Patients Say No (To Save Money): An Essay on the Tectonics of Health Law, 41 Connecticut Law Review 743 (2009). 
the disclosure needs to be revised or enhanced. For example, despite a long and long-standing list of mandated disclosures in mortgage agreements, an epidemic of irrational and devastating borrowing produced a sub-prime mortgage disaster, a foreclosure surge, and a broad financial crisis. Despite proposals to regulate mortgages substantively and oversee lenders more closely, ${ }^{143}$ commentators and reformers still consider disclosures central to the solution. ${ }^{144}$ For example, the Housing and Economic Recovery Act requires lenders to disclose the new, allinclusive version of the APR three days before the deal. ${ }^{145}$

For all these reasons, law-makers rarely inquire into disclosure's effectiveness or burden. For example, "only limited discussions of the potential costs and benefits of the PSDA occurred during the legislative process." informed consent barely asked whether patients want to make medical decisions, whether doctors could provide and patients could use the mandated information, whether patients would make better decisions with more information, or what informed consent would cost. ${ }^{147}$

In short, when law-makers are pressed to act, mandated disclosure is appealing. Its critics are few. ${ }^{148}$ The law-maker can be seen to have acted. The fisc is unmolested. The people most visibly burdened - the disclosers - rarely dare resist vigorously and prefer disclosure to yet harsher regulation. Easy alternatives are few. Disclosure's political utility does much to explain its use and over-use. ${ }^{149}$

${ }^{143}$ Kathleen C. Engel and Patricia M. McCoy, A Tale of Three Markets: The Law and Economics of Predatory Lending, 80 Tex. L. Rev. 1255, 1269 (2002); Pottow, Tort liability for reckless lending; See also U.S. Dep't of Hous. \& Urban Dev. \& U.S. Dep't of Treasury, Curbing Predatory Home Mortgage Lending: A Joint Report 17 (2000) (http://www.huduser.org/publications/hsgfin/curbing.html).

${ }^{144}$ HUD-Treasury Report, supra note 10, at 67 (proposing that originators be required to provide an accurate, within a prescribed tolerance, Good Faith Estimate (GFE) of, among other things, the APR). See also FinANCIAL REgUlatory REFORM 63-65 (Dept of Treasury 2009) (proposing new formats for financial disclosures that would be less technical and tested for their readability). See Elizabeth Renuart and Diane E. Thompson, The Truth, The Whole Truth, and Nothing but the Truth: Fulfilling the Promise of Truth in Lending, 25 Yale. J. Reg. 181 (2008) (Proposing a comprehensive APR measure); Oren BarGill, The Law, Economics, Psychology of Subprime Mortgage Contracts, 94 Cornell L. Rev. (2009) (providing one of the more nuanced and careful views of disclosure reform).

${ }^{145}$ Housing and Economic Recovery Act of 2008, Pub.L. 110-289, Sec. 2502(a), 15 U.S.C. 1638(b)(2).

146 Jeremy Sugarman et al., The Cost of Ethics Legislation: A Look at the Patient Self-Determination Act, 3 Kennedy Institute of Ethics Journal 387, 389 (1993).

${ }^{147}$ See, e.g., Canterbury v. Spence, 464 F2d 772 (D.C. Cir. 1972).

${ }^{148}$ For some early skepticism, see Jordan \& Warren, Disclosure of Finance Charges: A Rationale, 64 Mich. L. Rev. 1285, 1320-22 (1966); Kripke, Gesture and Reality in Consumer Credit Reform, 44 N.Y.U.L. Rev. 1, 1-11 (1969); Note, Consumer Legislation and the Poor, 76 Yale L.J. 745 (1967). Some economists who expect businesses to volunteer information if consumers want it have criticized mandated disclosure, if faintly. See, e.g., Grossman, Sanford J., The Informational Role of Warranties and Private Disclosure of Product Quality, 24 J. Law \& Econ. 461 (1981); Michael J. Fishman and Kathleen M. Hagerty, Mandatory Disclosure, in 2 THE NEW PALgRAVE DictionaRY OF ECONOMICS AND THE LAW 605 (P. Newman, Ed. 1998); A. Mitchell Polinksy and Steven Shavell, Mandatory Versus Voluntary Disclosure of Product Risks, Stanford Olin Working Paper, No. 327 (2006).

${ }^{149}$ See, e.g., William N. Eskridge, One Hundred Years of Ineptitude: The Need for Mortgage Rules Consonant with the Economic and Psychological Dynamics of the Home Sale and Loan Transaction, 70 Va. L. Rev. 1083 (1984) (describing the shift from usury laws to disclosure regulation). 


\section{What Is the Proper Scope of the Disclosure Mandate?}

Mandated disclosure's appeal to law-makers and the allure of the more-is-better mantra lead law-makers to mandate disclosure too often and too broadly. Furthermore, disclosure's logic is inherently expansive. Only broad disclosure accommodates the variety of disclosees and circumstances. One can always imagine a disclosee for whom one more datum might help. Furthermore, it is hard to anticipate what data will prove useful, so safety seems to lie in broad mandates.

For example, what information about conflicts of interests ought researchers disclose? Conflicts may include "the award of stock contingent on certain occurrences, licensing rights, 'put' options, seed money for commercial start-ups, limited partnership and other joint venture opportunities, royalty-based payments, and specialized grant funding to individual investigators and to institutions." ${ }^{150}$ Worse, incentive's effects "vary in intensity and impact depending on the overall context, such as the number of other investigators sharing the same incentive, how the incentive is actually calculated, the amount of money to be earned compared to an investigator's other compensation sources, the time period over which the incentive is applied, and whether the institution as a whole shares in the incentive." ${ }^{\prime 51}$ All these data might be relevant; what can be excluded?

Mandates also multiply when nobody knows what information disclosees need. For example, hospitals, physicians, and schools must disclose "report cards"-information about their performance, where performance depends both on the skill and effort of the producer and the characteristics of their patients/students. However, despite decades of research, scholars have not found reliable indicia of medical quality, principally because it has proved impossible to factor out all the influences on medical success. And since exceptional doctors attract risky cases, success may not reflect skill.

In addition, trouble stories never stop. No regulation can eliminate problems, and mandated disclosure barely reduces them. So there is constant pressure to expand the mandate to cover newly noticed contingencies, and the scope of mandates ratchets ever up, never down.

One might set the mandate's scope by asking consumers what information they want. Alas, they say "virtually everything." When choosing health-care plans, they want to know about "(1) access . . . ; (2) amount of paperwork; (3) benefits; (4) choice of provider . . . ; (5) communication/interpersonal skills/caring of provider; (6) convenience . . . ; (7) coordination of care; (8) costs; (9) courtesy . . . ; (10) hospital ratings; (11) good value for the money; (12) plan administrative hassles; and (13) quality ...."152 In one large study, $76 \%$ of the patients

150 Richard S. Saver, Medical Research Oversight From the Corporate Governance Perspective: Comparing Institutional Review Boards and Corporate Boards, 46 William \& Mary Law Review 619, 716 (2004).

${ }^{151}$ Ibid at 717.

152 James S. Lubalin and Lauren D. Harris-Kojetin, What Do Consumers Want and Need to Know in Making Health Care Choices?, 56 Med Care Res \& Rev 67, 72 (1999). 
questioned "would want to hear of any adverse effects [of a treatment], no matter how rare." And $83 \%$ wanted to know about any "serious adverse effect, no matter how rare.", 53

If people knew how much they are asking for, they would not say such things. Given much less information, they still use much less than that. For example, "the Minnesota Health Data Institute distributed a 16-page, statewide report card that featured comparison tables and color-coded graphs of consumer satisfaction within categories of health plans and compared 38 plans based on 20 performance measures." However, "[c]onsumers found the report cards cumbersome, complex, and detailed."154

Furthermore, in at least some areas (like medicine) people numerously profess themselves pleased with the amount of information they have, however scant it is. For example, one review of the literature reports that "[p]atient satisfaction with the quality of information provided, was usually high, despite frequent poor recall."

Another reason mandates expand is that disclosees interpret information unexpectedly. Thus while patients and research subjects are supposed to be warned of the evils of doctors' and researchers' conflicts of interest, at least one study found that some people "perceived financial interests as a positive sign that the investigator would be invested in ensuring a study was done well." 155 Such problems drive law-makers to insist on broader disclosures so that disclosees really understand the problem right away. ${ }^{156}$

\section{Can the Quantity Question Be Answered?}

We have argued that several forces drive law-makers to over-use mandated disclosure and to setting its scope expansively. All this leads to the recurring and crucial "quantity question." The quantity question has two principal aspects. The first is the familiar "overload" effect. When disclosure mandates are too detailed, both disclosers and disclosees have trouble coping with it. The forms become so complex and so long that disclosers have trouble assembling and organizing the information. Disclosees do not read them, and cannot understand and assimilate and analyze the quantity of information they contain. ${ }^{157}$

The classic overload statement is Miller's "magical number seven," "158 that being more or less the number of items people can keep in their short-term memory. This number is surprisingly easy to exceed. For example, Miranda warnings average 96 words and range up to

\footnotetext{
${ }^{153}$ Paul B. Ginsburg, Shopping for Price in Medical Care, 26 Health Aff w208, w213 (2007).

${ }^{154}$ Judith H. Hibbard et al, Informing Consumer Decisions in Health Care: Implications from DecisionMaking Research, 75 Milbank Q 395, 398 (1997).

155 Christine Grady et al, The Limits of Disclosure: What Research Subjects Want to Know About Investigator Financial Interests, 34 Journal of Law, Medicine \& Ethics 592, 598 (2006).

${ }^{156}$ See, e.g., William N. Eskridge, One Hundred Years of Ineptitude: The Need for Mortgage Rules Consonant with the Economic and Psychological Dynamics of the Home Sale and Loan Transaction, 70 Va. L. Rev. 1083 (1984) (describing the shift from usury laws to disclosure regulation).

${ }^{157}$ Cite [overload studies in product and drug warnings]

${ }^{158}$ George A. Miller, The Magical Number Seven, Plus or Minus Two: Some Limits on Our Capacity for Processing Information, 63 Psychological Review 81 (1956).
} 
408 words. Rogers invokes Miller's number and concludes that even with "verbal chunking" (combining smaller items into a single item for easier memory storage) "the upper limit of information processing for Miranda warnings is likely less than 75 words . ..." Even cued, people "with less than a 12 th grade education recalled only $55.8 \%$ of the verbal material." And this overstates understanding, since "many suspects have cognitive deficits and are further impaired by highly stressful circumstances" and since "the mere recitation of concepts cannot be equated with genuine understanding." 159 The same problem proliferates in medicine. In one study, for example, "[a]nesthesiologists and nurse practitioners vastly exceeded patients' shortterm memory capacity." 160

Law-makers have no good solution to this problem. If they mandate incomplete disclosure, people may be unable to choose knowledgeably. Law-makers lack good criteria for eliminating information. A sophisticated law-maker could recognize that "less is more" but at the same time fear that "less is not enough."

The quantity question's second aspect - one that has not been noticed until now - is the "accumulation" problem: While law-makers consider disclosure issue by issue, in real life each disclosure competes for a disclosees' time and attention with other mandated disclosures, with knowledge people obtain without mandates, and with everything people do besides collect information for and make decisions. One disclosure by itself may seem trivial, but many disclosures may be overwhelming.

Law-makers are largely shielded from the accumulation problem. What law-maker would oppose a consumer financial disclosure rule because too many disclosures - in unrelated areasare already - and are competing for people's attention. Law-makers simply don't make such macro evaluations. Even if law-makers wanted to thin down the disclosure landscape by selecting only a few critical areas in which disclosure rules ought to be used, they have neither the competence nor and incentives to make such selections, and the legislative process offers few opportunities for trying.

\section{Can the Standard of Disclosure Be Articulated Effectively?}

Suppose the lawmaker has identified a genuine problem, it is appropriate for mandated disclosure, and the mandate's scope has been well gauged. The lawmaker must now articulate the mandate. A wide continuum of standards ranges from vague general statements to lists of specific data. Informed consent exemplifies the former end: What information would a reasonable patient want in making the decision? Miranda exemplifies the latter end: a set of words so fixed and specific that television addicts recite them from memory. Alas, both ends of the continuum are problematic. The specific end requires extraordinary prescience and precision. Perversely, this is likeliest when information is already well known. Thus it became easier to write intelligible cigarette warnings after smoking's dangers were common knowledge. The vague end of the spectrum may solve these problems, but it gives disclosers scant guidance. And

${ }^{159}$ Ibid at 778-779 (2008).

${ }^{160}$ Elisabeth H. Sandberg et al., Clinicians Consistently Exceed a Typical Person's Short-Term Memory During Preoperative Teaching, 53 Survey of Anesthesiology 131, 131 (2009) (doi: 10.1097/01/SA.0000349836.50647.15). 
without specific guidance, disclosers that fear enforcement of the disclosure regime will seek safety in overbroad disclosures.

Law-makers may be concerned not only with what must be disclosed, but also with how. A hint of the difficulties this poses is provided by the problem of disclosing conflicts of interest to research subjects. In one survey of researchers and regulators, some thought

that the financial disclosure should occur early in the consent process, and some respondents suggested that a disclosure statement should appear near the top of the consent document. There was also support for highlighting the disclosure in some way, but this suggestion raises the concern that such highlighting might communicate to potential research participants that the financial disclosure is more important than other components of the consent document. ${ }^{161}$

To put the point differently, the law-maker has an inherently difficult task. Both the market-failure and the autonomy rationales for mandated disclosure assume that disclosees and their circumstances, preferences, and choices are various. Given all this variety, the law-maker's task is baffling.

In sum, the law-maker's incentives are to use mandated disclosure even where it is inappropriate and to mandate disclosure too broadly. Furthermore, those incentives persist even after the law-maker has initially acted. Trouble stories continue to reveal that any current disclosure regime has not ended the trouble. And experience continually reveals new data that might reasonably improve disclosees' decisions. Thus, disclosure mandates tend to grow and rarely shrink.

\section{B. Disclosers}

The second prerequisite to mandated disclosure is that the disclosers provide the mandated information. Even under the optimistic assumption that disclosers will strive to comply with disclosure requirements, much will keep them from doing so usefully.

\section{Interpreting the Mandate}

First, the discloser must determine what to disclose. But for reasons we just explained, law-makers' mandates can be frustratingly vague. Consider contract law's disclosure norms. The seller cannot practically imagine and describe everything about a contract any imaginable buyer might ever want to know. But if not everything, how much? The common law has struggled to find a formula. Some non-disclosures are regarded as fraudulent concealment and are subject to standard anti-fraud sanctions, but mandated disclosure is intended to go beyond anti-fraud rules. The Restatement of Contracts requires disclosure of facts that would "correct a mistake of the other party as to a basic assumption on which that party is making the contract."162 But the ambiguity of this suggests why legislators had to supplement it with brighter-line rules on, say, which advertising practices are deceptive.

\footnotetext{
${ }^{161}$ Ibid at 590 .

${ }^{162}$ Restatement of Contracts (2d) §161(b).
} 
Or consider doctors" duty to provide information "a reasonable person . . . would be likely to attach significance [to] . . . in deciding whether or not to forego the proposed therapy"). ${ }^{163}$ You're the doctor. A drug's side effects include

excess stomach acid secretion, irritation of the stomach or intestines, nausea, vomiting, heartburn, stomach cramps, bronchospasm, stomach ulcers, intestinal ulcers, hepatitis, stomach or intestinal bleeding, inflammation of skin, redness of skin, itching, hives, rash, wheezing, trouble breathing, life-threatening allergic reaction, giant hives, rupture in the wall of the stomach or intestines, hemolytic anemia, large skin blotches, decreased blood platelets, decreased white blood cells, and decreased appetite. ${ }^{164}$

Which side effects do you describe? The likeliest? The gravest? Does your answer change if you know the drug is aspirin?

The informed-consent standard is yet more problematic than this, since it requires the disclosure of information patients need to make a decision, not just disclosure of side-effects of treatment. A common problem, for example, is that "patients may regard a particular outcome of treatment as highly undesirable but then . . . learn to tolerate it well." 165 For example, while many people initially refuse colostomies, they commonly adapt to them. So what should the doctor tell the patient? Ubel et al examine a standard "relatively complete" description of colostomies and find that even it "lacks relevant details. What does it mean, for example, to have 'no voluntary control' of the colostomy? What is involved in maintaining a colostomy? What percentage of men will develop impotence? Moreover, the description never really shows people what a colostomy looks like or how it operates." In sum, descriptions of illnesses and treatments "are necessarily incomplete, and patients and the public are likely to fill in the blanks idiosyncratically, with information based on their own personal experiences or stereotypes.",166

When a mandate is stated broadly, disclosers might think that duty requires - or prudence demands - disclosing everything. For example, HIPAA obliges providers to tell patients what providers may legitimately do with patients' health information. This has produced disclosures so detailed and deadly that we relegate our gruesome example to a footnote. ${ }^{167}$

${ }^{163}$ Canterbury v. Spence, 464 F2d 772, 7 _(DC Cir1972).

${ }^{164}$ www.webmd.com/drugs/drug-1082-

aspirin. aspx ?drugid $=1082 \&$ drugname $=$ aspirin $\&$ source $=1 \&$ pagenumber $=6$.

${ }^{165}$ Norman F. Boyd et al, Whose Utilities for Decision Analysis?, 10 Med Decision Making 58 (1990).

${ }^{166}$ Peter A. Ubel et al, Whose Quality of Life? A Commentary Exploring Discrepancies Between Health State Evaluations of Patients and the General Public, 12 Quality of Life Research 599, 601 (2003).

167 "Examples of these activities include obtaining accreditation from independent organizations like the Joint Commission for the Accreditation of Healthcare Organizations, the National Committee for Quality Assurance and others, outcomes evaluation and development of clinical guidelines, operation of preventive health, early detection and disease management programs, case management and care coordination, contacting of health care providers and patients with information about treatment alternatives, and related functions; evaluations of health care providers (credentialing and peer review activities) and health plans; operation of educational programs; underwriting, premium rating and other activities relating to the creation, renewal or replacement of health benefits contracts; obtaining reinsurance, stop-loss and excess loss insurance; conducting or arranging for medical review, legal 
The problems with aspirin's side effects came from a vague mandate, the problems with HIPAA from a broad one. Equally baffling problems can come from complex mandates. For example, the Federal Reserve issued Regulation $\mathrm{Z}$ to tell creditors how to comply with TILA:

Regulation Z, while it did not salvage Truth-In-Lending's basic goals, did succeed in making the statute too complex to be complied with. Well-meaning creditors could not comply with it. Well-counseled creditors could not comply with it. The pamphlets published by the Federal Reserve Board to help creditors comply with it did not comply with it. . . . [M] any [creditors] found Regulation $\mathrm{Z}$ a conundrum too deep for either good will or high-priced intellect to solve." 168

Similarly, politicians, patients, and physicians have wanted to require disclosure of conflicts of interest created by capitation methods of paying doctors. But nobody knows which interests matter, especially when potential conflicts are mediated by factors such as "size of the patient panel, amount of the capitation sum, refinement of risk adjustments, dollar value of stoploss provisions, and scope of risk ... [It also depends on] such relative intangibles as the force of professional ethics and fear of malpractice suits. ${ }^{169}$ As the president of one HMO association said, HMOs "can tell people whether we have a withhold, bonus payments or capitation" but "there are literally over 100,000 ways to pay, and these systems are very proprietary" and "the plans change them all the time." 170

A damning illustration of how hard it is to determine what disclosures are required comes from the IRB system. There a regulatory agency (the IRB), not the discloser, decides what information to give potential research subjects. Yet faced with a single protocol, IRBs disagree enormously about what subjects should be told and how they should be told it. ${ }^{171}$ This illustration is damning because the discloser - with all its reasons to flout mandates - is removed from the picture, and the decision has been handed over to an experienced and presumably expert agency.

\section{Assembling the Data}

services, and auditing functions, including fraud and abuse detection and compliance programs; business planning and development; and business management and general administrative activities, including data and information systems management, customer service, resolution of internal grievances, and sales, mergers, transfers, or consolidations with other providers or health plans or prospective providers or health plans." University of Michigan Health Services, Notice of Privacy Practices, online at http://www.med.umich.edu/quality/toolkit/npp.htm.

168 Edward L. Rubin, Legislative Methodology: Some Lessons from the Truth-in-Lending Act, 80 Georgetown L. J. 233, 236-237 (1991).

${ }^{169}$ Lawrence D. Brown, Management by Objection?: Public Policies to Protect Choice in Health Plans, 56 Medical Care Research \& Review 145, 161 (1999).

${ }^{170}$ Ibid.

${ }^{171}$ For two examples among many, see Lee A. Green et al, IRB and Methodological Issues: Impact of Institutional Review Board Practice Variation on Observational Health Services Research, 41 HSR: Health Services Research 214 (2006); Keith Humphreys et al, The Cost of Institutional Review Board Procedures in Multicenter Observational Research 139 Annals of Internal Med 77 (2003). 
If the discloser can ascertain what data to reveal, it must next locate and assemble them. But such information is often inaccessible or laborious to collect. For example, an Illinois statute requires private business and vocational schools to state their enrollments and their student's graduation, licensing, placement, and employment rates and salaries. ${ }^{172}$ How many educational institutions ordinarily keep all that information? Or get it even with much effort (not least because much of it must come from former students)?

Some information is effectively too complex to assemble. For example, consumerdirected health-care information is endlessly intricate. Innumerable kinds of care might be offered. Infinite permutations of reimbursement systems are possible. Plan organization is endlessly variable. Quality is virtually impossible to measure. Costs are too complex and dynamic to describe.

Assembling data is also hard where information is speculative. How does a biobank tell people all the ways donations might be used decades into the future? How does a large-firm lawyer anticipate the conflicts of interest that might develop over a lengthy representation?

Information must not only be collected, it must be monitored and updated. Disclosers must hunt down changes and then repeat the travails of interpreting the law and assembling the data. And in at least some areas the conventional wisdom is that disclosees need detailed updates often. For example, Wendler and Rackoff argue that consent to participate in research expires when significant changes have occurred in "(a) the nature of the research itself, as determined by its purpose, risks, potential benefits, requirements, and alternatives; (b) the person's personal and medical situations; and (c) the person's preferences and interests," and that elaborate reconsent then is necessary. ${ }^{173}$

\section{Implementing the Mandate}

Suppose the discloser can identify the information to be disclosed, can assemble it, and now must present it. How? (Here we are discussing only disclosers' problems in deciding how to communicate information; we later discuss disclosees' problems reading it.) This question has looked easy to law-makers and commentators; but consider a relatively simple mandate Miranda. Two large recent surveys "yielded 945 distinct Miranda warnings from 638 jurisdictions that were augmented by research on 122 juvenile English warnings . . . and 121 general Spanish warnings ...." These warnings "range from 21 to 408 words with an average of 95.60 words." 174 Further, "[r]emarkable differences in reading levels are observed across Miranda warnings/waivers." A fifth are written below a sixth-grade reading level, most require a sixth to eighth grade level, and $2 \%$ "require at least some college education.",

\footnotetext{
${ }^{172}$ See Barber, Cosmetology, Esthetics, and Nail Technology Act, 225 ILCS 410/3B-12(a) (Illinois, 1985) (numerous disclosures required in school enrollment agreements).

${ }^{173}$ Dave Wendler \& Jonathan Rackoff, Consent for Continuing Research Participation: What Is It and When Should it be Obtained?, 24 IRB: Ethics and Human Research 1, 1 (May/June 2002).

${ }^{174}$ Richard Rogers, A Little Knowledge is a Dangerous Thing . . . Emerging Miranda Research and Professional Roles For Psychologists, 63 American Psychologist 776, 778 (2008).

${ }^{175}$ Ibid at 779.
} 
One problem is that ambiguity is startlingly hard to avoid. Words are slippery. For example, even "[a]bsolute terms when placed in a medical setting appear to be open to interpretation. Only $80.3 \%$ agreed that 'certain' meant 100 of 100 people, and only $67.8 \%$ agreed that 'never' meant zero of 100 people."176 One study "found that physicians' interpretations of the term 'likely' (with regard to risk probability) ranged from 25 to $75 \%$, and another study "reported that interpretations of the term 'very likely' ranged from 30 to $90 \%$, even when presented in a restricted medical context."177

Numbers present similar puzzles for disclosers. For example, risks can be described as either rates or proportions. Genetic counselors (presumably specialists in describing risks to the naïve) have conventionally believed "that women understand proportions better than rates." Yet there is "no scientific evidence to support that convention." On the contrary, in one study "more than three times as many women judged risks correctly with rates alone, compared with only proportions." And "[m]any women did not understand either format." 178

Presumably responding to such problems, two law-makers - the European Union and the UK Medicines and Healthcare products Regulatory Agency - proposed substituting words for numbers. However, the EU's terms "have been shown to lead to considerable overestimations of risk by patients, doctors and the general public. For example, according to EU guidelines the term 'common' is assigned to side effects that occur in 1-10\% of people taking the medicine . . . [O]n average, patients interpreted the word to mean around 45\%, while doctors estimated the risk to be around 25\%." But "even the patients receiving information as percentages assessed the risk as higher than the actual risk." 179 And these disasters came not from recalcitrant disclosers, but from law-makers themselves.

Other problems abound, many too well known to require reiteration here. For instance, the way a fact is framed notoriously affects perceptions of it. People react differently if a treatment is said to have an $80 \%$ chance of success instead of a $20 \%$ chance of failure. Yet all information comes in some kind of frame. ${ }^{180}$

\section{Resisting the Mandate}

We've argued that even disclosers striving to obey a mandate will encounter crippling problems. But disclosers presumptively have reasons to disobey, since mandates are usually imposed because law-makers think disclosers are deliberately withholding information. Some of these reasons may be illegitimate. For example, some disclosures are mandated because

\footnotetext{
${ }^{176}$ Kimberley Koons Woloshin et al, Patients' Interpretation of Qualitative Probability Statements, 3 Archives of Family Medicine 961 (1994).

177 Dianne C. Berry et al, Patients' Understanding of Risk Associated with Medication Use, 26 Drug Safety 1, 2 (2003).

${ }^{178}$ David A. Grimes \& Gillian R. Snively, Patients' Understanding of Medical Risks: Implications for Genetic Counseling, 93 Obstetrics \& Gynecology 910 (1999).

179 Peter Knapp et al, Communicating the Risk of Side Effects to Patients: An Evaluation of UK Regulatory Recommendations, 32 Drug Safety 837, 838-839 (2009).

${ }^{180}$ For entry to a large literature, see Annette Moxey et al, Describing Treatment Effects to Patients: How They Are Expressed Makes a Difference, 18 J General Internal Medicine 948 (2003).
} 
disclosers are withholding discreditable information from consumers. And an enterprise that unscrupulously withheld information before the mandate might do so afterwards.

Nevertheless, policy ought not be driven by stereotypes about evil and greedy nondisclosers. Many disclosers are none of these things, many disclosers have good reasons to behave well, and many disclosers dutifully obey mandates. ${ }^{181}$ Furthermore, even scrupulous disclosers may resist mandates for understandable, sensible, and even admirable reasons. For example, a disclosure mandate is often one of many commands, incentives, and pressures. Usually, disclosers' primarily want to get their work done, and disclosure mandates can be irrelevant to and even inconsistent with doing so. For example, doctors and hospitals face many disclosure requirements, if only because they have so much information patients might want. ${ }^{182}$ But doctors and hospitals properly think their principal task is to cure illness and sooth suffering, and that task alone wholly outstrips the time available for it. For example, a typical doctor has insufficient time to provide just the preventive services the U.S. Preventive Services Task recommends. ${ }^{183}$ And "current practice guidelines for only 10 chronic illnesses require more time than primary care physicians have available for patient care overall."184 Obviously mandated disclosures are not the only desirable activity doctors must scant or forego.

Disclosers may also consider a mandate burdensome but ineffective and even harmful. Disclosers may, for example, discover that a disclosure is costly but unread and unheeded.

Disclosers may also discover that no matter how precisely they speak, disclosees tend to give more weight to data than the data merit. For example, no matter how side effects are revealed, patients tend to over-estimate their importance. Doctors may plausibly believe that such overestimates discourage patients from complying with treatment instructions, and doctors know that baseline noncompliance is astonishingly high (50\% is a common estimate). Such doctors may conclude that the risk of bad outcomes from noncompliance exceeds the risk of bad outcomes from undisclosed side-effects. For example, in a French study "[o]nly 44\% of the rheumatologists regularly told their patients about possible serious side effects and only $7 \%$ about life-threatening side effects." However, "[i]Information about the adverse effects of not taking prescribed drugs was given to patients 'all the time' to 'fairly often' by as many as $88 \%$ of the rheumatologists." The researchers thought that a "central concern among rheumatologists may be that concern about side effects may cause poor compliance." "185

Disclosers also discover that the human situation they encounter is more complex than the situation the law-maker anticipated. For example, disclosers who must deliver bad news are

\footnotetext{
${ }^{181}$ Florencia Marotta-Wurgler, Are 'Pay Now, Terms Later' Contracts Worse for Buyers? Evidence from Software License Agreements, NYU Law and Economics Working Paper No. 05-10 (2005).

${ }^{182}$ Kenneth J. Arrow, Uncertainty and the Welfare Economics of Medical Care, 53 American Economic Rev 941 (1963).

${ }^{183}$ Kimberly S. H. Yarnall et al, Primary Care: Is There Enough Time for Prevention?, 93 Am J Public Health 635, 637 (2003).

${ }^{184}$ Truls Ostbye et al, Is There Time for Management of Patients With Chronic Diseases in Primary Care?, 3 Ann Fam Med. 209, 209 (2005).

185 Jean-Marie Berthelot et al, Informing Patients About Serious Side Effects of Drugs: A 2001 Survey of 341 French Rheumatologists, 70 Joint Bone Spine 52, 55 (2003).
} 
likely to want to soften it, and doctors and patients alike often believe that that is desirable. ${ }^{186}$ Thus cancer patients are even more optimistic about their prognoses than their optimistic doctors partly because of "physician communication behaviors such as avoidance of discussing prognosis, withholding prognostic information, or presenting overly optimistic information." 187

Disclosers that wish to resist a mandate have many options. Mandates can be ignored, apparently even in quite conspicuous circumstances. For example, "EU Legislation passed during the 1990s made it mandatory for drug packaging to contain a leaflet providing all the information that is provided to health professional in the summary of product characteristics, including all adverse effects, but in a form understandable to the patient." However, in a recent study $40 \%$ of the leaflets "gave no indication of the likelihood of any adverse effect."188

When disclosers may choose their own disclosure language, they can usually beautify it. When health plans had to reveal how their doctors were paid, "almost none" mentioned "the potential negative impact that incentive arrangements might have on physician behavior." They more often painted "incentives in a positive light," by saying, for example, that they rewarded better care. $^{189}$

Disclosers can also obey the letter of a mandate but not its spirit. ${ }^{190}$ A doctor may use an informed-consent form rather than try to educate the patient. (One unit of the University of Michigan hospital has a single statement for all its varied procedures that is thrust at the patient just before the procedure.) An insurance company may have customers sign disclosure forms, even when customers plainly do not read and cannot understand them. Mechanical compliance is chronic when disclosers rely on agents. Indifferent agents notoriously deliver information like automata, radiating boredom and impatience, urging disclosees to sign without reading, intimating that disclosures are meaningless technicalities. The poster example is the title company's closing agent, the funnel for many mortgage, real estate, and safety disclosures. In addition, disclosers can sometimes work outside the mandate's technical reach. For example, police may try to induce waivers of and question suspects "outside Miranda."191 Similarly,

\footnotetext{
${ }^{186}$ Error! Main Document Only."Mildly but unrealistically positive beliefs can improve outcomes in patients with chronic or terminal diseases. . . Moreover, unrealistically optimistic views have been shown to improve quality of life." Peter A. Ubel, Truth in the Most Optimistic Way, 134 Annals of Internal Medicine 1142, 1143 (2001).

187 Tracy M. Robinson et al, Patient-Oncologist Communication in Advanced Cancer: Predictors of Patient Perception of Prognosis, 16 Support Cancer Care 1049, 1050 (2008) (doi: 10.1007/s00520-0070372-2).

${ }^{188}$ Neil Carrigan et al, Adequacy of Patient Information on Adverse Effects: An Assessment of Patient Information Leaflets in the UK, 31 Drug Safety 305, 306 (2008) (doi:0114-5916/08/0004-0305/\$48.00/0).

${ }_{189}$ Mark A. Hall, The Theory and Practice of Disclosing HMO Physician Incentives, 65 Law \& Contemporary Problems 207, 227 (2002).

${ }^{190}$ On this point, see James C. Scott, Seeing Like a State: How Certain Schemes to Improve the Human Condition Have Failed (Yale U Press, 1998).

${ }^{191}$ See Leo, supra note 133, at 1009-10.
} 
lending disclosure requirements may "create incentives for lenders to draft contract terms that evade current disclosure regulations and continue to obscure the actual contract terms."

Do such disclosers run risks? If like Holmes' bad man they ask what "courts are likely to do in fact," they generally answer "not much." Most nondisclosures injure nobody enough to provoke litigation. For example, apparently few informed-consent suits are brought except as pendants to malpractice suits, few are won, and damages are modest.

Disclosers may react to mandates in subtler ways. Consider our conflict-of-interest example. Disclosure might "deter advisors from giving biased advice by increasing their concern that estimators (now thought to be alerted by disclosure) will completely discount extreme advice or attribute corrupt motives to advice that seems even remotely questionable. On the other hand, advisors might be tempted to provide even more biased advice, exaggerating their advice in order to counteract the diminished weight that they expect estimators to place on it ... .193 Cain et al speculate that disclosure requirements give disclosers not only "strategic reason," but also "moral license," to "exaggerate their advice." 194

Where the law-maker distrusts disclosers, it may try to dictate how information is provided by, for example, specifying details of disclosure forms (like font size) and the precise data to be disclosed (like serving sizes in nutrition-fact boxes). Such specifications can reach ambitious proportions. For instance, some rent-to-own regulations require conspicuous disclosures of as many as seventeen items, including aspects of the goods, payments, charges, risk allocations, options, and more. ${ }^{195}$ Similarly, some jurisdictions require describing more than thirty aspects of a used car's condition.

In sum, even a willing discloser encounters many impediments to making useful disclosures. For good reasons and bad, not all disclosers are willing, and reluctant disclosers have many ways to resist the ideal disclosure the lawmaker originally envisioned.

\section{An Illustrative Vignette}

A vignette may help us review the problems disclosers encounter. The Jeanne Clery Disclosure of Campus Security Policy and Campus Crime Statistics Act ${ }^{196}$ grew out of trouble stories like the tragedy of a Lehigh student who was raped and murdered in her dorm.

The Clery Act requires roughly 6,600 institutions of higher education to publish an "Annual Campus Security Report" for prospective and current students and employees that

192 Susan Block-Lieb \& Edward J. Janger, The Myth of the Rational Borrower: Rationality, Behavioralism, and the Misguided "Reform" of Bankruptcy Law, 84 Texas Law Review 1481, 1560 (2005-2006).

${ }^{193}$ Daylian M. Cain et al, The Dirt on Coming Clean: Perverse Effects of Disclosing Conflicts of Interest, 34 Journal of Legal Studies 1, 6-7 (2005).

${ }^{194}$ Ibid at 22.

195 See, e.g., Ohio Rev. Code Ann. $§ 1351.02$, .04 (requiring 17 items of disclosure). See also James P. Nehf, Effective Regulation of Rent-to-Own Contracts, 52 Ohio St. L. J. 751, 841-43 (1991).

${ }^{196} 20$ USC $§ 1092$ (f). 
includes crime statistics for three years, policy statements, descriptions of crime-prevention programs, and procedures for handling sex offenses. The Act makes schools keep a public log of reported crimes and give warnings of crimes that are a threat to safety. The Department of Education assures us that the Act "provides students and families, as higher education consumers, with the information they need to make informed decisions." "197 The Department warns that

[c]ompliance with the Clery Act is not simply a matter of entering statistics into a Web site or publishing a brochure once a year. Compliance is a whole system of developing policy statements, gathering information from all the required sources and translating it into the appropriate categories, disseminating information, and, finally, keeping records. Many people at your institution-from the president on down-should be involved. ${ }^{198}$

So "[c]olleges spend a good deal of money putting out crime reports of questionable value. How much the process costs, including percentages of staff salaries, is so hard to calculate that even those who work on the reports could not guess how much. The Clery Act's complexity requires perpetual training, especially as amendments continue to change colleges' reporting requirements."199

Are Clery Act disclosees better informed? Crime statistics are notoriously unreliable because defining a crime and determining its incidence are so hard. "Campus officers routinely struggle with the crime classifications . . . N Nuances of a crime's location are especially confounding .. . ." How could these officers not struggle with regulations in which "[a]ggravated assaults, for example, get counted by victim, but robberies - even of five people by one perpetrator - should be counted by incident"? So one expert "fields five or six calls a week from colleges that need help figuring out what to report. When she travels to institutions for audits, she always turns up errors in the way they are counting crimes. 'Not once,' she says, 'have I found a campus that's completely in compliance.'”

If the Department of Education cannot write standards colleges can understand, if colleges are confused about the rules and interpret them differently, even an expert cannot understand their reports. And the intended audience is prospective and current students and college employees, none of whom will have any idea of how crimes are reported and tallied and of the interpretive problems colleges face. Furthermore, "reports include total crimes, not rates," so figures have little meaning unless readers somehow convert them to rates.

All this assumes the college is trying to comply with the law. But experts "suspect that many institutions simply import numbers from the 'Clery complaint' software program sold to police departments and send off their reports." Worse, "some colleges may manipulate their numbers."

\footnotetext{
${ }^{197}$ Office of Postsecondary Education, US Department of Education, The Handbook for Campus Crime Reporting 3 (2005).

${ }^{198}$ Ibid at 1.

199 Sara Lipka, Do Crime Statistics Keep Students Safe?, 55 The Chronicle 1, A15 (2009). Unless otherwise ascribed, the remaining quotations in this section are all from this article.
} 
Overall, then, the money colleges spend complying with the Clery Act - and pass on to their students in much-deplored higher tuition - is simply wasted. ${ }^{200}$ Worse, the Act creates perverse incentives. The more policing colleges do, and the more they encourage students to report crimes, the likelier they are to uncover crimes to report. Thus virtuous colleges look dangerous. Furthermore, the resources the Clery Act commandeers would be better spent making colleges safer. Thus one criminologist called the Act's reporting regulations "symbolic politics" and said that greater safety is likelier to come from practices like blue-light telephones and security cameras: "That's just one fix, he says, for a system that revolves around complex annual reports, a huge investment with little return. 'The focus,' Mr. Sloan says, 'ought to shift from producing a bunch of statistics that are basically useless.'"

\section{Disclosees}

We now must make some heroic assumptions. The law-maker has accurately indentified the information the consumer needs and has stated the mandate correctly and comprehensibly. The discloser has read, understood, and obeyed the mandate, has assembled the required information, and has disclosed it effectively. Ultimately, mandated disclosure's success depends on how much better disclosees make important, complex, and unfamiliar decisions when thus given information. In this section, we argue that many practical factors conspire to keep disclosees from using the information they are given profitably. More fundamentally, we argue that mandated disclosure rests on the false assumptions that people want to make all the consequential decisions about their lives and want to do so by assembling all the relevant information, reviewing all the possible outcomes, reviewing all their relevant values, and deciding which choice best promotes their preferences. These assumptions so poorly describe how human beings live that mandated disclosure cannot reliably improve people's decisions and thus cannot be a dependable regulatory mechanism.

\section{Disclosures and the World of Chris Consumer}

Before we identify the individual factors that keep disclosees from using disclosures, we present the "trump" card-the accumulation problem. People encounter too many disclosures to be able to digest all of them. Our introduction to this problem is Chris - the poster child of the disclosure paradigm — who reads all the disclosures he meets.

Chris starts his morning taking his daily medication, reading the mandated warnings and disclosure of risks, and his daily vitamins, reading another set of mandated warnings. He plugs in the toaster, after reading the sticker on the cord warning of electricity risks. Chris likes toast with butter and jam but virtuously scrutinizes the label's nutrition data and scrapes on a microlayer. He now has no time to read his newspaper and contents himself with the invoice for it, with its full statement of itemized charges.

\footnotetext{
${ }^{200}$ Nor do disclosees scrutinize Clery Act data. "A few years ago, when the law required colleges to print and distribute their annual crime statistics, Ms. Stafford would make a point to visit freshman dormitories on the day of delivery. 'There were trash cans full of them,' she says. 'It was a colossal waste of money."”
} 
This morning Chris' car won't start, so he calls a towing company, listens to prerecorded statements, and sends for help. The driver presents the form that discloses the company's charges, policies, and insurance. Chris reads it carefully, signs, and directs the driver to the repair shop. It gives Chris a detailed disclosure of its repair and pricing policies.

At the office, Chris skims sport scores on usatoday.com and the news on nytimes.comafter reading the usatoday.com "terms of service (3350 words) and the nytimes.com "privacy policy" (only 800 words). These are not directly mandated, but contract law requires that they be prominent enough that the user can read them. True, he's read these "browsewraps" before, but they are modified occasionally, and blessed are the prudent.

The car shop calls to tell Chris the charges for parts and labor. This, for once, is information Chris readily understands and really wants. The charges seem inflated, but Chris can hardly tow the car to another shop. He grudgingly consents. He calls his bank to make a balance transfer for his monthly credit card payment and is made to go online to complete an electronic form and click to accept the terms (another legalese boilerplate he nobly reads).

Fedex arrives. Chris signs the form after reading the terms on the back. The package contains documents from the property-insurance company the office has used for years. The policy has changed somewhat, and Chris sedulously reads it.

Chris lunches with colleages at a bistro where a sign warns him about food that is not overcooked. The menu warns him of the calories in each dish -thanks to a recent municipal ordinance. Thus chastened, Chris eats cautiously. Still hungry after his unsatisfying breakfast and lunch, Chris stops off for a 1000-calorie sundae (to which no disclosure law applies).

Returning, Chris passes a construction site where signs tell him about the building project and how he can learn more. He makes a mental note to visit city hall and read the additional information.

That afternoon, Chris goes for a flu shot. A two-page form recites the risks of the shot, including Guillain-Barré Syndrome and death. He glooms through the form and signs. Unfortunately, his one concern - a rumor that a version of the shot is "unsafe" - is not discussed (as far as he can tell). Before leaving, Chris refills a prescription, after getting a form stating that HIPAA requires the pharmacy to provide a notice "that describes how we may use your information for treatment, payment and other purposes that details your rights regarding the privacy of your health and medical information." Chris pauses to parse the sentence, fails, and turns to the notice (2,023 words).

Before dinner, Chris sits down to look through the papers he must read before deciding whether to refinance his house. He starts on this project of thousands of words but soon drifts into sleep. After dinner, Chris looks forward to Monday Night Football, but first he must buy a wedding gift through an online gift registry, get tickets from an airline's website, and register his daughter for a soccer league. He opens an account in the registry website-a quick choice of user ID and password and a slow read through terms and conditions before clicking "I ACCEPT." He also must accept the airline's terms and so clicks on the link to the terms. Lastly 
he studies the soccer league's disclosure on its rules and policies. He turns on the football game-midway through the $3^{\text {rd }}$ quarter-only to hear that "[t] his telecast is intended solely for the private, non-commercial use of our audience. Any publication, reproduction, retransmission, or any other use of the pictures, description, or accounts of this game without the express written consent of...." And so, to bed.

Thank heavens this is only a normal day in the life the law-makers have prescribed for Chris. Many important decisions didn't come up: choosing a credit card, getting a cell-phone carrier, buying a car (and taking out a car loan), buying insurance, reviewing his health-plan, purchasing pre-need burial services, and so endlessly on. Such decisions arise irregularly but routinely, and they give Chris an even denser thicket of reading.

Truly, in the modern sense of an old-fashioned word, Chris was a saint. Was he free? Was he happy? Did he enjoy a robust sense of autonomy? The question is absurd. Had anything been wrong, we should certainly have heard. Of course the moral of Chris's story hardly needs to be drawn. Chris expended a remarkable part of his day reading disclosures he did not want, could not understand, and did not use. He did have decisions to make, but he did not make them better because of the disclosures. And the time he spent attending to mandated disclosures he took away from things he needed to do, things he enjoyed doing, and decisions he was actually interested in learning about. In other words, the mandated disclosure paradigm mistakenly asks whether someone making a decision would be better off with more information. If that person had nothing in life but that decision, perhaps the answer would be yes. But since information that could be useful in a single-decision world becomes useless in the real world, the answer is generally no.

With Chris's sobering life in mind, let us return to our project of identifying all the conditions that would need to be met for mandated disclosure to work. We now must ask what disclosees must do if disclosures are to serve their purpose.

\section{Acquiring Disclosed Information}

Disclosees cannot use information until they acquire it. But consumers often don't know it exists, where it is, or how to find it, and they often doubt that they need it or that it would justify its acquisition costs. And so the long path from law-maker to discloser to disclosee ends because disclosees don't know about or take up the proffered information. Literally or metaphorically, all those Clery Act reports are on the floor and in the wastebasket.

For example, the updated credit-card agreement arrives. Why? Is its information new? Relevant? Necessary? Or the tow truck comes. Do you know that the driver has information about the towing service? Would that information lead you to dismiss that service and look for one offering better terms?

People have many reasons not to seek out information. Many consumers do not know how much the quality of goods and, especially, services varies. "[M]ost consumers do not believe clinical quality varies significantly across doctors, hence the low consumer demand for 
clinical quality report cards." ${ }^{201}$ For example, patients see LASIK (a kind of eye surgery) as a commodity and shop for it only on the basis of price, when in fact quality differs considerably across providers. ${ }^{202}$ Also confidence can lead people to over-estimate the adequacy of their knowledge. So "investors often do not recognize how difficult these choices are and instead rely on a belief that their innate abilities will lead to a good investment result." ${ }^{203}$ And one "of the most disconcerting findings" of a study of doctors' attempts to educated patients about end-oflife care "was that patients expressed strong preferences about treatments that they did not understand." 204

Even when people know they need information, they may not want it enough to labor to acquire it. First, they must find the right document, and then the right place in the document. (Try finding the water damage exclusion in your home owners insurance policy, or the privacy policy in a credit-card contract.) Disclosure documents are notoriously long: HIPAA disclosures easily run to six large pages of small type. IRBs can require consent forms of twenty pages. To pile Pelion on Ossa, these documents are infamously a farrago of convoluted language, serpentine sentences, tiny print, and irrelevancies. ${ }^{205}$

With all these barriers to acquiring information, no wonder, for example, that while people widely think the quality of care is the most important factor in choosing a health plan, hardly any patients review the data disclosed under mandates from Quality Report Cards statutes. Indeed, less than $1 \%$ of patients surveyed knew the rating of their hospital or surgeon. ${ }^{206}$

\section{Understanding the Information}

${ }^{201}$ Ha T. Tu and Johanna R. Lauer, Word of Mouth and Physician Referrals Still Drive Health Care Provider Choice, 9 Center for Studying Health System Change 1, 5 (2008), online at http://www.hschange.org/CONTENT/1028/ (visited Feb 11, 2009).

${ }^{202}$ LASIK may be "relatively simple surgery with low complication rates, but for patients whose eyes have certain 'problem' characteristics (for example, abnormal topography, large pupils, thin corneas), quality differences can be critical." Ha T. Tu \& Jessica H. May, Self-Pay Markets In Health Care: Consumer Nirvana Or Caveat Emptor?, Health Affairs - Web Exclusive w217, w222 (February, 2007).

${ }^{203}$ Stephen J. Choi and A.C. Pritchard, Behavioral Economics and the SEC, 56 Stanford L Rev 1, 12 (2003).

${ }^{204}$ Gary S. Fischer et al, Patient Knowledge and Physician Predictions of Treatment Preferences After Discussion of Advance Directives, 13 Journal of General Internal Medicine 447 (1998).

${ }^{205}$ Chris Consumer faced these problems when prescribed Prozac. Googling turned up a website (Epilepsy.com) that told him "How to Read a Package Insert" (2,443 words). It said inserts have nine sections: "Description," "Clinical Pharmacology," "Indications and Usage," "Contraindications," "Warnings," "Precautions," "Adverse Reactions," "Overdosage," and "Dosage and Administration." Chris balked but read on: "It's a good idea to review the package insert for any new medicine and to look at it again if anything about your health changes. If it raises any questions in your mind, contact your doctor or nurse for an explanation." Chris sighed and reached for his Stedman's medical dictionary. And, then, for the insert. It told him to "[r]ead the Medication Guide that comes with PROZAC before you start taking it and each time you get a refill" ${ }^{205}$ (to catch any changes). Chris embarked dutifully on the guide's 1,993 words.

206 Arnold M. Epstein, Rolling Down the Runway: The Challenges Ahead for Quality Report Cards, 16 Journal of American Medical Affairs 1691 (1998). 
Now suppose disclosees locate information, recognize its relevance and importance, and try to understand it. Many will fail.

\section{a. Illiteracy and Innumeracy}

Illiteracy prevents many people from understanding much disclosed information. Illiteracy can mean several things: Not knowing what word a combination of letters represents. Not knowing what a word means. Not knowing what words combined in a sentence mean. Not knowing how to extract information from a combination of several sentences. Well over 40 million adults are functionally illiterate, "and another 50 million have marginal literacy skills."207 Eighty percent of the population cannot understand the definition of "peremptory challenge" used to educate prospective jurors. ${ }^{208}$ Sector-specific illiteracy - like health or financial literacy is common. Four out of ten patients could not "comprehend directions for taking medication on an empty stomach."209 Many patients do not understand common clinical terms like "acute," "stable," and "progressive.,"210

Rates of innumeracy are even worse than rates of illiteracy. A standard test of numeracy asks people how often a flipped coin comes up heads in 1,000 tries, what $1 \%$ of 1,000 is, and to turn a proportion (1 in 1000) into a percentage. Thirty percent of women of above-average literacy "had 0 correct answers, 28\% had 1 correct answer, 26\% had 2 correct answers, and 16\% had 3 correct answers." ${ }^{211}$ Most of the people in another study had at least some college education, but $40 \%$ "could not solve a basic probability problem or convert a percentage to a proportion." 212 No wonder that "[a]fter receiving quantitative risk reduction data about the benefit of mammography, most women did not apply this information correctly when asked to estimate their risk for death from breast cancer with and without mammography."213

Furthermore, mandated disclosures are regularly written at forbidding reading levels. Financial-privacy notices are written at a third- or fourth-year college reading level. ${ }^{214}$ Twothirds of the privacy forms academic medical centers use require some college education, and almost all (90\%) are "difficult." Practically all the Quality Report Cards given patients use

207 Ad Hoc Committee on Health Literacy for the Council on Scientific Affairs, American Medical Association, Health Literacy: Report of the Council on Scientific Affairs, 281 JAMA 552, 552 (1999).

${ }^{208}$ National Center for Education Statistics, Adult Literacy in America: A First Look At the Results of the National Adult Literacy Survey 82 - 83 (U.S. Department of education, 1993).

209 Ad Hoc Committee on Health Literacy for the Council on Scientific Affairs, American Medical Association, Health Literacy: Report of the Council on Scientific Affairs, 281 JAMA 552 (1999).

${ }^{210}$ Michele Heisler, Helping Your Patients With Chronic Disease: Effective Physician Approaches to Support Self-Management, 8 Seminars in Medical Practice 43, 49 (2005).

${ }^{211}$ Lisa M. Schwartz et al, The Role of Numeracy in Understanding the Benefit of Screening Mammography, 127 Annals of Internal Medicine 966 (1997).

${ }^{212}$ Isaac M. Lipkus et al, General Performance on a Numeracy Scale Among Highly Educated Samples, 21 Medical Decision Making 37, 40 (2001).

${ }^{213}$ Accuracy ranged from $7 \%$ to $33 \%$. Lisa M. Schwartz et al, The Role of Numeracy in Understanding the Benefit of Screening Mammography, 127 Annals of Internal Medicine 966 (1997).

214 Mark Hochhauser, Lost in the Fine Print: Readability of Financial Privacy Notices, online at http://www.privacyrights.org/ar/GLB-Reading.htm (July 2001). 
indicators patients do not understand. ${ }^{215}$ HIPAA authorization forms add two pages to informed consent materials and are in language "similar in complexity to that in corporate annual reports, legal contracts, and the professional medical literature." 216 And only 3-4\% of the population can understand the language in which contracts are drafted. ${ }^{217}$

Even lawyers of the utmost sophistication retire defeated. During oral argument before the New Jersey Supreme Court, Chief Justice Weintraub said of an insurance policy, "I don't know what it means. I am stumped. They say one thing in big type and in small type they take it away." Justice Haneman admitted that he couldn't "understand half of my insurance policies." Justice Francis got "the impression that insurance companies keep the language of their policies deliberately obscure." ${ }^{218}$ Credit card contracts, subject to mandated disclosures, are no better. As Elizabeth Warren said of one, "I teach contract law at Harvard, and I can't understand half of what it says." 219

The standard response to these facts is to advocate simpler forms. But experts have labored intelligently and earnestly for decades to present complex information accessibly, and it is now clear that disappointingly little progress is possible. For example, one sophisticated attempt at a simple guide for prostate-cancer patients had "a readability score of $7^{\text {th }}$ grade," which would exclude roughly half the population. ${ }^{220}$ A recent study of mutual-fund disclosures is to like effect. ${ }^{221}$ And there is a reason for this failure: complexity cannot be explained simply. Sophisticated vocabularies and professional languages encapsulate complex thoughts. If only simple words can be used, everything must be lengthily spelled out. This returns us to the overload problem. Many words, even if simple, make forms repellently long and cognitively overwhelming. ${ }^{22}$ Thus one effort "to come up with a 'simplified' Miranda warning backfired when several Miranda components were included in a 32-word sentence."223

${ }^{215}$ Judith Hibbard and Jacquelyn Jewett, Will Quality Report Cards Help Consumers?, Health Affairs, Vol. 16. No. 3 (1997), 218-228.

${ }^{216}$ Peter Breese et al, The Health Insurance Portability and Accountability Act and the Informed Consent Process, 141 Annals of Internal Medicine 897, 897 (2004). Similarly, HIPAA forms in "major healthcare institutions" were (median) 6 pages long in 10-point fonts. A "median of $80.0 \%$ of persons in the surrounding area would have difficulty understanding the privacy notices." Peter Breese, Readability of Notice of Privacy Forms Used by Major Health Care Institutions, 293 JAMA 1593, 1593 (2005).

${ }^{217}$ Alan M. White \& Cath Lesser Mansfield, Literacy and Contract, 13 Stan. L. \& Pol'y Rev. 233 (2002); Melvin A. Eisenberg, Text Anxiety, 59 S.Cal L.Rev. 305 (1986);

${ }^{218}$ Gerhardt v. Continental Insurance Cos. 48 NJ. 291, 225 A.2d 328 (1966).

${ }^{219}$ See http://www.youtube.com/watch?v=1Yd08e5Cjvs\&feature=player_embedded\#

${ }^{220}$ Margaret Holmes-Rovner et al, Readability and Suitability Principles for Decision Aids (forthcoming). [Check published version for exact words.]

${ }^{221}$ John Beshears et al., How Does Simplified Disclosure Affect Individuals' Mutual Fund Choices, NBER Working Paper No. w14859 (April 2009).

${ }^{222}$ Even one of the fathers of the IRB system thinks it "necessary to use polysyllabic words in consent forms; it is in the nature of the language. If the prospective subject has systemic mastocytosis and we want to invite him or her to participate in a controlled clinical trial of cimetidine versus disodium cromoglycate, we must say so.” Robert J. Levine, IRB 8 (January 1982) (letter).

${ }^{223}$ Richard Rogers, A Little Knowledge is a Dangerous Thing . . . Emerging Miranda Research and Professional Roles For Psychologists, 63 American Psychologist 776, 779 (2008). 
Consider one of the plainer contracts drafted in lay language - eBay's User Agreement, which affects millions of people. ${ }^{224}$ The easy-to-understand terms are those people already know, without reading the agreement, like the "fees and services" provision. But in sticky areas - those that might provoke problems - even the lay language is confusing. Like this: "when you give us content, you grant us a non-exclusive, worldwide, perpetual, irrevocable, royaltyfree, sublicensable (through multiple tiers) right to exercise the copyright, publicity, and database rights (but no other rights) you have in the content, in any media known now or in the future." In this syntactical tangle, ten adjectival terms come between the article ("a") and the noun ("right"). The terms mean little until you reach "right" and find out what they are modifying. Almost all the sentence's terms require special knowledge. "Content," "non-exclusive," "perpetual," "irrevocable," "royalty-free," "sublicensable," "tiers," "copyright," "publicity," "database," "rights," and "media" are terms people don't use in the contract's sense, if at all.

What if disclosures were spoken, not written? At best, this would only partly solve the literacy problem (and probably exacerbate the numeracy problem). Extracting information from speech is like listening to a foreign language you know moderately well. At first you think you understand; you hear a word you don't instantly recognize; you pause to identify it; you return to find the speaker several words along in the sentence and you struggle to catch up. Soon it's hopeless. Reading at least lets you choose your pace and reread puzzling passages. And many disclosures are far too long to state orally.

Oral disclosures can reduce comprehension in other ways. Disclosees are often under stress, insecure, anxious, and rushed. Such people cannot take in what they are told and to use it effectively. For example, one paramedic being told she had cancer "was in a bubble. I saw his mouth moving and I was aware of a flow of words, but I was unable to process most of the information. He might as well have been speaking a different language." 225 Even Yale faculty and students who had been practicing civil disobedience and who were interviewed in their own homes by relatively mild law-enforcement officials were nervous and discomfited. ${ }^{226}$

The evidence about oral disclosures confirms its limited usefulness. For example, patients may need to know about end-of-life care, particularly cardiopulmonary resuscitation, since CPR is less effective and more unpleasant than popularly supposed. Unfortunately, doctors' conversations with patients about medical decisions at the end of life are rare and unsuccessful. In one study, discussions "did not usually concern specifics of treatment, such as artificial ventilation or cardiopulmonary resuscitation, but rather tended to deal with generalities and avoided details." ${ }^{227}$ A study of how experienced clinicians discussed advance directives with patients whom they know well found median conversations lasting 5.6 minutes and little enlightening: "Physicians used vague language to describe scenarios, asking what patients would want if they became 'very, very sick' or 'had something that was very serious.' They

224 Ebay's "Your User Agreement" at http://pages.ebay.com/help/policies/useragreement.html? trksid=m40, last visited on March 10, 2008.

${ }^{225}$ Rosalind MacPhee, Picasso's Woman: A Breast Cancer Story 41 (Kodansha, 1996).

${ }^{226}$ John Griffiths \& Richard E. Ayres, A Postscript to the Miranda Project: Interrogation of Draft Protestors, 77 Yale L J 300 (1967).

${ }^{227}$ Jaya Virmani et al, Relationship of Advance Directives to Physician-Patient Communication, 154 Arch Intern Med 909, 912-13 (1994). 
rarely attempted to define vague situations or to ascertain the meaning of such terms ...." Further, "qualitative terms were used loosely to describe outcome probabilities." These brief conversations scanted "the more common, less clear-cut predicaments surrounding end-of-life care." 228 Even patients told about "mechanical ventilation had a poor understanding of what this procedure entails, and a significant number harbored important misconceptions." 229 If such discussions of such issues with such people leave disclosees so ignorant, what hope for the average run of disclosures.

Furthermore, the best-informed speakers are also busy and expensive. So doctors tell nurses to "consent" the patient, or use substitutes like videotapes, instead of having the careful discussion advocates of informed consent envision. Corporations shift communication to automation and spoken formulas. This can mean an operator reading (slowly, wearily, and uncomprehendingly) terms drafted by lawyers. As Judge Easterbrook said sardonically, "if the staff at the other end of the phone for direct-sales operations had to read the four-page statement of terms before taking the buyer's credit card number, the droning voice would anesthetize rather than enlighten many potential buyers." 230

Finally, disclosure mandates are often aimed at people who may be particularly disadvantaged in trying to understand them. For example, sicker patients are considerably more vulnerable to the complexities of informed consent than healthier patients."231

\section{b. Making Sense of Information}

Illiteracy is not the only impediment to understanding disclosures. Simply understanding disclosures of the kind that are commonly mandated takes intelligence, sometimes a good deal of it, especially when misunderstanding even a single datum can badly mislead the disclosee. "High intelligence is a useful tool in any life domain, but especially when tasks are novel, untutored, or complex and situations are ambiguous, changing, or unpredictable." ${ }^{232}$ Yet in areas in which mandated disclosure is likeliest to be used, full and accurate understanding is vanishingly rare. What is more, there is little reason to suppose that people can regularly be brought to do so. ${ }^{233}$

When people receive information, they rarely record the data in their minds exactly as they received them. Rather, they need to interpret the data as they receive it, to try to make sense of it. This means that people interpret data by putting it in the framework of their current

\footnotetext{
228 James A. Tulsky et al, Opening the Black Box: How Do Physicians Communicate About Advance Directives?, 129 Annals of Internal Medicine 441 (1998).

${ }^{229}$ Gary S. Fischer et al, Patient Knowledge and Physician Predictions of Treatment Preferences After Discussion of Advance Directives, 13 Journal of General Internal Medicine 447 (1998).

${ }^{230}$ Hill v. Gateway 2000, 105 F.3d 1147 ( $7^{\text {th }}$ Cir. 1997).

231 See, e.g., L. Jamie Fitten \& Martha S. Waite, Impact of Medical Hospitalization on Treatment Decision-Making Capacity in the Elderly, 150 Archives of Internal Medicine 1717 (1990), who found that those in the "critically ill" or "severely distressed" category "failed to substantially understand key issues in treatment despite language and form simplification of consent documents."

${ }^{232}$ Linda S. Gottfredson \& Ian J. Deary, Intelligence Predicts Health and Longevity, But Why?, 13 Current Directions in Psychological Science 1, 2 (2004).

${ }^{233} \mathrm{We}$ cite numerous examples of this failure in our material on the effectiveness of mandated disclosure, especially the material on the failure of informed consent.
} 
understanding. When people make decisions in their ordinary lives, their "understanding of the rapid flow of continuing social events ... [depends] on a rich store of general knowledge of objects, people, events, and their characteristic relationships." Some of this knowledge may be represented as beliefs or theories, that is, reasonably explicit propositions about the characteristics of objects or object classes. People use these theories for organizing and explaining the information they receive. ${ }^{234}$ In short, people can misunderstand mandated disclosures because they lack necessary background information, because they misunderstand background information, and because they have no theories or have only the wrong theories for interpreting what they are told.

For example, patients misunderstand medical information because they don't know what their organs do, where they are, or even what they are called. ${ }^{235}$ Patients interpret information about CPR in light of the misleading picture they get from television shows. ${ }^{236}$ Similarly, few people applying for mortgages know what amortization is and how it conventionally works in paying off mortgages, which makes even lucid descriptions of balloon payments and fluctuating interest rates mysterious. In fact, many borrowers think the "amount financed" disclosed in the TILA statement is the loan amount, not the loan minus prepaid finance charges; or that the "discount fee" in the Good Faith Estimate is a discount they receive, not a fee they are charged. $^{237}$

Likewise, few people understand even the basics of the market for health care. ${ }^{238}$ This means, at best, that consumers generally lack, as Sage writes, "baseline information that could provide context for required disclosure. Therefore, health care consumers can easily misinterpret even accurate data." ${ }^{239}$ In one study, for example, prospective health-plan enrollees thought high hospitalization rates for pneumonia showed leniency in approving inpatient treatment rather than a failure to administer vaccinations. ${ }^{240}$ Similarly, the Yale faculty and students who waived their Miranda rights knew they could refuse to answer but did not know the practical consequences of waiving those rights. "Their waiver of the right to a lawyer's advice was even less informed,

\footnotetext{
${ }^{234}$ Donald A. Schön, The Reflective Practitioner: How Professionals Think in Action 60 (1983).

${ }^{235}$ Ben Watt was literate enough to have written a memoir of his illness, but had "always thought bowel was just a colloquial term like guts and meant somewhere near your arse."

236 See Susan J. Diem et al, Cardiopulmonary Resuscitation on Television: Miracles and Misinformation," 334 New England J Medicine 1578, 1578 (1996). E.g., on television "only 28 percent of the patients had primary cardiac arrests," while in life "75 to 95 percent of arrests result from underlying cardiac disease." Compare Professor Dresser's argument that research subjects "confuse research with therapy" not just because of inadequate consent forms: "Patients are inundated with messages equating study participation with medical treatment." Rebecca Dresser, The Ubiquity and Utility of the Therapeutic Misconception, 19 Social Philosophy \& Policy, 271, 271 (2002).

237 James Lacko and Janis Pappalardo, Improving Consumer Mortgage Disclosures: An Empirical Assessment of Current and Prototype Disclosure Forms (FTC Bureau of Economics Staff Report, June 2007, online at www.ftc.gov/opa/2007/06/mortgage.shtm.

${ }^{238}$ For example, $30 \%$ of those surveyed in one study knew almost nothing about HMOs. Of the remaining patients, only 16 percent had adequate knowledge (scores of 76 percent or higher) to choose between traditional Medicare and an HMO."

${ }^{239}$ William M. Sage, Regulating Through Information Disclosure Laws and American Health Care, 99 Columbia L Rev 1701 (1999).

240
} 
since their ignorance of the significance of the right to silence was compounded by their ignorance of the functions a lawyer might have performed for them." ${ }^{241}$

\section{Remembering the Information}

Receiving and analyzing information about complex and unfamiliar subjects take time, which means disclosees must remember what they have been told. But memory is fallible. Studies of informed consent, for example, repeatedly find that people correctly remember about a third of what of the basic information they are given if asked open-ended questions and about half if asked multiple-choice questions. Worse, people misremember what they are told.

All this is inevitable. Even in the best of circumstances it is hard to remember what you have learned without work. But information is especially hard to remember if you are not familiar with a subject. That is, things are most easily remembered if you can place them in some kind of context, a template, or a story. Thus jurors do reasonably well at remembering the facts of a case (and at helping each other remember the facts) but do quite badly at remembering the judge's instructions about the law. ${ }^{242}$ As the jurors hear the facts, they put them in the framework of a story. The law is a set of rules which do not fit in a story and for which jurors have no template.

Furthermore, people are better at remembering pleasant thoughts than unpleasant ones. Information contained in mandated disclosures is often stark and pessimistic, dealing with things that can go wrong and with contingent problems. For example, "Retention of information is selective and the expected benefits of surgery are recalled much better than the potential risks." ${ }^{243}$ This is not the place to explore all the reasons for such selective memory. It might have to do with cognitive biases, or it may reflect defense mechanisms such as suppression or denial. One implication, however, is that such factors may contribute to physicians' tendency to avoid discussing prognoses, withhold prognostic information, or present overly optimistic information. $^{244}$

\section{Analyzing the Information in Decision-Making}

Mandated disclosure attempts to solve social problems by requiring the disclosure of information. We have now looked at the likelihood that the disclosee will receive, understand, and remember the information whose disclosure is mandated. We have seen that each of these is so problematic that often the disclosee will not encounter the information, will not try to assimilate it, will not read or hear it correctly, will not understand it, or will misunderstand. The whole point of mandated disclosure is to provide people with good information. If they do not take up the information and learn it accurately, mandated disclosure fails.

\footnotetext{
241 John Griffiths \& Richard E. Ayres, A Postscript to the Miranda Project: Interrogation of Draft Protestors, 77 Yale L J 300, 311 (1967).

${ }^{242}$ Error! Main Document Only.Phoebe C. Ellsworth, Are Twelve Heads Better Than One?, 52 L. and Contemporary Prob. 205 (1989).

${ }^{243}$ R. Lemaire, Informed Consent: A Contemporary Myth?, 88 J. of Bone \& Joint Surgery 2, 4 (2006).

244 Tracy M. Robinson et al, Patient-Oncologist Communication in Advanced Cancer: Predictors of Patient Perception of Prognosis, 16 Support Cancer Care 1049, 1050 (2008).
} 
We might well end our discussion of mandated disclosure here. But mandated disclosure has another fault. It addresses a large problem with a partial remedy. People make bad decisions not just because they lack information. They also make bad decisions because they cannot use the information they have well. This problem mandated disclosure does not solve. And particularly in the kinds of areas to which mandated disclosure is directed, people can have considerable - even disabling - difficulties making good decisions.

A vast and growing literature in social psychology and behavioral economics has now begun to catalog the ways in which people distort information and ignore and misuse it in making decisions. We don't need to chaperone our readers through this literature to get from it one of its crucial insights: you do not solve the problem of bad decisions just by giving people information. It may be a necessary condition; it is not a sufficient one. The whole exercise of mandating disclosure to give people information is useless if the information does not lead people to make better decisions. We have concentrated on disclosees' cognitive problems with disclosed information and argued that those cognitive problems are generally so great that people often lack an adequate command of the information they need to make good decisions. But even if disclosees were offered, accepted, understood, and remembered all the information relevant to a decision, they would still be likely to encounter such serious difficulties in using the information to make a good decision that the information will do them little good. To put the point differently, mandated disclosure is fundamentally misconceived because its solution to the problem of choice is information alone, but people's problems with their choices go well beyond informational insufficiency. In the remainder of the section, we will discuss several problem people have in analyzing the information and using it to make decisions.

\section{a. Calculating}

We have already said that complex information in large quantities makes it hard for disclosees to acquire and understand disclosures. The problem worsens when disclosees try to use such information to make good decisions. People can keep only a few factors in mind when analyzing a problem. A "large body of empirical work suggest[s] that the integration of different types of information and values into a decision is a very difficult cognitive process. Evidence shows that people can process and use only a limited number of variables." 245 In fact, further information may decrease the reliability of people's decisions: "That is, when individuals had more information, their ability to use it "consistently' declined." In one study, for instance, Slovic asked expert handicappers to predict horse races. The more information the handicappers had, the more confident they were, but their predictive ability was as good with 5 variables as with 10,20 , or $40 . "$ Worse, "reliability of the choices decreased as more information was made available." 246

It is not surprising, then, that consumers borrow more than is rational. The calculations required to borrow shrewdly are many and knotty. They involve comparing relative costs of credit and cash, comparing different financial products such as short versus long term or secured

\footnotetext{
245 Judith H. Hibbard, et al, Informing Consumer Decisions in Health Care: Implications from DecisionMaking Research, 75 The Milbank Quarterly 395, 397 (1997).

${ }^{246}$ Ibid. at 398
} 
versus unsecured, setting the proper level of saving versus consumption, factoring in the time value of money and how it might evolve, and according each factor some relative weight. In the face of all this complexity, it is hard not to overweight a few simple, easily understood factors like low present interest rates.

Indeed, confronted with unfamiliar and complicated choices, people often seek to simplify the task by pruning away the factors they consider, and at the extreme they consult a single factor. "Making trade-offs to integrate conflicting dimensions into an overall choice is such a complex cognitive task that people tend to use heuristic shortcuts that may not produce optimal decisions. These simplified strategies include selecting only one dimension and ignoring others or focusing on concrete, easy to understand concepts such as cost rather than more complicated and less precise factors such as quality indicators." ${ }^{247}$ The more overwhelming a decision, the better radical shortcuts look. ${ }^{248}$

So (perhaps because of the anchoring heuristic) the rule for borrowing seems to be: Can I afford the monthly payment? This requires minimal calculation, but it also distorts the cost of credit. It obscures comparisons between the cost of credit and the cost of paying for a household purchase out of savings and comparison of competing credit offers. Most importantly, it renders disclosure of APR and related credit terms interesting but irrelevant.

Another example. Choices for treating treat breast cancer are - as these things go relatively simple, specialists have much experience presenting those choices to patients, and much attention has been paid to how to do so. Still, one study concluded that the leading "influence on decision-making behavior" was "perceived salience." In other words, patients let one aspect of the treatment determine the decision. These patients "did not report conflict about what course to take or the need for further information or deliberation."249 And indeed breastcancer patients seem regularly to choose a treatment with nothing approaching adequate understanding of their choices.",250

Finally, even employers' specialists choose health plans crudely. Only about a fifth used "some kind of system for making trade-offs and identifying high-performing, cost-effective plans," and the "system" could be as primitive as a four-cell matrix. "Twelve percent reported

\footnotetext{
${ }^{247}$ Lubalin \& Harris-Kojetin, 56 Medical Care Research \& Review at 88.

${ }^{248}$ Hanoch \& Rice, 84 Milbank Quarterly at 41.

249 Penny F. Pierce, Deciding on Breast Cancer Treatment: A Description of Decision Behavior, 42 Nursing Research 20 (1993). Schneider observed "similarly truncated courses of decision" in prospective dialysis patients. They often listened until they heard some arresting fact and then based their decision on it. "[A]s soon as some patients hear that hemodialysis requires someone to insert two large needles into their arm three times a week, they opt for whatever the alternative is." Carl E. Schneider, The Practice of Autonomy: Patients, Doctors, and Medical Decisions (Oxford U Press, 1998). For an extended development of these points, see ibid at $92-99$.

${ }^{250}$ Angela Fagerlin et al, An Informed Decision? Breast Cancer Patients and Their Knowledge About Treatment, 64 Patient Education \& Counseling 302 (2006). "[A] considerable number of studies have reached similar conclusions."
} 
that they made their choices on the basis of a single dimension such as cost or geographic access. ${ }^{251}$

\section{b. Choosing}

disclosure is not mandated to give disclosees a cognitive workout; its purpose is to help them make good decisions. Disclosure will be pointless, if people can understand the information they are given but are kept by other problems in handling information from resolving questions more successfully.

The mandated-disclosure formula assumes that disclosees take the information they are provided and use it to work out which choice best serves their preferences. However, when people consider subjects as to which they lack well-developed preferences, that lack can make it hard for them to use disclosed information productively. For example, someone considering insurance against a peril usually knows little about the coverage sought. The person might come to understand the risks, probabilities, and deductibles but be unsure which package of policy limits, exclusions, deductibles, and premia is preferable. Of course more coverage, fewer exclusions, smaller deductions, and cheaper premia are better. But would someone unused to trading off these factors know how to weigh them?

Or a patient with a possibly fatal disease must choose between a treatment with a relatively low chance of success but a low risk of death and other serious side effects and a treatment with a high chance of success but a high risk of death and other serious side effects. Patients have preferences that are relevant here - they want to avoid death and to avoid side effects. But few patients have values that will help them beyond this.

We are, of course, not arguing that people generally don't know their preferences. Our (narrower) argument is that few people can (or want to) develop finely calibrated preferences in the often-technical mandated-disclosure areas quickly and accurately enough to use in making decisions. Few have the ability to identify the fine distinctions about their own preferences and the tradeoffs among them in those technical areas that are subject to many of the disclosure mandates.

Another requirement for using disclosed information is making two kinds of predictions - predicting how you will react to your choice and how you will feel about your choice once you have started living it. A considerable and bemusing literature reveals that both predictions are hazardous. Even in some familiar situations people mispredict their behavior. ${ }^{252}$ They go on dates planning to behave chastely, engage in foreplay expecting to use a condom, and initiate sex planning to stop before the critical moment. ${ }^{253}$ In less familiar situations, the problem intensifies. For example, many credit card users wrongly expect to maintain a zero credit balance. Or,

251 Judith H. Hibbard et al, Choosing a Health Plan: Do Large Employers Use the Data?, 16 Health Affairs 172, 177 (1997).

${ }^{252}$ See, generally, Oren Bar-Gill, Informing Consumers about Themselves (NYU Working Paper, 2007).

${ }^{253}$ On such mispredictions, see, e.g., Daniel T. Gilbert \& Timothy D. Wilson, Miswanting: Some Problems in the Forecasting of Future Affective States, in Joseph P. Forgas, ed, Feeling and Thinking: The Role of Affect in Social Cognition 178-197 (Cambridge U Press, 2000). 
consumers joining health clubs at the flat rate option often chose incorrectly, overestimating their future usage by more than 100 percent. ${ }^{254}$

People's ability to use mandated disclosures effectively can be compromised by, for example, a tendency to overestimate how unhappy a bad outcome will make them and to underestimate their ability to diminish that unhappiness. So people react to disease and disability less despairingly than they expect. ${ }^{255}$ The sick generally evaluate their lives differently from the way the well evaluate them, ${ }^{256}$ and despite the "quality of life is more important than quantity" mantra, many patients would yield much quality even for slightly more quantity. ${ }^{257}$

\section{c. Expertise}

In most of the situations in which disclosure is mandated, more than facts are needed. Expertise - accumulated knowledge and experience - is also needed. The experts with whom disclosees deal - bankers, doctors, police, businesses, and so on - have a comparable kind of experience in their area of expertise, and that experience allows them to make better decisions in their area than a novice. As experts accumulate experience, they develop sets of patterns in their minds. These patterns describe the way things in their area usually work. When experts with this kind of experience encounter a new problem, they can consult their file of patterns to see what is recognizable in the problem and in the solution. In other words, "As a practitioner experiences many variations of a small number of types of cases, he is able to 'practice' his practice. He develops a repertoire of expectations, images, and techniques. He learns what to look for and how to respond to what he finds." ${ }^{258}$ More precisely, "Decision makers recognize the situation as typical and familiar ... They understand what types of goals make sense (so the priorities are set), which cures are important (so there is not an overload of information), what to expect next (so they can prepare themselves and notice surprises), and the typical ways of responding in a given situation. By recognizing a situation as typical, they also recognize a course of action likely to succeed." 259

This kind of experience and skill in making particular kinds of decisions is developed by practice and cannot be taught simply by providing information. Reaching a good decision is not an exercise in analytical logic or an application of a simple theory. Rather, a good decision

\footnotetext{
${ }^{254}$ See Stefano Della Vigna \& Ulrike Malmendier, Paying Not to Go to the Gym, 96 Amer. Econ. Rev. 694 (2006).

${ }^{255}$ For example, Tsevat et al found interviewed AIDS patients. Half said "their life was better currently than it was before they were aware that they had HIV," while only $29 \%$ said life was worse. Joel Tsevat et al, The Will To Live Among HIV-Infected Patients, 131 Annals of Internal Medicine 194 (1999).

${ }^{256}$ Peter A. Ubel et al, Whose Quality of Life? A Commentary Exploring Discrepancies Between Health State Evaluations of Patients and the General Public, 12 Quality of Life Research 599 ( 2003).

${ }^{257}$ Tsevat et al's HIV patients had a "mean time-tradeoff score was $0.95 \pm 0.1$ " over a five-year period, "indicating that, on average, patients did not have a clear preference between living 5 years in their current state of health and 4.75 years . . . in excellent health." Joel Tsevat et al, The Will To Live Among HIV-Infected Patients, 131 Annals of Internal Medicine 194 (1999). To like effect, see Joel Tsevat et al, The Will To Live Among HIV-Infected Patients, 131 Annals of Internal Medicine 194 (1999).

${ }^{258}$ Donald A. Schön, The Reflective Practitioner: How Professionals Think in Action 60 (Basic Books, 1983)

${ }^{259}$ Gary Klein, Sources of Power: How People Make Decisions 24 (MIT Press, 1998).
} 
results from technical experience and savvy, gained by practice, trial-and-error, and some measure of intuition - factors that cannot be passes along by simple communication. It is based on knowledge that is implicit, rather than articulate. ${ }^{260}$ Indeed, experts "usually know more than they can say. They exhibit a kind of knowing-in-practice, most of which is tacit." ${ }^{261}$ This tacit knowledge has also been described as a kind of "[i]ntuition [that] depends on the use of experience to recognize key patterns that indicate the dynamics of the situation." 262

This is of course not to say that novices can never understand information. But novices' lack of expertise places on them another burden in interpreting disclosures. In the areas in which mandated disclosure is most used, operates, novices cannot easily understand the facts they are given, how to put them in context, how to analyze them, and how to act on them. To be sure, the range of expertise called for in the areas regulated by mandated disclosure is great. But when one surveys, for example, the list of disclosers described in the fourth paragraph of this article, one realizes that most of them need a good deal of experience to understand their work and the choices they present to their clients.

This brings us back to the quantity question. We have just suggested that experts deal with it in ways that are not available to novices. For example, by long experience they build up sets of patterns they can consult almost intuitively. They build up standard solutions to problems. Like seasoned watchmakers, they break down complex problems into sub-problems, reducing the complexity. In short, experts find ways to simplify choices so that they make them with as few data and as little labor as possible.

\section{d. Decision Aversion}

Mandated disclosure assumes that people want to make decisions themselves, and that they do so by gathering and evaluating information about their choices. In areas subject to mandated disclosure, both parts of this assumption are unreliable. The empirical evidence shows that people resist making even crucial decisions, and that when they do make decisions they do with little information and scant reflection on it. For example, people numerously resist making their own medical decisions, and the sicker and older they are - and thus the more consequential their decisions - the more they resist. In one study, asked if they wanted information, patients' mean score was 80 on a 0 - 100 scale; asked if they wanted to make their own decisions, the mean score was $33 .^{263}$

\footnotetext{
${ }^{260}$ Stephen Marglin, Towards the Decolonization of the Mind, in DominATING KNOWLEDGE: From Development to Dialogue 24 (F. Appfel Marglin and S.A. Marglin, Eds., Oxford 1990).

${ }^{261}$ Schön at viii.

${ }^{262}$ Gary Klein, Sources of Power: How People Make Decisions 31 (MIT Press, 1998).

263 Jack Ende et al, Measuring Patient's Desire for Autonomy: Decision Making and Information-Seeking Preferences Among Medical Patients, 4 J Gen Intern Med 23, 26-27 (1989). Carl E. Schneider, The Practice of Autonomy: Patients, Doctors, and Medical Decisions (Oxford U Press, 1998). Chapter 2 surveys the empirical data at tiresome length.
} 
Similarly, people avoid financial decisions and use less information than they need and could get. For example, people famously avoid rational retirement planning. ${ }^{264}$ "Only 42 percent of workers report they and/or their spouse have tried to calculate how much money they will need to have saved." 265 Rather than choosing investments, employees often leave pension money wherever their employer puts it. ${ }^{266}$ Despite easily available advice about the basics of retirement planning, employees hold employer stock in risky proportions. ${ }^{267}$

Of course many people make many decisions willingly and well. Many decisions are normally made personally (like choosing a school or a spouse). Some decisions some people enjoy making (like buying shotguns or shoes). And acquiring information can be fun (like reading box scores or gossip columns). But decisions-especially the subset of decisions mandated disclosure seeks to improve - are generally a means, not an end, a distraction, not a pleasure. The drudgery of learning, the agony of indecision, the risks of responsibility, the inevitability of incompetence, the recognition of perils, are avoided.

Seeking plenary control can interfere with the things that really matter to you. Control means constantly making choices, which is time-sapping and soul-sucking. As Whitehead wonderfully said, "It is a profoundly erroneous truism, repeated by copy-books and by eminent people when they are making speeches, that we should cultivate the habit of thinking about what we are doing. . . . Operations of thought are like cavalry charges in a battle: they are strictly limited in number, they require fresh horses, and must only be made at decisive moments."268

Not only may people resist making the kinds of decisions mandated disclosure addresses, they also resist making them in the way mandated disclosure intends. For most people facing such decisions, the more-is-better mantra is wrong. In many areas, and particularly where people are confused and need "protection," knowledge is not intrinsically valued. People can want to know less, not more. They can find information a burden, not a privilege. They begrudge the time and effort it takes to learn and use the amount and kind of information mandated-disclosure provides. They don't like to read contracts, manuals, warnings, notices, forms, charts, instructions, or to burrow through endless data. An extreme example is the finding that sixty percent of criminal suspects did not go to the labor of understanding and using their Miranda rights partly because they hoped "that they could go home if they 'cooperated' with the interrogation and confessed."269

\footnotetext{
${ }^{264}$ See, e.g., James J. Choi et al., For Better or For Worse: Default Effects and 401(k) Savings Behavior, in Perspectives in the Economics of Aging (David Wise, ed.); James J. Choi et al., Optimal Defaults, 93 Amer. Econ. Rev. 180 (2003)

${ }^{265}$ Ruth Helman et al, Encouraging Workers to Save: The 2005 Retirement Confidence Survey, 280 EBRI Issue Brief 1, 6 (2005).

${ }^{266}$ James J. Choi et al, Defined Contribution Pensions: Plan Rules, Participant Choices, and the Path of Least Resistance, Prepared for Tax Policy and the Economy 32 (2001).

${ }^{267}$ James J. Choi et al., Are Empowerment and Education Enough? Undiversification in 401(k) Plans, 2 Brookings Papers on Economic Activity 150 (2005).

${ }^{268}$ Alfred North Whitehead, An Introduction to Mathematics 61 (n.d.).

269 Richard Rogers, A Little Knowledge is a Dangerous Thing . . . Emerging Miranda Research and Professional Roles For Psychologists, 63 American Psychologist 776, 783 (2008).
} 
Yet everywhere people turn, they are bombarded with excess information. So they try to stem the waste of time and attention required to sort through the information. Google triumphs because it gives people less information - the useful information, the "top hits" - not more. They become, in short, numb to information delivered in mandated disclosures.

Instead, people look for cues, signals, something familiar to latch onto-indicators that are largely inconsistent with the comprehensive, systematic information toward which disclosures tend. People hope to make decisions with less information, not more; to break the information down to easy, modular, pieces, not to assemble it to comprehensive wholes; to minimize exposure to unknown decisions and replace them with familiar ones. The ideal underlying mandated disclosure-provision of more systematic information-flouts these preferences.

\section{Some Unintended EfFects of MANdATEd Disclosure}

We have examined the potential of mandated disclosure to inform people and improve their decisions. But disclosures can affect transactions and interactions in other ways, by creating indirect benefits and imposing selective costs. In this section, we first look at some possible indirect benefits of mandated disclosure and then examine some indirect and unintended costs.

\section{A. Indirect Benefits of Mandated Disclosure}

Mandated disclosure's core purpose is to supply the information people need to make better decisions. We have just described a long series of requirements that would have to be met for mandated disclosure to serve that purpose, and we argued that these requirements would rarely all be met. If a mandated-disclosure regulation fails to accomplish its purpose, it cannot be justified even if its cost is small.

But might mandated disclosure be justified on the basis of indirect benefits that have so far been overlooked? First, might mandated disclosure serve some goals other than directly informing people? Second, might mandated disclosure be made to work more effectively?

\section{An "Agency" Benefit}

An influential law-and-economics argument maintains that a few sophisticated readers of disclosures can discipline disclosers and force them to offer better term, eschew hidden traps, and behave efficiently. ${ }^{270}$ Mandated disclosure can be regarded as a way to inform these sophisticated readers, whose presence would benefit all disclosees. We doubt, however, that sophisticated disclosees are "reading agents" for other disclosees.

First, this theory conflicts with the premise of mandatory disclosure. The sophisticated readers are supposed to induce businesses voluntarily to disclose information and avoid self-

\footnotetext{
${ }^{270}$ Alan Schwartz and Louis L.Wilde, Intervening in Markets on the Basis of Imperfect Information: A Legal and Economic Analysis, 127 U.Pa. L. Rev. 630 (1979); George L. Priest, A Theory of the Consumer Product Warranty, 90 Yale L.J. 1297. But see Clayton P. Gillette, Rolling Contracts as an Agency Problem, 2004 Wis. L.Rev. 679, for a critical view.
} 
serving behavior. That is, recognizing the presence of sophisticated consumers and seeking to please them, businesses voluntarily disclose information and make it useful. Failure to do so would either drive the sophisticates away or reduce their willingness to pay. Mandated disclosure, by contrast, assumes that without a mandate, there will be no disclosure. It thus assumes that there are not enough sophisticated consumers who know to demand and are able to scrutinize the information. And this assumption is ordinarily correct. The factors that discourage disclosees from scrutinizing disclosures apply to even sophisticated disclosees. If nobody reads disclosures, it matters not that some non-readers are sophisticated.

Even if there were enough readers, they cannot be good agents for other consumers unless they are reasonably typical. But the eccentric with the time, knowledge, skill, and determination to plow through these documents is anything but typical. Furthermore, businesses can try to identify and segregate these readers, so that the benefits they know to insist on will not leak to the non-reading majority. Sophisticated readers could selectively enjoy the "good" terms in the contract because they are buried in the fine print and take some digging to find. And even if agency readers were subject to the same oppressive terms as everybody else, they might negotiate ad hoc accommodations. ${ }^{271}$ That is, the agency account works only for a market in which disclosers cannot distinguish readers from nonreaders and must give all consumers the better deal readers insist on. But disclosure is often mandated where these conditions are not met, as in medical situations (like informed consent), Miranda situations, and in warnings about products - product-liability law, cigarette warnings, etc. - all areas in which different people use or enjoy the information differently.

There are market entities who specialize in reading disclosures. Consumer watch dogs and groups whose agenda is to assess complex products and disseminate the information to the general public could serve as reading agents. Thus, mandated disclosures might inform these market intermediaries who, in turn, might disseminate the information to the population. But it is not clear that mandated disclosures help such groups fulfill their mission. Like other sophisticated readers, they can and do get the information even if it were not mandated. Moreover, it is not clear that information they provide is based on the content of disclosures. Instead, it is often based on feedbacks and test trials which the watch dogs conduct. Finally, it is not clear that the information disseminated by such entities is more accessible to consumers than the disclosures themselves.

\section{An Educational Benefit}

Could mandated disclosure be salvaged if it used better educational techniques? As Kapp writes, informed consent's champions place "much faith . . . in the potential effectiveness of various educational tools to empower patients to comprehend and manage adequately the basic information needed to satisfy informed consent aspirations." These tools include "more sophisticated decision aids in the form of information technology; the provision of written handouts to patients; presentation of information in qualitative, quantitative, and graphic formats,

\footnotetext{
${ }^{271}$ For example, the Comcast arbitration clause discussed above is a "Right to Opt Out" which requires the reader to notify Comcast. Only sophisticated readers that do so enjoy the benefit; naïfs enjoy no spillover. On such techniques, see Gilo and Porat, The Unconventional Uses of Transactions Costs', in O. Ben-Shahar (ed), Boilerplate: Foundations of Market Contracts (2006) 66-81.
} 
simplified to reach the lower literate patient; and the showing of videotapes." ${ }^{272}$ It is said that mandated disclosure could work if supported by more general attempts to educate people about the area in which they must make decisions. Chairman Bernanke is one of many who believe that financial education is a critical component of a robust and effective financial marketplace. It is also said that while mandated disclosure may not directly improve people's decisions, it helps educate them about problems they may face.

Tocqueville thought "one of the most remarkable features of America" was the "universal and sincere faith that they profess here in the efficaciousness of education." 273 Attempts to make mandated disclosure work through education have consistently disappointed that faith. For example, efforts to educate workers about $401(\mathrm{k})$ retirement savings regularly fail. Only about $15 \%$ of the people who leave investment seminars planning to change their investments actually do so. ${ }^{274}$ One study even suggests that high school students who have taken a financial education course score less well than other students. ${ }^{275}$ Similarly, considerable "evidence indicates that early efforts to educate consumers [of health-care plans] have not been very effective...,276 Lubalin and Harris-Kojetin hope that "[w]ith appropriate education, over time consumers may begin to understand the role that plan structure plays relative to doctor performance in affecting their care and plan experiences." 277 But researchers have long striven to create that appropriate education with dismal results. ${ }^{278}$

Education presents much the same problems that make mandated disclosure so problematic. And when education is intended for general purposes and not to help someone with a particular decision it is likely to work even less well. The problems of mandated disclosure as education are not just cognitive and not just difficulties of time and attention, although they are importantly all these things. The problems also arise because behavior is affected by so many things that do not respond well to one-size-fits-all education.

${ }^{272}$ Marshall B. Kapp, Patient Autonomy in the Age of Consumer-Driven Health Care: Informed Consent and Informed Choice, II Journal of Health \& Biomedical Law 1, 13-14 (2006).

${ }^{273}$ Quoted in A. Bartlett Giamatti, A Free and Ordered Space: The Real World of the University 33 (Norton 1988).

${ }^{274}$ James J. Choi, et al, Defined Contribution Pensions: Plan Rules, Participant Decisions, and the Path of Least Resistance, in 16 TAX POLICY AND THE ECONOMY, 67 -113, (James Poterba, ed., 2002); Colleen E. Medill, Challenging the Four "Truths" of Personal Social Security Accounts: Evidence from the World of 401(k) Plans, 81 N. Carolina L. Rev 901 (2003).

275

${ }^{276}$ Cunningham et al, 20 Health Affairs at 165 .

${ }^{277}$ Lubalin and Harris-Kojetin, 56 Medical Care Research \& Review at 73

278 A chastening perspective on education and mandated disclosure comes from continuing medical education (CME). Despite many reasons to expect CME to work, its record is discouraging, and it delivers "messages in ways that are most often ineffective." Karen Tu \& Dave Davis, Can We Alter Physician Behavior by Educational Methods? Lessons Learned from Studies of the Management and Follow-Up of Hypertension, 22 Journal of Continuing Education in the Health Professions 11, 20 (2002). And despite the ineffectiveness of didactic CME, "[t]here is clear evidence that CME offerings today in North America consist mostly of the less effective change strategies such as conferences." Dave Davis, Does CME Work? An Analysis of the Effect of Educational Activities on Physician Performance or Health Care Outcomes, 28 International Journal of Psychiatry in Medicine 21, 31 (1998). 
Smoking is a particularly clear example of the unexpected complexity and difficulty of public education. Smoking rates are much lower. But is it because of warnings on cigarette packaging? Surely change comes principally from more fundamental policies that changed social attitudes, mobilized social pressures, and affected prices. These include laws driving smokers from the company of their fellows; higher sales taxes; and bans in places like offices, hotels, airplanes, and restaurants. The increasingly medical and social recognition of the mortality and morbidity smoking causes has also been central. Educational efforts were correlated with these changes, but it is not clear how much they caused them. And it is even less clear that the mandated labeling has had any role in driving the educational campaign.

Finally, and perhaps most sobering, is the accumulation problem-yet again. Even if consumers could be adequately educated in one area, they cannot begin to master the many areas in which they must act. Consumers must do more than just buy goods and services intelligently. For example, defined-contribution pensions oblige us to manage retirement accounts. Other financial issues proliferate, like handling debt. "Education" is the magic solution invoked in almost every area of mandated disclosure. People have to be educated about financial decisions, health insurance choices, pensions, health care and sickness prevention, privacy protection, internet shopping, eating habits and nutrition, risk management, smoking, gambling, and a long and growing list of other issues related to physical and financial health and safety.

\section{B. The Costs of Mandated Disclosure}

It is no easier to measure the costs of mandated disclosure than its benefits. But there are several reasons to believe that those costs can be considerable. We first discuss some direct implementation costs, and then examine a variety of indirect, more subtle costs, that are often unrecognized and unintended by law-makers.

\section{Implementation Costs}

In Part III, we charted all the things law-makers, disclosers, and disclosees must do for mandated disclosure to succeed. We did so to show why mandated disclosure so often fails, but many of these arguments can be understood as a catalog of the implementation costs of mandated disclosure. For example, disclosers may be put to some expense in figuring out what disclosures are actually mandated, as the rise of industries intended to tell disclosers their obligations under HIPAA, the Clery Act, and so on suggests. TILA regulations became so complicated that even expert counsel could prove inadequate. Issuers of securities always consult specialized legal counsel.

In addition, we canvassed disclosers' costs of assembling and providing information. Costs can be especially great when information has not previously been assembled. Providing information can be expensive if it has to be mailed, and particularly if it has to be mailed regularly, as, for example, some financial privacy statements must be. Often disclosers must fund bureaucracies to comply with disclosure mandates. It cost the Johns Hopkins Hospital $\$ 114,528$ to establish its PSDA program, and it "incurs on-going incremental costs including document copying, file folders, audits, and personnel. It also has on-going total costs including 
continued training and physician education regarding advance directives." ${ }^{, 279}$ And that hospital is only one of thousands of institutions subject to the PSDA.

A much larger and growing bureaucracy administers the IRB system, whose principal function is to supervise the researchers' disclosures to prospective subjects. IRBs now have professional staffs, ${ }^{280}$ but the principal personnel cost is the time IRB members - who are primarily physicians, scientists, and other expensive people - spend reviewing, discussing, and monitoring researchers' disclosures. And IRBs can be so populous that "[m]any social sciences and humanities departments are smaller than the IRB committee . . .."281 Researchers are also expensive people, and their time is also considerably taxed by the IRB system. For example, one rather modest research program spent $17 \%$ of its total budget dealing with its IRB. ${ }^{282}$

As a rule, disclosees bear a large share of the cost of mandated disclosure, if only because in commercial relationships disclosers' costs are passed on in part to disclosees. But disclosees have direct costs of their own. Under the most optimistic view, that disclosees actually read, interpret, and store the information, disclosees have to incur the nonmonetary cost of such acts.

\section{Unintended Harms of Mandated Disclosure}

Mandated disclosure has the potential to impose considerable costs in the form of damaged individual and social interests. These are unintended costs, and they do not arise in every setting. But there are increasing reasons to worry about their pervasiveness.

First, mandated disclosure can crowd out useful information. Because disclosers can proffer, and disclosees can receive, only so much information, mandated disclosures effectively keep disclosees from acquiring other information. If learning the mandated information is actually what the disclosee most wants and need to do, this will not matter, but as we have shown, mandates rarely if ever achieve such precision. Richard Craswell pointed out that mandated disclosures may "reduce the attention consumer pay to other information, conceivable leading to worse decisions rather than better ones" and give the example of brokerage fee disclosures that cause consumer to overestimate the total cost of the loan. ${ }^{283}$

Similarly, in medicine marginally useful mandated information drives out vitally useful unmandated information. Drug warnings are so overloaded with information that users are

\footnotetext{
${ }^{279}$ Jeremy Sugarman et al, The Cost of Ethics Legislation: A Look at the Patient Self-Determination Act, 3 KIEJ 387 (1993).

280 "At Northwestern the Office for the Protection of Research subjects grew from two full-time professionals in the late 1990s to 25 professionals and an administrative staff of 20 last year." Todd J. Zywicki, Institutional Review Boards as Academic Bureaucracies: An Economic and Institutional Analysis, 101 Northwestern U L Rev 861 (2007).

${ }^{281}$ John H. Mueller, Ignorance Is Neither Bliss Nor Ethical, 101 Northwestern University Law Review 809, 822 (2007).

282 Keith Humphreys et al, The Cost of Institutional Review Board Procedures in Multicenter Observational Research 139 Annals of Internal Med 77 (2003).

${ }^{283}$ Richard Craswell, Taking Information Seriously: Misrepresentation and Nondisclosure in Contract Law and Elsewhere, 92 Virg. L. Rev. 565, 584 (2006).
} 
numbed by the quantity. This "crying wolf" dynamic is everywhere. Providers must tell patients about advance directives (the PSDA), privacy policies (HIPAA), treatment choices (informed consent), and safety (tort law and malpractice insurance). How much attention is left in the patients' reservoir (and the providers') to learn about thing that are life- and health-saving like, say, how to manage a chronic illness? The common estimate is that compliance rates with treatment regimes are around $50 \%$. Patients must be taught and persistently prompted to get the medicine, ingest it by the right route, take the right dose at the right time, and keep taking it as long as necessary. ${ }^{284}$ But such strenuous teaching is crowded out by disclosures.

Second, mandated disclosure can have anticompetitive effects. Disclosure costs are substantially "fixed costs"; a substantial fraction of them does not vary with the scope of activity or with the frequency of disclosures. These fixed costs - collecting information, drafting forms, training employees - are roughly the same for both large and small disclosers. This gives larger disclosers a relative advantage: their average burden of disclosure per "unit" is smaller. This, in turn, reduces the ability of new small-size companies to enter and compete in the market. ${ }^{285}$ Such anti-competitive effects are well illustrated by disclosures vocational schools are often required to make. In some states, they must provide statistics on as many as twenty topics, including graduation rates, re-enrollments, exam pass rates, graduates' job prospects, and much more. ${ }^{286}$ Setting up a system that collects this information requires investments in bureaucracy and record-keeping and disproportionately burdens small schools. It also requires internal monitoring of standardization, another fixed cost that burdens the smaller competitors. These burdens are recognized in the context of calorie labeling in food establishments. New York city's law applies only to chains of 15 or more restaurants. ${ }^{287}$

Third, mandated disclosure can undermine other consumer-protection regulations. For example, the doctrine of unconscionability is an alternative protection device that allows courts to strike oppressive terms from contracts. Contracts are unconscionable if they are substantively intolerable and if there was some unfair procedural flaw in making the contract. Often that procedural flaw requirement is met by a finding that an oppressive term was "hidden," or that it came by surprise to the consumer. If, however, disclosure of the oppressive term was performed as mandated - if the discloser can point to a form that was handed to the consumer in a way that complied with regulatory requirements and which the consumer received and signed-the "hidden" element is not satisfied. That is, an empty but formally correct disclosure can keep the

\footnotetext{
${ }^{284}$ Todd M. Ruppar et al, Medication Adherence Interventions for Older Adults: Literature Review, 22 Research and Theory for Nursing Practice: An International Journal 114 (2008) (doi: 10.1891/08897182.22.2.114).

${ }^{285}$ This argument was made in the context of securities regulation by Frank H. Easterbrook and Daniel R. Fischel, Mandatory Disclosure and the Protection of Investors, 70 Virg. L. Rev. 669671 (1984)

${ }^{286}$ Private Business and Vocational Schools Act, 105 ILCS 425/15.1 (Illinois disclosure statute applying to enrollment in vocations schools); Barber, Cosmetology, Esthetics, and Nail Technology Act, 225 ILCS 410/3B-12(a) (Illinois, 1985) (numerous disclosures required in school enrollment agreements); Cal. Veh. Code. $\S 11200(1)$ (2007) (disclosure by traffic violator schools); NJSA 13:23-5.16 (disclosure by driving schools).

${ }^{287}$ Section 81.50 of the New York City Health Code.
} 
contract from being struck as unconscionable, however problematic its terms. The relief courts might otherwise grant is undercut. As Robert Hillman noted, the disclosure can thus backfire. ${ }^{288}$

A similar backfire effect can arise when the discloser who complies with the disclosure mandate is freed to engage in other forms of sharp dealing. The discloser would have both a strategic reason to counteract the chilling effect of the disclosure by giving false and biased assurances, and the "moral" legitimacy to act in harsher ways against the adequately protected consumer. This effect is noted in the context conflict-of-interest disclosures. ${ }^{289}$

Mandated disclosure may not only undermine other protections, it may inhibit their development. To the extent that protections need to emerge from legislative and regulatory effort, law-makers devising disclosure mandates would regard their mission accomplished and escape the onerous work of devising more imaginative, more effective, and perhaps more politically controversial alternatives.

Fourth, mandated disclosure can lead to inequity. Mandated disclosure helps most those who need help least and helps least those who need help most. Information is more useful to welleducated and well-off people who have the resources to locate, interpret, and use the revealed information well. $^{290}$ For example, in more than one study, consumer knowledge of credit markets was related closely to family income and education. One study found that disclosures of a used car's history, odometer readings, warranties, and more did not help the poor. The poor consistently get worse terms than other buyers (for many reasons), and disclosure mandates may have exacerbated this difference (perhaps because they are comparatively less capable of utilizing the disclosures). ${ }^{291}$ Another context where this happens is contract boilerplate: disclosed terms give additional value to sophisticated consumers, for which all consumers pay. For example, Comcast included this provision in the fine print it must send customers:

"Right to Opt Out : If you do not wish to be bound by this arbitration provision, you must notify Comcast in writing within 30 days of the date that you first receive this agreement by visiting www.comcast.com/arbitrationoptout, or by mail."292

\footnotetext{
${ }^{288}$ Robert A. Hillman, Online Boilerplate: Would Mandatory Web Site Disclosure of e-Standard Terms Backfire?, in Boilerplate: Foundations of Market Contracts 83-94 (O. Ben-Shahar, Ed., 2006); Riensche v. Cingular Wireless, LLC, 2006 U.S. Dist. LEXIS 93747 (W.D. Wash. Dec. 27, 2006) (rejecting the unconscionability claim because the consumer had unlimited time to review the arbitration clause and thus a reasonable opportunity to understand the term.)

${ }^{289}$ Daylian M. Cain et al, The Dirt on Coming Clean: Perverse Effects of Disclosing Conflicts of Interest, 34 Journal of Legal Studies 1, 22 (2005).

${ }^{290}$ Consumers' understanding of credit and of mandated disclosures is positively associated with their income and education. See Jean Kinsey and Ray McAlister, Consumer Knowledge of the Costs of Open End Credit, 15 J. Consumer Affaris 249 (1981); Lewis Mandell, Consumer Knowledge and Understanding of Consumer Credit, 7 J. Consumer Affairs 23 (1973).

291 Kenneth McNeil et al., Market Discrimination Against the Poor and the Impact of Consumer Disclosure Laws: The Used Car Industry, 13 Law \& Society Rev. 695, 699 (1979).

${ }^{292}$ Comcast Agreement for Residential Services $§ 13$ (October 2007).
} 
People who opt out of mandatory arbitration may bring suits and perhaps class actions, something only the sophisticated would know. But Comcast's cost of exposure to such litigation is rolled into the costs everyone pays. Likewise, advantages sophisticated credit-card users secure (like low APRs and airline miles) are funded by the fees and high interest rates the unsophisticated pay. ${ }^{293}$ Disclosures that help the sophisticated avoid these fees and high rates exacerbate the cross subsidy.F

Perhaps nowhere is the inequity of mandated disclosure mFore apparent or disheartening than in health care. "A lower education level was found in most studies [of medical patients] to have a negative influence on comprehension and memory. Recall of information was also negatively influenced by older age. Studies on elderly patients have shown that both comprehension and memory performance varied directly with vocabulary level.,294

It is obvious and well-proved that there are "large health disparities between the disadvantaged in the United States and those who are more privileged." 295 Resources spent obeying disclosure mandates are resources that cannot be spent giving the poor what they most need - better care. At the same time, these are resources that help the privileged more, because literature helps the literate most. ${ }^{296}$ Here, mandated disclosure increases the disparity between rich and poor.

Not only does mandated disclosure help the rich more than the poor; it perversely and unintentionally obliges the poor to subsidize the rich. Good deals must be paid for. Vendors often incorporate the cost of good deals for the sophisticated in the price everybody pays. ${ }^{297} \mathrm{We}$ already mentioned the redistributive effect of hospital report cards, where mandated disclosure of "quality of care" measures disproportionately helps less sick patients and reduces the well being of sicker ones. ${ }^{298}$

Inequity is built into the principle of mandated disclosure. The poor begin with more troubles and fewer resources. They must pay higher interest rates than people better situated to make the payments, deal with less reputable lenders, know less of financial affairs, are likelier to encounter crippling financial reverses, find it harder to locate competent professional help, and so on. They have harder decisions than the prosperous. Yet the principle of mandated disclosure

\footnotetext{
${ }^{293}$ Ronald J. Mann, Contracting for Credit, in Boilerplate: Foundations of Market Contracts 106, 110 (O. Ben-Shahar, ed., 2006).

${ }^{294}$ R. Lemaire, Informed Consent: A Contemporary Myth?, 88 The Journal of Bone and Joint Surgery 2, 4 (2006) (doi: 10.1302/0301-620X.88B1.16435).

${ }^{295}$ David Mechanic, Disadvantage Inequality and Social Policy: Major Initiatives Intended to Improve Population Health May Also Increase Health Disparities, 21 Health Affairs 48, 49 (2002).

${ }^{296}$ Ad Hoc Committee on Health Literacy for the Council on Scientific Affairs, American Medical Association, Health Literacy: Report of the Council on Scientific Affairs, 281 JAMA 552, 553 (1999). Carl E. Schneider \& Mark A. Hall, The Patient Life: Can Consumers Direct Health Care? 35 American Journal of Law \& Medicine 7, 62 - 65 (2009), examines these inequities.

${ }^{297}$ For a general description of this phenomenon, see David Gilo and Ariel Porat, The Unconventional Uses of Transactions Costs, in Boilerplate: Foundations of Market Contracts 66, 70-71 (O. Ben-Shahar, ed., 2007).

298 David Dranove et al, Is More Information Better? The Effects of 'Report Cards' on Health Care Providers, 111 J. Pol. Econ. 555 (2003).
} 
is to make people responsible for decisions by giving them information. The poor, that is, have in general harder problems that require more information and experience but have less ability to use the information. Giving all people access to a favor that some - the "elite" - are better able to use promotes inequity, inequity which is only aggravated if the cost of this favor is shared by the prosperous and poor alike.

\section{Conclusion: Beyond Mandated Disclosure}

This article has had four purposes. First, to identify a regulatory method that is much used but has not been analyzed across doctrinal boundaries. Second, to show how widely - one might even say indiscriminately - that method is used. Third, to demonstrate that that method is failure-prone. Fourth, to explain why it doesn't work and how unreliable its mechanisms are.

We might have had a fifth purpose: To prescribe a regulatory alternative. That, however, is a large question outside the scope of the article. But the logic of our argument is that that question cannot be answered in any straightforward way, if it can be answered at all. If mandated disclosure has been used in a wild variety of circumstances, if the decisions mandated disclosure is addressed to are enormously various, if the people mandated disclosure is supposed to help are also various, it would be surprising if any single substitute for it is plausible. In what follows, however, we warn against a few possible misunderstandings and point the way to a few useful paths of inquiry.

\section{A. Simple Information}

We have spent much of this article describing problems people have in acquiring and using information. As we have repeatedly said, we are not arguing that information is never useful. Where people make a decision regularly, they become expert at making those decisions. And sometimes very simple information is easily understood and useful. For instance, Los Angeles County puts sanitation "grade cards" in restaurant windows, and they seem to have influenced consumers (and led restaurants to improve their hygiene). ${ }^{299}$ This is information anyone can understand, and the single datum is significant enough to change customers' choice of restaurants.

The question, obviously, is whether there is some way to boil down complicated facts to simple ratings. The desirability of this has long been evident, and hopes for it have long been cherished. Some mandated disclosures already use simpler rating scores. And an FTC report, for example, suggests TILA mortgage forms can be significantly simplified and be better understood by borrowers. ${ }^{300}$

Unfortunately, the cure for the mandated disclosure failure is not as straightforward as merely make-them-simple. Sometimes even a simple mandate to disclose simple information has undesirable consequences. For example, there is evidence that laws requiring that each item

299 Ginger Zhe Jin \& Phillop Leslie, The Effect of Information on Product Quality: Evidence from Restaurant Hygiene Grade Cards, Quar. J. Econ 409 (2003).

${ }^{300}$ See Lacko and Pappalardo, supra note Error! Bookmark not defined.. 
sold have a price on the item itself detectibly raises the price of goods sold. ${ }^{301}$ More generally, we can identify several impediments to the success of even the simplest forms of disclosure.

First, disclosures are aimed to convey an actual element of quality: calorie count, hospital death rate, cost of credit, or a risk feature of the product. For this to be useful, people must be able to predict the effect of the disclosed parameter on their satisfaction. But satisfaction depends on a host of other inputs. Moreover, people vary in their ability to use the information, and weaker market participants - poor, uneducated, high-need individuals - must find the information less readily useful. This was shown to be the case with respect to hospital report cards; and it is likely to be the case with respect to the new "Country of Origin" food labeling laws. $^{302}$

Second, people are heterogeneous in their preferences and concerns, and the disclosed parameter may matter to them in different degrees. Indeed, it is this very heterogeneity that is at the ideological base of mandated disclosure, that makes mandated disclosure seem so necessary to both free marketers and autonomists. Some borrowers care about APRs, others about overdraft fees or the structure of the debt. And the transactions that are subject to mandated disclosures are complicated and multi-dimensional. There are aspects to these transactions that might matter to some people but not to others. Simple quality disclosures fix people's attention on a particular aspect, which might fail to capture the key to their satisfaction. So between the heterogeneity of the disclosees and the complexity of the relevant information, it is normally hard to find a way of boiling down an evaluation to a simple score.

Third, mandated disclosure will work only if law-makers do their work well. Even if some ideal set of disclosures or some ideal summary of data can be imagined, it would need to be identified by the law-maker and maintained by the law-maker in that form. But as we said earlier, there is much that drives law-makers toward over-using mandated disclosure and toward setting its standards of disclosure too broadly. In particular, an endless flow of trouble stories induces regulatory responses. The simple, effective, disclosure is likely to be augmented over time with additional disclosures aimed to address new problems, not resolved by the original disclosure. For the very feature that makes some disclosures effective - their simplicity - also keeps them from responding to the heterogeneity of problems and people. But once a simple disclosure is bolstered and more parameters are added to it, the accumulation problem returns. Indeed, nutrition labeling is already on this path, as more and more is added to the package (e.g., the food's origin, GMO information, allergy warnings, as well as a finer breakdown of nutrients and toxins).

While we sound a skeptical tone regarding the potential of simple mandated disclosure, we don't take the position that no disclosure can ever work. Failure is not inherent to any information regime, nor is it the mandatory aspect that guarantees failure. Rather, it is the regulatory dynamic of this institution - the desire to solve too many problems merely by informing unsophisticated decision makers and expecting them to make affirmative thoughtful decision- that undermines the effectiveness the system.

301

30219 U.S.C. 1304; 7 U.S.C. 1621; 70 C.F.R. 60 


\section{B. From Information Toward Advice}

When single data won't do the job, when considerable information is required to make a good decision, and when experience is required to use information well, mandated disclosure confronts the many daunting problems we have described.

The premise of mandated disclosure is that information will help people toward the right decisions. We have shown that the empirical history of mandated disclosure is a history of failure. We have shown that the quantity question is generally unanswerable. The overload problem cannot usually be solved without making disclosures fatally simple-minded, incomplete, and misleading. The accumulation problem would defeat mandated disclosure even if individual overload problems could be managed. We have shown that the ideological thrust of mandated disclosure - its origins in both market and autonomy theory - is to place choice, and thus risk and responsibility, onto the ill-informed and inexpert person facing a novel and complex decision. We have shown that that can have especially lamentable consequences for the vulnerable, but it also leaves the ordinary person trapped facing decisions ill-prepared and illequipped.

As we have already explained, we cannot offer a new panacea to supplant the old one. But we can offer at least a line of hypothesis and inquiry: Mandated disclosure asks what people should know to make a good decision. We ask what they want to know. When we abandon the unreal world of mandated disclosure and ask how people really make decisions, we see that they generally seek - and that the market often supplies - not data, but help, advice.

Facing important choices, people sensibly ask friends for advice. Whether seeking a plumber, a dentist, an insurance agent, or a mortgage broker, they consult their private network for the kind of information they trust and know how to use. Much of that information comes in the form of recommendations, since the best way to predict one person's satisfaction is to assess other people's satisfaction. The broader the network of recommendations, the sounder the information, but the greater the challenge of aggregating recommendations into useful guidance.

Many markets have sua sponte provided such evaluations in a particularly useful form by aggregating recommendations from users of a good or service. Many markets depend on peer ratings. The eBay business model relies on the willingness of buyers to pay upfront for goods sold by anonymous sellers, a phenomenon that is largely due to the reliability of sellers' ratings - a single score that tallies the percentage of satisfied customers. Similarly, Expedia.Com rates hotels, Zagat rates restaurants, Cnet.Com rates electronic appliances and retailers, Amazon rates used book sellers (and every imaginable good), and Netflix.com rates movies. Some services try to improve scores by asking people to rate the raters, thus creating a smart weighted ratings average. In short, innumerable market transactions and services are rated by consumers, from blenders and pizzas to doctors and professors.

Another source of help - as opposed to just information - for consumers is to give them expert advice. Expert advice comes in two forms. In some of the areas in which disclosures are mandated, an expert gives personalized advice to a particular client. This happens all the time with doctors, financial advisers, accountants, brokers, and so forth. For example, after hearing 
an insurance agent go through the mandated disclosures, many people have the agent make ("recommend") the decision. Next time, they skip the disclosures. Similarly, patients frequently prefer that a doctor propose a treatment, explain it, and get their (largely symbolic) confirmation.

The problem with expert help, of course, is that it needs to be genuinely expert and genuinely in the service of the client. These things are not easy to assure. Unfortunately, mandated disclosure has been one of the principal means of trying to do so. Our article has questioned whether clients are best served by a requirement that the expert provide them with information - a solution that may tend to make the expert feel less responsible for and be less helpful to the client. ${ }^{303}$

The second form of expert advice is advice made generally available, by purchase or otherwise. Significant elements of the market have long sought to inform people about the views of experts. Expert evaluations can be bought, as Consumer Report's long history suggests, but many are free. For example, when electing a senator, voters can consult ratings by the Environmental Defense Fund or the NRA. When choosing a restaurant, patrons count Michelin stars. And buying wine, many of us check Robert Parker's wine scores.

Some very simple disclosures and many ratings systems can provide help in another way that does not burden the consumer with data. It appears that the hygiene grade restaurants in Los Angeles must post leads some restaurants to try to get their grades up. It seems likely that consumer ratings can have the same effect. Our personal experience is that people selling on eBay are generally quite concerned to avoid receiving negative ratings. Insofar as disclosure works to cause disclosers to behave better (and not merely manipulate the feedbacks and the ratings scores), disclosees need not rely on the disclosed data but can instead (as they say) shop with confidence.

Sometimes advice - whether the aggregated experience of the multitude or the opinions of the expert - will not adequately help the naïve in their dealings with the sophisticated. Another way to try to help people toward good decisions is for the law to "channel" people's choices, without mandating them. ${ }^{304}$ The core of channeling is not to make decisions for people but rather to create defaults and incentives that lead them toward presumptively wise decisions, while leaving people to reject those choices if they wish. ${ }^{305}$ For example, defaults may be set so that people start off and can most easily stay in the position most people would prefer. This is what intestacy statutes already do with apparent success. Because a considerable consensus supports encouraging people to save for retirement, some employers put pension funds directly into retirement savings account, letting employees opt out if they wish. Another channeling

${ }^{303}$ See, e.g., Carl E. Schneider, The Practice of Autonomy: Patients, Doctors, and Medical Decisions (Oxford U Press, 1998). Compare the medical principle of informed consent with the very different principles that govern the relationships of lawyers and clients.

${ }^{304}$ See, e.g., Carl E. Schneider, The Channelling Function in Family Law, 20 Hofstra Law Review 495 (1992); Scott D. Halpern et al, Harnessing the Power of Default Options to Improve Health Care, 357 New England Journal of Medicine 1340-1344 (2007).

${ }^{305}$ Cass Sunstein and Richard Thaler, Nudge Improving Deisions About Health, Wealth, and Happiness (Yale University Press, 2008). [I believe the reference is on pages 70-71, or 83-87???] 
device is to require vendors to offer a basic, uniform option. ${ }^{306}$ This makes apples-to-apples comparisons easier and improves competition. Vendors would remain free to offer more complex choices as well.

A more aggressive way to use the law to help the naïve is to outlaw practices that are too likely to result in disaster. Whether some choices are so likely to be so bad for so many people that they should be outlawed is beyond the scope of this article. Recent reform in credit card markets eliminated some choices that borrower traditionally had, which often led to poor outcomes. $^{307}$

Obviously such prohibitions close options some people would benefit from. Risky mortgages let some people buy and keep homes who otherwise could not have done so. But at some point the benefits of such prohibitions exceed their costs. The lawmaker's challenge is to identify that point. The contribution of this article is not in finding this prohibition point. The contribution is in recognizing that such policies are sometime inevitable and cannot be sidestepped by utilizing easier solutions based on the disclosure paradigm. If, as we have argued, mandated disclosure rarely works, law-makers must undertake the hard work of analyzing each social problem to find the best way to promote good decisions. In any event, the idea that people's autonomy is bolstered by "empowering" them to make choices through mandated disclosures needs to be abandoned.

306 A proposal in this spirit was recently advanced by the Obama administration. See also FINANCIAL REGULATORY REFORM 66-67 (Dept of Treasury 2009). 
Readers with comments should address them to:

Professor Omri Ben Shahar

University of Chicago Law School

1111 East 60th Street

Chicago, IL 60637

omri@uchicago.edu 
Ben-Shahar and Schneider:

\section{Chicago Working Papers in Law and Economics (Second Series)}

For a listing of papers 1-450 please go to Working Papers at http://www.law.uchicago.edu/Lawecon/index.html

451. Tom Ginsburg, Public Choice and Constitutional Design (January 2009)

452. Richard Epstein, The Case against the Employee Free Choice Act (January 2009)

453. Adam B. Cox, Immigration Law’s Organizing Principles (February 2009)

454. Philip J. Cook, Jens Ludwig, and Adam M. Samaha, Gun Control after Heller: Threats and Sideshows from a Social Welfare Perspective (February 2009)

455. $\quad$ Lior Jacob Strahilevitz, The Right to Abandon (February 2009)

456. M. Todd Henderson, The Nanny Corporation and the Market for Paternalism (February 2009)

457. Lee Anne Fennell, Commons, Anticommons, Semicommons (February 2009)

458. Richard A. Epstein and M. Todd Henderson, Marking to Market: Can Accounting Rules Shake the Foundations of Capitalism? (April 2009)

459. Eric A. Posner and Luigi Zingales, The Housing Crisis and Bankruptcy Reform: The Prepackaged Chapter 13 Approach (April 2009)

460. Stephen J. Choi, G. Mitu Gulati, and Eric A. Posner, Are Judges Overpaid? A Skeptical Response to the Judicial Salary Debate (April 2009)

461. Adam B. Cox and Eric A. Posner, The Rights of Migrants (April 2009)

462. Randal C. Picker, The Google Book Search Settlement: A New Orphan-Works Monopoly? (April 2009, revised July 2009)

463. Randal C. Picker, The Mediated Book (May 2009)

464. Anupam Chander, Corporate Law’s Distributive Design (June 2009)

465. Anupam Chander, Trade 2.0 (June 2009)

466. Lee Epstein, William M. Landes, and Richard A. Posner, Inferring the Winning Party in the Supreme Court from the Pattern of Questioning at Oral Argument (June 2009)

467. Eric A Posner, Kathryn Spier, and Adrian Vermeule, Divide and Conquer (June 2009)

468. John Bronsteen, Christopher J. Buccafucso, and Jonathan S. Masur, Welfare as Happiness (June 2009)

469. Richard A. Epstein and Amanda M. Rose, The Regulation of Soveriegn Wealth Funds: The Virtues of Going Slow (June 2009)

470. Douglas G. Baird and Robert K. Rasmussen, Anti-Bankruptcy (June 2009)

471. Bernard E. Harcourt, Alon Harel, Ken Levy, Michael M. O’Hear, and Alice Ristroph, Randomization in Criminal Justice: A Criminal Law Conversation (June 2009)

472. Bernard E. Harcourt, Neoliberal Penality: A Brief Genealogy (June 2009)

473. Lee Anne Fennell, Willpower and Legal Policy (June 2009)

474. Richard A. Epstein, How to Undermine Tax Increment Financing: The Lessons of ProLogis v. City of Chicago (June 2009)

475. Randal C. Picker, Online Advertising, Identity and Privacy (June 2009)

476. M. Todd Henderson, Credit Derivatives Are Not "Insurance" (July 2009)

477. Lee Anne Fennell and Julie Roin, Controlling Residential Stakes (July 2009)

478. Douglas G. Baird, The Holmesian Bad Man’s First Critic (August 2009)

479. Douglas G. Baird, The Bankruptcy Exchange (August 2009)

480. Jonathan Masur and Eric A. Posner, Against Feasibility Analysis (August 2009)

481. Lee Anne Fennell, The Unbounded Home, Property Values beyond Property Lines (August 2009)

482. Bernard E. Harcourt, Henry Louis Gates and Racial Profiling: What's the Problem? (September 2009)

483. Stephen J. Choi, Mitu Gulati, Mirya Holman, and Eric A. Posner, Judging Women (September 2009)

484. Omri Ben-Shahar, One-Way Contracts: Consumer Protection without Law (October 2009)

485. Ariel Porat, Expanding Liability for Negligence Per Se (October 2009)

486. Ariel Porat and Alex Stein, Liability for Future Harm (October 2009)

487. Anup Malani and Ramanan Laxminrayan, Incentives for Surveillance of Infectious Disease Outbreaks (October 2009) 
488. Anup Malani, Oliver Bembom and Mark van der Laan, Accounting for Differences among Patients in the FDA Approval Process (October 2009)

489. David Gilo and Ariel Porat, Viewing Unconsconability through a Market Lens (October 2009)

490. David Weisbach, Instrument Choice Is Instrument Design (October 2009)

491. M. Todd Henderson, Justifying Jones (November 2009)

492. Eric A. Posner, ProCD v. Zeidenberg and Cognitive Overload in Contractual Bargaining (November 2009)

493. Randal C. Picker, Antitrust and Innovation: Framing Baselines in the Google Book Search Settlement (November 2009)

494. Richard A. Epstein, Against Permititis: Why Volunteer Organizations Should Regulate the Use of Cancer Drugs (November 2009)

495. Richard A. Epstein, Heller’s Gridlock Economy in Perspective: Why There Is Too Little, Not Too Much, Private Property (November 2009)

496. Richard A. Epstein, NRA v. City of Chicago: Does the Second Amendment Bind Frank Easterbrook? (November 2009)

497. Randal C. Picker, Easterbrook on Copyright (November 2009)

498. Omri Ben-Shahar, Pre-Closing Liability (November 2009)

499. Randal C. Picker, Assessing Competition Issues in the Amended Google Book Search Settlement (November 2009)

500. Saul Levmore, Ambigious Statutes (November 2009)

501. Saul Levmore, Interest Groups and the Problem with Incrementalism (November 2009)

502. Tom Ginsburg, The Arbitrator as Agent: Why Deferential Review Is Not Always Pro-Arbitration (December 2009)

503. Nuno Garoupa and Tom Ginsburg, Reputation, Information and the Organization of the Judiciary (December 2009)

504. Eric A. Posner and Alan O. Sykes, Economic Foundations of the Law of the Sea (December 2009)

505. Jacob E. Gersen and Anne Joseph O'Connell, Hiding in Plain Sight? Timing and Transparency in the Administrative State (December 2009)

506. Richard A. Epstein, Impermissible Ratemaking in Health-Insurance Reform: Why the Reid Bill is Unconstitutional (December 2009)

507. Tom Ginsburg and Eric A. Posner, Subconstitutionalism (January 2010)

508. Stephen J. Choi, Mitu Gulati, and Eric A. Posner, What Do Federal District Judges Want? An Analysis of Publications, Citations, and Reversals (January 2010)

509. Joseph Isenbergh, The Future of Taxation (January 2010)

510. Lee Epstein, William M. Landes, and Richard A. Posner, Why (and When) Judges Dissent: A Theoretical and Empirical Analysis (January 2010)

511. Tom Ginsburg, James Melton, and Zachary Elkiins, The Endurance of National Constitutions (February 2010)

512. Omri Ben-Shahar and Anu Bradford, The Economics of Climate Enforcement (February 2010)

513. Neta-li E. Gottlieb, Free to Air? Legal Protection for TV Program Formats (February 2010)

514. Omri Ben-Shahar and Eric A. Posner, The Right to Withdraw in Contract Law (March 2010)

515. Richard A. Epstein, Inside the Cosean Frim: Competence as a Random Variable (March 2010)

516. Omri Ben-Shahar and Carl E. Schneider, The Failure of Mandated Disclosure (March 2010) 